NBER WORKING PAPER SERIES

\title{
PLACE-BASED REDISTRIBUTION
}

Cecile Gaubert

Patrick M. Kline

Danny Yagan

Working Paper 28337

http://www.nber.org/papers/w28337

\author{
NATIONAL BUREAU OF ECONOMIC RESEARCH \\ 1050 Massachusetts Avenue \\ Cambridge, MA 02138 \\ January 2021
}

We thank David Atkin, Alan Auerbach, Roger Gordon, Nathan Hendren, Louis Kaplow, Emmanuel Saez, Ben Sprung-Keyser, Nancy Stokey, Juan Carlos Suarez-Serrato, Dmitry Taubinsky, Damian Vergara, and Matthew Weinzierl for helpful discussions and Akcan Balkir, Katie Donnelly Moran, Clancy Green, and Damian Vergara for outstanding research assistance. Thanks also go to seminar participants at Yale, Stanford, MIT, TSE, Dartmouth, Brown, Wharton, the Harris School, the Paris Trade Seminar, Oslo, the Women in Macro Conference, the Paris-London Public Economics Conference, the NBER Cities, Labor Markets, and the Global Economy Conference, the 2020 UEA meetings and the NBER Summer Institute. This research was funded by the Berkeley Opportunity Lab and the Smith Richardson Foundation. Cecile Gaubert acknowledges support from NSF CAREER grant \#1941917 and the Clausen center at UC Berkeley. The views expressed herein are those of the authors and do not necessarily reflect the views of the National Bureau of Economic Research.

NBER working papers are circulated for discussion and comment purposes. They have not been peer-reviewed or been subject to the review by the NBER Board of Directors that accompanies official NBER publications.

(C) 2021 by Cecile Gaubert, Patrick M. Kline, and Danny Yagan. All rights reserved. Short sections of text, not to exceed two paragraphs, may be quoted without explicit permission provided that full credit, including $\odot$ notice, is given to the source. 
Place-Based Redistribution

Cecile Gaubert, Patrick M. Kline, and Danny Yagan

NBER Working Paper No. 28337

January 2021

JEL No. H20,R10

\begin{abstract}
$\underline{\text { ABSTRACT }}$
Governments around the world redistribute to distressed areas by conditioning taxes and transfers on location. We show that when poor households are spatially concentrated, transfers from one location to another can yield equity gains that outweigh their efficiency costs, even when incomebased transfers are set optimally. Expressions for the optimal transfer size depend on the mobility of households, the earnings responses of movers, and sorting patterns. Surveys find support for targeting tax credits to poor Americans who live in distressed places. A calibration exercise finds optimal transfers of the same order of magnitude as prominent American zone policies.
\end{abstract}

Cecile Gaubert

Department of Economics

University of California, Berkeley

687 Evans Hall

Berkeley, CA 94720

and NBER

cecile.gaubert@berkeley.edu

Patrick M. Kline

Department of Economics

University of California, Berkeley

530 Evans Hall \#3880

Berkeley, CA 94720

and NBER

pkline@econ.berkeley.edu
Danny Yagan

Department of Economics

University of California, Berkeley

530 Evans Hall, \#3880

Berkeley, CA 94720

and NBER

yagan@berkeley.edu 


\section{Introduction}

Place-based policies tie economic benefits to geographic locations and are prevalent throughout the world (Glaeser and Gottlieb, 2008; Kline and Moretti, 2014b; Ehrlich and Overman, 2020). For example, U.S. Empowerment Zones provide a capped earnings subsidy for eligible full-time workers who live and work in one of forty urban and rural areas. The espoused rationale for such programs is often redistributive: because poor people are concentrated in certain places, targeting these areas helps disadvantaged households. However, national governments already redistribute to such households through progressive income taxes and income-based transfers like food stamps. Should poor residents of poor places receive an extra transfer based on their location?

Glaeser (2008) articulates the traditional answer of economists that have studied these programs:

"Help poor people, not poor places"...is something of a mantra for many urban and regional economists... [Place-based] aid is inefficient because it increases economic activity in less productive places and decreases economic activity in more productive places.

In line with this view, most academic research on place-based policies has focused either on their efficiency costs (e.g., Glaeser and Gottlieb, 2008; Albouy, 2009; Fajgelbaum et al., 2018; Gaubert, 2018; Austin et al., 2018) or the potential for such programs to correct market failures by internalizing productivity spillovers or other local externalities (e.g., Kline, 2010; Kline and Moretti, 2014a; Fajgelbaum and Gaubert, 2020; Rossi-Hansberg et al., 2019; Austin et al., 2018; Fu and Gregory, 2019). To date, however, little effort has been devoted to formalizing the redistributive goals that often motivate these policies in the first place.

In this paper, we study conditions under which place-based redistribution (henceforth, PBR) schemes are able to improve on the equity-efficiency tradeoffs posed by "place-blind" transfers implemented through income taxation. At a high level, there are two reasons why PBR might improve on place-blind taxation. First, conditioning transfers on place may lower the efficiency costs of redistributing between households with different levels of pre-tax earnings. Second, PBR may generate welfare gains that income-based redistribution cannot, if society values targeting transfers to residents of distressed areas, even within earnings levels.

We study these two rationales formally through the lens of a spatial equilibrium model. To connect our results to the urban economics literature, we work with a standard discrete choice formulation of household location decisions (McFadden, 1978; Bayer et al., 2007; Busso et al., 2013; Kline and Moretti, 2014b; Ahlfeldt 
et al., 2015). Households choose to live in one of two locations: Distressed or Elsewhere, the latter of which may have better amenities, greater labor productivity (i.e., higher wages), and a higher cost of living. Households differ in their skill and in their relative tastes for the Distressed location. Each household chooses where to live, how much housing to consume, and how much to earn given the national tax system and locational characteristics. A utilitarian planner designs policy instruments to maximize a weighted average of household utilities. As in classic optimal tax problems (e.g., Mirrlees, 1971), household types are private information but the planner observes each household's earnings level and choice of location. ${ }^{1}$ The planner redistributes across earnings levels using a conventional place-blind income tax schedule and can also implement a PBR scheme whereby a lump-sum tax is levied on residents of Elsewhere and rebated to residents of Distressed. When poor households sort to Distressed, transferring a dollar from the average Elsewhere resident to the average Distressed resident will tend to raise welfare. However, spatial targeting yields efficiency costs by inducing Elsewhere residents to move to Distressed, which can entail a reduction in earnings and thereby tax revenue.

Our first result explains how the planner resolves the equity-efficiency tradeoff presented by PBR under a fixed (potentially sub-optimal) income tax system. At an optimum, the equity gains of the place-based subsidy equal its corresponding efficiency costs. The optimal subsidy to Distressed grows large when less skilled households are concentrated in Distressed, when few households are indifferent between the two locations, when productivity differences across areas are small, or when the marginal utility of consumption declines slowly with income. The formula highlights the earnings effects associated with migration responses as a "sufficient statistic" - in the sense described by Chetty (2009) and Kleven (2020) - for the efficiency costs of place-based policies, providing guidance for future empirical research on place-based transfers.

An important question left unanswered by this formula is whether PBR can improve on an optimal income tax system. Classic results in public economics establish conditions under which redistribution via differential taxation of commodities - e.g., taxes on expensive watches - can improve welfare over and above redistribution via optimal non-linear income taxes and transfers (Atkinson and Stiglitz, 1976; Saez, 2002). The prototypical result in this literature is that differential commodity taxation will tend to be superfluous whenever heterogeneity in consumption bundles across earnings groups is entirely attributable to the causal effect of earnings. In this polar case, commodity taxes distort labor supply as much as income taxes, while

\footnotetext{
${ }^{1}$ Our perspective therefore differs from Albouy (2012) and Fajgelbaum and Gaubert (2020), who derive optimal spatial transfers when the types of all households are observed by the planner.
} 
also distorting consumption choices, thereby generating excess efficiency costs.

However, place-based taxation differs from traditional commodity taxation problems in several respects. First, locational choice may directly affect the wage faced by households, as productivity varies across space. Second, while commodity taxes are typically constrained to be linear to prevent tax avoidance via resale, place-based taxes can be nonlinear, as place of residence is a discrete choice that is typically straightforward for governments to verify (Moretti and Wilson, 2019). Third, location choice affects the price of other goods in the consumption basket, specifically housing, the rental price of which covaries strongly with productivity. Finally, there are good reasons to believe that poor households locate in poor places for reasons other than that they are poor. Indeed, microeconometric models designed explicitly to recover income effects in the demand for neighborhood quality typically cannot explain empirical sorting patterns without allowing locational tastes to covary with earnings ability (e.g., Epple and Sieg, 1999; Epple et al., 2020). Other modern empirical approaches to locational choice attribute the segregation of income groups to taste heterogeneity (Bayer et al., 2007), mobility costs (Kennan and Walker, 2011; Bayer et al., 2016; Fu and Gregory, 2019), comparative advantage (Dahl, 2002; Baum-Snow and Pavan, 2011; De La Roca and Puga, 2017) or combinations of these factors (Bayer et al., 2014; Diamond, 2016) - possibilities that are all encompassed by our framework.

To determine whether PBR improves on optimally chosen income taxes in this modeling environment, we compare PBR to the income tax reform that yields the same equity gains across pre-tax earnings levels as a small lump-sum transfer to Distressed. The income tax reform can induce some households to move and can also affect the labor supply of households that do not change location. We show that the efficiency costs of redistributing across earnings levels via income taxation can exceed those generated by PBR when migration responses are small compared to income-tax-induced labor supply distortions. Furthermore, even when the income tax reform entails lower efficiency costs than PBR, the optimal transfer to Distressed may still be positive if the planner has a motive to transfer from residents of Elsewhere to residents of Distressed who have the same earnings. In this case, PBR is desirable because it yields unique equity benefits that income-based tools cannot achieve.

Extending the latter argument, we discuss several reasons why a planner might favor spatial redistribution among households with identical earnings. One is that a dollar spent on residents of Distressed goes further due to the lower cost of living there, an idea we show can be formalized with standard preference 
specifications. A second motive for within-income group redistribution arises when amenities and consumption are q-substitutes, in which case the residents of Distressed will tend to exhibit higher marginal utilities of consumption than residents of Elsewhere with the same earnings. For example, disamenities like crime and pollution can raise the marginal utility of consumption goods that help families avoid crime or treat asthma. Finally, place-based policies are sometimes motivated on non-utilitarian grounds, such as to redress past injustices, concerns which can be formalized with generalized social welfare weights (Saez and Stantcheva, 2016).

Whether PBR in fact yields unique equity benefits depends ultimately on the nature of social preferences regarding spatial redistribution. To advance the measurement of such preferences, we conducted a survey on Amazon's Mechanical Turk platform. The survey asks respondents to choose between three equally costly policies offering tax credits to poor households: a transfer to all poor households, a transfer targeted to poor households living in "distressed" areas, and a transfer targeted to poor households living in "thriving" areas. Remarkably, we find that about half the respondents support targeting tax relief to poor households in distressed locations. Our findings suggest social motives exist not only for redistribution across earnings levels, but also within earnings levels across space.

We conclude our analysis with a detailed quantitative calibration, investigating the potential magnitude and direction of optimal place-based transfers. To avoid stacking the deck in favor of PBR, we consider a conventional utilitarian planning problem exhibiting no motives for spatial redistribution within earnings levels. Hence, our analysis effectively studies the potential of PBR to reduce the efficiency costs of redistributing across earnings levels. Household preferences are chosen to exhibit isoelastic labor supply, additively separable valuations of locational amenities, and extreme value taste shocks. We calibrate the model to match Census data on rents and income distributions across groups of U.S. census tracts classified according to their poverty rates. Spatial productivity differences are calibrated according to the estimates of Hornbeck and Moretti (2019).

Using the calibrated model, we solve numerically for the optimal place-blind income tax as well as the optimal lump-sum transfer to residents of the poorest $1 \%$ of U.S. Census tracts. We find that the optimal per capita transfer to these tracts, when the optimal place-blind income tax system is also implemented, ranges between $\$ 3,000$ and $\$ 6,000$ depending on the specification. In our baseline calibration, sorting is driven by heterogeneous preferences for locational amenities and the optimal transfer is approximately $\$ 5,500$ per 
resident. The optimal place-based transfer falls somewhat when the wage-migration elasticity is quadrupled, when productivity differences are doubled, or when the planner is constrained to finance the place-based transfer through increases in the top tax rate only. When, as in U.S. Empowerment Zones, the transfer is restricted to take the form of a capped subsidy to earnings, the optimal subsidy rate ranges from $24 \%$ to $39 \%$, depending on the parameter values used. Finally, we show that introducing additional sorting motives into the model by allowing plausible complementarities between worker skill and locational productivity or income effects in housing consumption leads to an optimal subsidy that lies between $\$ 3,100$ and $\$ 4,200$. We also find that PBR continues to complement an optimal income tax when comparative advantage and income effects are the only motives for sorting (i.e., when skill-taste correlation is eliminated).

While our calibration results are only suggestive, they concur strongly with the theoretical message of our paper that PBR may serve as a useful complement to place-blind taxation when income groups are geographically segregated by easing the efficiency costs of redistributing across household earnings levels. The benefits of PBR are arguably even greater if, as our survey suggests, society also favors spatial redistribution within earnings levels. The urban economist's mantra warrants revision: there is good reason to consider helping poor people and poor places.

\section{Motivating Facts}

To set the stage for a theoretical analysis, we begin by briefly highlighting some simple stylized facts regarding the uneven spatial distribution of economic outcomes in the United States. The key motivation underlying place-based redistribution is that disadvantage is spatially concentrated. Consider U.S. Census tracts, which are spatially contiguous land areas with typically between 2,500 and 8,000 people. A number of prominent place-based policies have been defined in terms of Census tracts including Empowerment Zones and most recently Opportunity Zones. The tendency of poor households to cluster into particular Census tracts has been extensively documented (Jargowsky, 1997; Reardon and Bischoff, 2011; Reardon et al., 2018). For example, according to pooled estimates from the 2013-2017 waves of the American Community Survey, Census tracts in the top centile of poverty rates have an average poverty rate of $65 \%$, despite a national poverty rate over this period of only $15 \%$.

Figure 1a illustrates the spatial concentration of poverty in Chicago, Illinois - America's third largest city. Darker areas indicate higher poverty tracts in the 2013-2017 ACS. Tracts on the West Side and on 
A. Poverty Rates by Chicago Census Tract

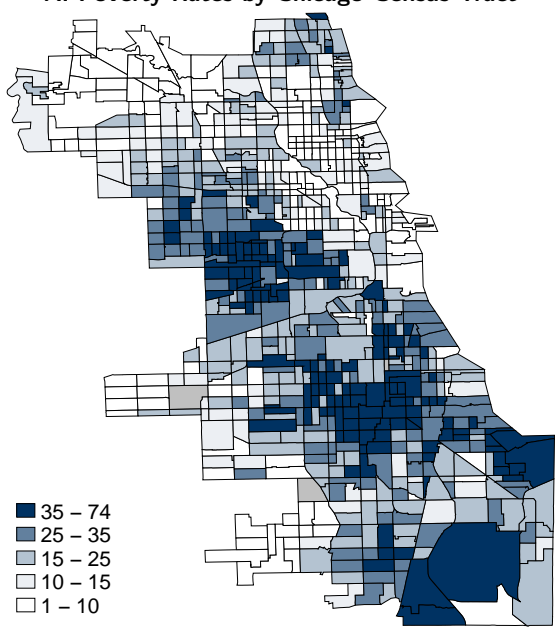

C. Rates of Paying Negative Income Taxes by Chicago ZIP Code

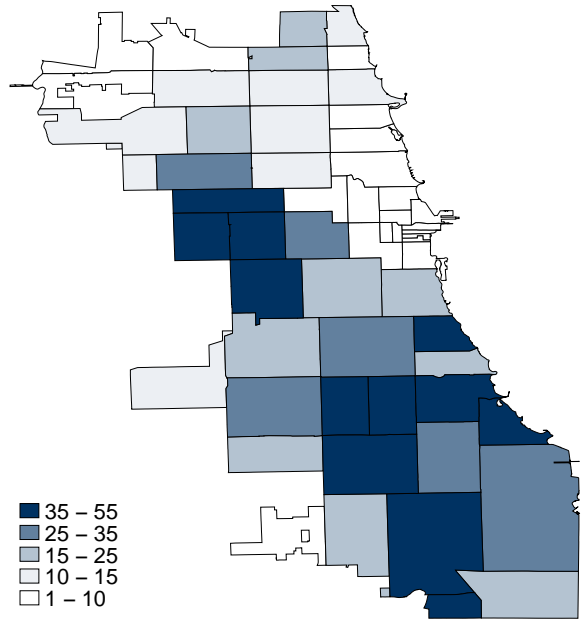

B. Poverty Rates by Mid-Atlantic County

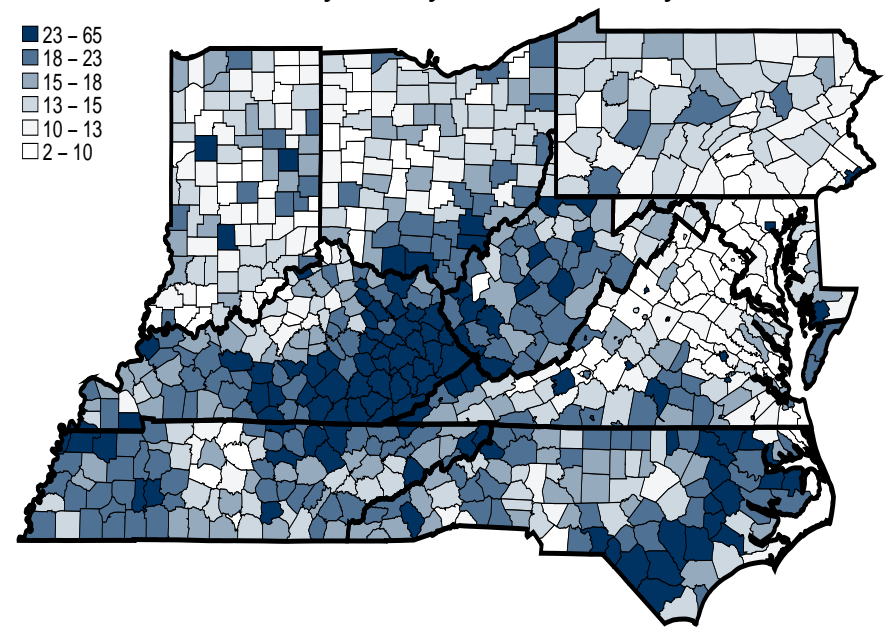

D. Rates of Paying Negative Income Taxes by Mid-Atlantic County

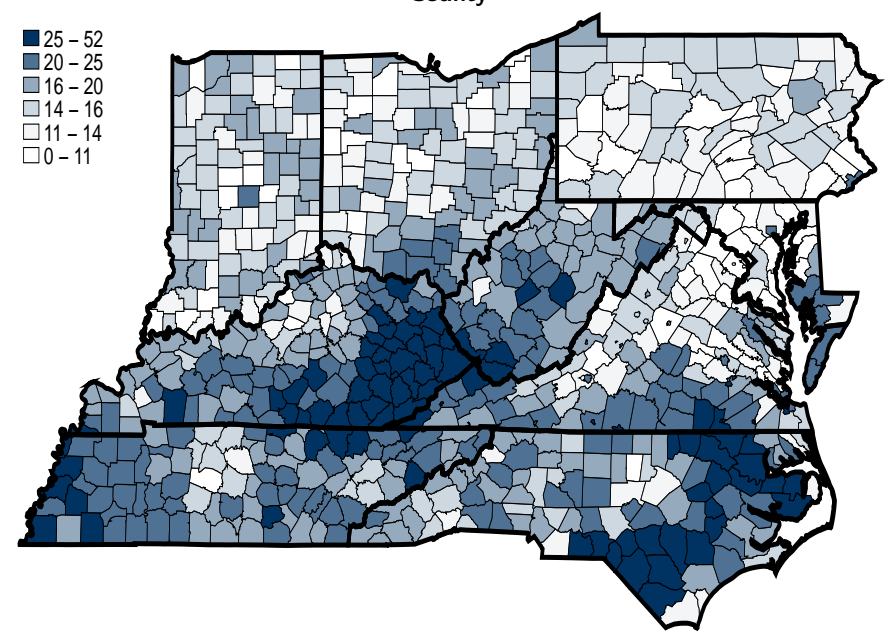

Notes: Panels A and B use the 2013-2017 American Community Survey to plot the share of households below the poverty line, for each Census tract in the city of Chicago and for each county in the Mid-Atlantic region. Panels C and D use 2016 Internal Revenue Service ZIP-level aggregates to plot the share of tax filers receiving a net transfer from the federal income tax due to the refundable Earned Income Tax Credit, for each Chicago ZIP code and for Mid-Atlantic county. 
the South Side have poverty rates exceeding $50 \%$, while tracts in and around the Gold Coast neighborhood in the northeast of the city have near-zero poverty rates. Clearly, place-based redistribution from the Gold Coast to the West and South Sides has the potential to yield equity gains. In fact, Chicago's Empowerment Zone comprises a contiguous section of the West Side and a separate contiguous section of the South Side.

Similar patterns exist at the regional level. Figure $2 \mathrm{~b}$ shows county-level poverty rates in Mid-Atlantic states. Poverty is heavily clustered in the rural Appalachian Mountain area of Eastern Kentucky, with rates comparable to those found in Chicago's West and South Sides. Place-based redistribution to residents of these heavily impoverished Eastern Kentucky counties has the potential to yield equity gains. Three of these counties compose the Kentucky Highlands Empowerment Zone.

Of course, place-blind transfers based on household income also redistribute to residents of poor areas. Figure 1c uses a ZIP-code map of Chicago to plot the share of tax filing units paying negative federal income taxes due to the Earned Income Tax Credit. Half of tax filers in parts of the West and South Sides have negative income tax bills. Similar rates of negative income tax filing are present in the Appalachian region, as shown in Figure 1d. Whether or not place-based transfers can usefully complement these place-blind transfers hinges in particular on their relative efficiency costs, as we examine in detail in the next section.

While both place-based and income-based redistribution can generate equity gains across earnings groups, place-based redistribution may additionally yield spatial equity gains. To the extent that society values redistribution from households in low-poverty areas to households with the same earnings levels that reside in high-poverty areas, place-based policies provide a targeting advantage over income-based transfers. Motives for within-earnings-group redistribution can stem from several sources. One channel is that disamenities in high-poverty areas can raise the marginal utility of consumption of neighborhood residents. Potentially relevant examples include local crime risks raising the value of car rides home and local pollution levels raising the value of asthma medication.

The next set of figures illustrates that high-poverty areas tend to also be high-disamenity areas, suggesting in turn that the marginal utility of consumption may be elevated there. Specifically, Figure 2a uses the precise geographic coordinates of crimes committed in America's five largest cities - New York City, Los Angeles, Chicago, Houston, and Philadelphia - to plot violent crime rates versus tract poverty rate. The figure shows that violent crimes are five times more prevalent per capita in the highest-poverty tracts than in the lowest poverty tracts. Figure $2 \mathrm{~b}$ further illustrates this fact using a map of murder rates in Chicago. 
FIGURE 2: High-Poverty Areas Have Disamenities and Histories of Discrimination
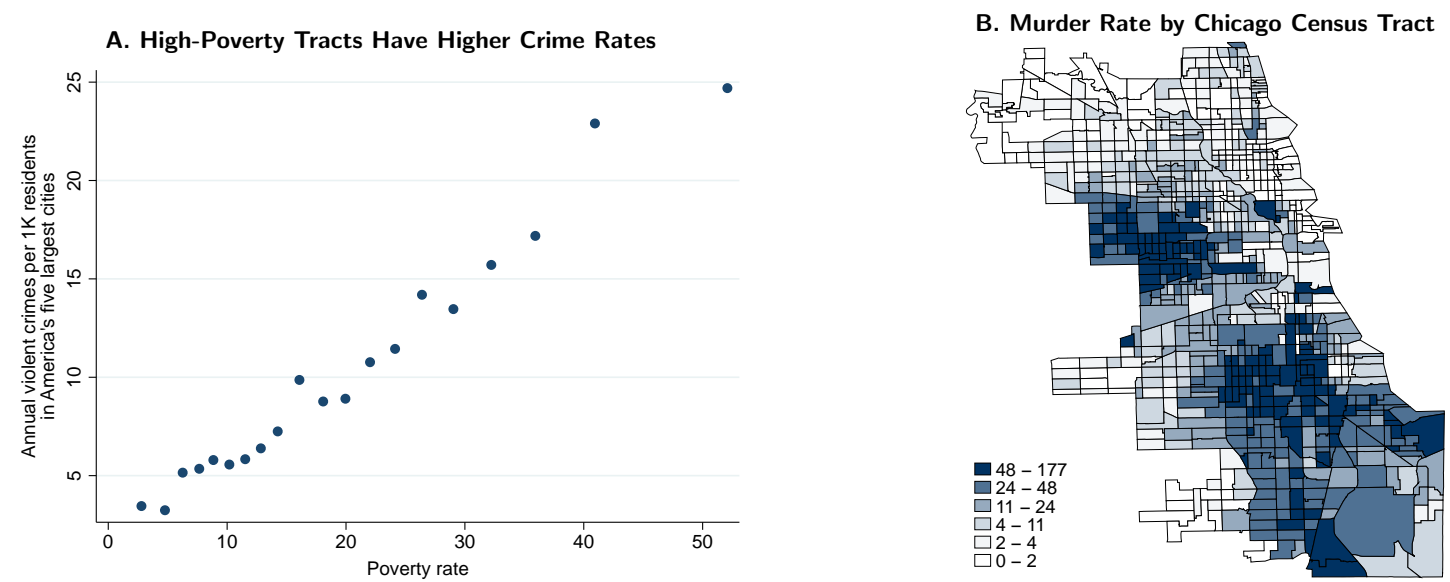

C. High-Poverty Tracts Have Higher Air Pollution

D. High-Poverty Tracts Were Redlined
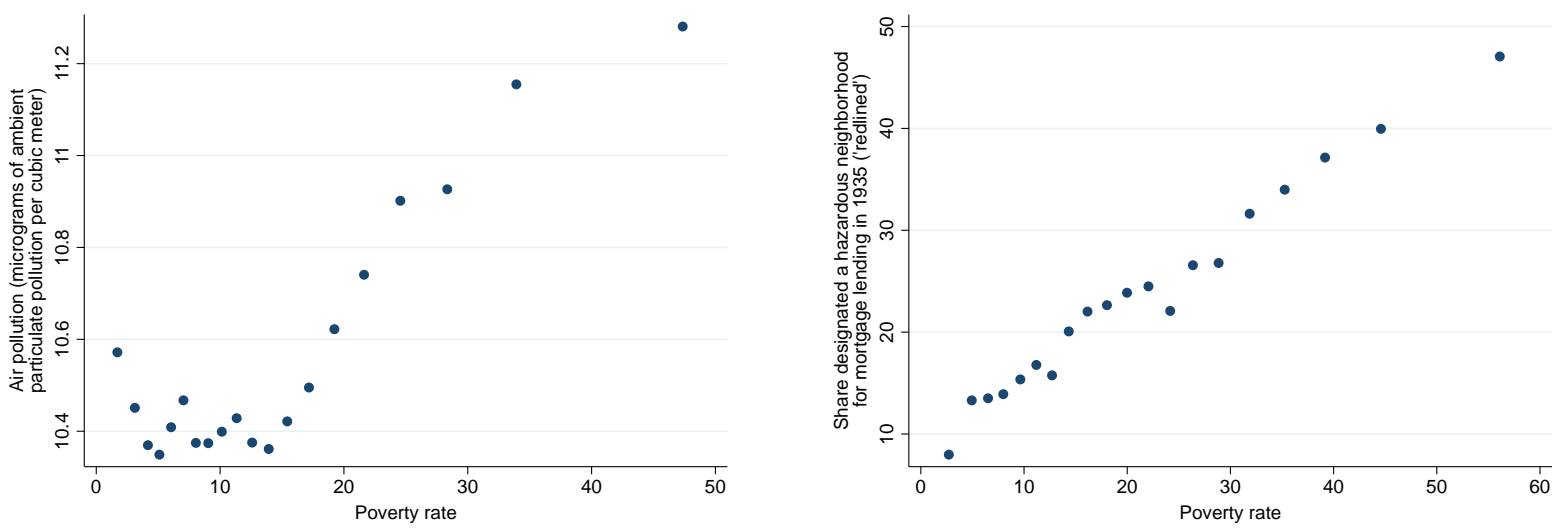

Notes: Panel A uses publicly released lattitudes and longitudes of every crime committeed in America's five largest cities - New York City (2006-2019), Los Angeles (2012-2016), Chicago (2001-2019), Houston (2011, 2013, 2015, and 2018), and Philadelphia (2006-2019) - and tract populations from the 2013-2017 American Community Survey to plot annual violent crimes per 1,000 residents in ventiles of tracts ranked by 2013-2017 ACS poverty rate. Panel B uses the Chicago data from Panel A to plot annual murders per 100,000 residents. Panel C uses satellite data on ambient air pollution (Fowlie et al. 2019) to plot mean pollution by ventile of tracts ranked by 2013-2017 ACS poverty rate. Panel D plots the share of tracts in 239 American cities that were redlined by ventile of tracts ranked by 2013-2017 ACS poverty rate. We define a tract as having been redlined if and only if over half of its land area was labeled as "hazardous" (and therefore colored in red) for mortgage risk in the 1935 Home Owners' Loan Corporation maps digitized by Nelson et al.'s (2020); see the text for more detail. 
Figure 2c repeats Figure 2a for the outcome of air pollution, as measured from satellite data for the entire United States (Fowlie et al., 2019). The figure shows that high-poverty tracts have substantially elevated air pollution levels relative to low-poverty tracts, a pattern that has persisted for decades (Colmer et al., 2020).

A desire to right place-based wrongs or other identifiable causes of hardship can also raise the marginal social value of redistribution to high-poverty areas. A prominent example is redlining, the now-prohibited practice of using borrower race or neighborhood racial composition in mortgage lending decisions. ${ }^{2}$ Concern over the legacy of redlining and potential ongoing housing discrimination has served as the impetus for a host of local and federal efforts to increase investment in predominantly minority neighborhoods (Ross and Tootell, 2004; Squires, 2011). Figure 2d plots the share of urban tracts in which at least half of the tract's land area was redlined by the 1935 Home Owners' Loan Corporation using digitized maps from Nelson et al. (2020). Today's high-poverty tracts are ten times as likely to have been redlined in the 1930s as today's low-poverty tracts.

\section{A Model of Place-Based Redistribution}

Against this backdrop, we characterize in this section the fundamental equity-efficiency trade-off posed by place-based redistribution. Redistributing to places where lower income households are segregated enhances equity. The cost of PBR comes from migration responses to the policy, as spatial subsidies lead some households to move to areas where they are less productive. Optimal PBR schemes balance the equity advantages of redistributing between areas with the efficiency costs of doing so.

To connect with traditional results on income taxation, we model PBR schemes as transferring income directly to households. In practice, place-based policies often channel spatial transfers through capital or wage subsidies to businesses (Slattery and Zidar, 2020) or through federal transfers to local governments (Oates, 1999). To the extent that the incidence of such policies falls on households, the guiding principles we derive here will hold. An additional goal of business tax incentives can be to correct market imperfections, for example by exploiting agglomeration economies (Kline and Moretti, 2014a; Fajgelbaum and Gaubert, 2020; Bartik, 2020); likewise, grants to local governments can be designed to correct fiscal externalities (Flatters et al., 1974; Albouy, 2012). We leave to future work the task of integrating such Pigouvian corrections with

\footnotetext{
2The name derives from 239 city maps commissioned in 1935 by the federally sponsored Home Owners' Loan Corporation. The maps used red shading to delineate areas deemed "hazardous" for mortgage lending, often with explicit reference to the racial makeup of the neighborhood (Jackson, 1987). The federal government banned redlining via the 1968 Fair Housing Act, but concerns regarding unequal treatment persist (e.g., Avenancio-León and Howard, 2019).
} 
the redistributive motives we study here into a common theoretical framework.

\subsection{Preliminaries}

Household preferences We consider an economy where a unit mass of households, who may differ in their skill level, choose to live in one of two communities, 1 ("Distressed") or 0 ("Elsewhere"). Households are characterized by a three-dimensional type $\Theta=\left(\theta, \varepsilon_{0}, \varepsilon_{1}\right)$. The parameter $\theta$ indexes the household's skill, while $\left(\varepsilon_{0}, \varepsilon_{1}\right)$ are idiosyncratic preference (or cost) shocks for living in location $j \in\{0,1\}$. These types are distributed according to a continuous three-dimensional cdf $F: \mathbb{R}^{3} \rightarrow[0,1]$.

Households have preferences over the consumption of a homogeneous traded good $c$ and local housing $h$, over the level of amenities $a$ of their community of residence, as well as over labor supply $\ell$. Their preferences are captured by a concave utility function $U$, with $U_{c}>0, U_{h}>0, U_{a}>0$, and $U_{\ell}<0$. The price of the traded good is common in both locations and taken as the numeraire. Locations may differ in three ways: their level of amenities $a_{j}$, their rental cost of housing $r_{j}$, and their productivity, as reflected in local wage rates. Specifically, each location $j$ has a wage schedule $w_{j}: \mathbb{R} \rightarrow \mathbb{R}_{+}$that is an increasing function of household skill. A household of type $\Theta$ that resides in location $j$ must therefore supply $\ell=\frac{z}{w_{j}(\theta)}$ units of labor to generate pre-tax earnings $z$. This formulation allows for some skill levels to possess a comparative advantage in producing in a given location.

We impose the restriction that each household's preference shock $\varepsilon_{j}$ for living in location $j$ impacts their utility additively, so that the utility of a household of type $\Theta$ living in location $j$ can be written: ${ }^{3}$

$$
u_{j}(\Theta)=U\left(c, h, a_{j}, \frac{z}{w_{j}(\theta)}\right)+\varepsilon_{j}
$$

Households choose where to live by maximizing (1) subject to the following budget constraint:

$$
c+r_{j} h=z-T_{j}(z)
$$

where $T_{j}(z)$ is the tax schedule, which may depend on place and income. Consequently, the indirect utility for a type $\Theta$ household of residing in location $j$ is:

$$
v_{j}(\Theta)=\max _{z, h} U\left(z-T_{j}(z)-r_{j} h, h, a_{j}, \frac{z}{w_{j}(\theta)}\right)+\varepsilon_{j} .
$$

\footnotetext{
${ }^{3}$ We discuss more general formulations in the Appendix, including non-additive preference shocks, as well as shocks on city-specific wage rates, and show how our results extend to these cases.
} 
Realized indirect utility is therefore $v(\Theta)=\max \left\{v_{1}(\Theta), v_{0}(\Theta)\right\}$.

Household behavior Let the symbol $j^{*}(\Theta)=\arg \max \left\{v_{1}(\Theta), v_{0}(\Theta)\right\}$ denote the choice of location made by a household of type $\Theta$. For every choice variable $x \in\{c, h, z, v\}$ we use $x_{j}^{*}(\Theta)$ to denote the value of $x$ that would be chosen by a household of type $\Theta$ if forced to reside in location $j$, while $x^{*}(\Theta)=$ $j^{*}(\Theta) x_{1}^{*}(\Theta)+\left[1-j^{*}(\Theta)\right] x_{0}^{*}(\Theta)$ gives the value of $x$ actually chosen by such a household. To economize on integral notation, we introduce the expectations operator $\mathbb{E}\left[x^{*}(\cdot)\right]=\int x^{*}(\Theta) d F(\Theta)$. The corresponding conditional expectations operator is defined $\mathbb{E}\left[x^{*}(\cdot) \mid y^{*}(\cdot)=y\right]=\frac{\int_{\Theta: y^{*}(\Theta)=y} x^{*}(\Theta) d F(\Theta)}{\int_{\Theta: y^{*}(\Theta)=y} d F(\Theta)}$. In what follows, we suppress the $(\cdot)$ notation when it is unambiguous to do so.

A key feature of our setup is that locational choice may exert a causal effect on household earnings. A type- $\Theta$ household's optimal earnings in Distressed $z_{1}^{*}(\Theta)$ may differ from its optimal earnings level in Elsewhere $z_{0}^{*}(\Theta)$ for three reasons. First, the household's wage $w_{j}(\theta)$ may vary across locations. Second, the household's marginal utility of leisure is potentially shaped by the quality of local amenities $\left(a_{j}\right)$, which may differ across locations. High quality amenities and entertainment options may encourage more leisure time; on the other hand, low amenity locations may depress hours of work if they lead to poor health, for instance. A third reason why earnings may differ across places for the same household is through income effects on labor supply: higher cost of living locations should induce longer working hours, all else equal.

The empirical literature has established that earnings do adjust when workers move between cities (Glaeser and Mare, 2001; Baum-Snow and Pavan, 2011; Dauth et al., 2018). A typical finding is that earnings fall when moving to smaller, less dense, metropolitan areas, which suggests employing assumptions that generate $z_{1}^{h}<z_{0}^{h}$. When thinking about place-based redistribution between residential neighborhoods of a given city that provide the same access to jobs, however, it might be reasonable to instead invoke primitives that yield $z_{1}^{h}=z_{0}^{h}$. To fix ideas, we frame the discussion below focusing on the case where $z_{1}^{h} \leq z_{0}^{h}$ for all households, but the formulas we derive apply more generally.

Planner's preferences A planner evaluates allocations subject to the welfare function:

$$
S W F=\int \omega(\Theta) v^{*}(\Theta) d F(\Theta)=\mathbb{E}\left[\omega v^{*}\right]
$$

where $\omega(\Theta)$ gives the Pareto weight assigned to a household of type $\Theta$. These weights capture any additional preference for redistribution across types $\Theta$ the planner may have beyond that driven by concavity in utility. 
The planner can redistribute using two instruments: a place-blind income tax schedule $T: \mathbb{R}_{\geq 0} \rightarrow \mathbb{R}$, as well as a place-based transfer indexed by $\Delta$. Letting $S$ denote the share of households who live in Distressed under a place-blind tax regime, we consider a very simple PBR scheme in which the $1-S$ households in Elsewhere face a lump-sum tax $\frac{\Delta}{1-S}$ while the $S$ households in Distressed receive a lump sum subsidy $\frac{\Delta}{S}$. The place-based tax faced by a household of type $\Theta$ is:

$$
\frac{S-j^{*}(\Theta, \Delta)}{S(1-S)} \Delta
$$

where we have indexed the function $j^{*}$ by $\Delta$ in order to highlight the potential influence of the PBR scheme on location choices. Overall, the tax schedule is therefore $T_{j}(z)=T(z)+\frac{S-j}{S(1-S)} \Delta$. Formally, the planner faces the budget constraint:

$$
\mathbb{E}\left[T\left(z^{*}\right)+\Delta \frac{S-j^{*}}{S(1-S)}\right]=R
$$

where $R$ is an exogenous revenue requirement faced by the government. The amount $\mathbb{E}\left[T\left(z^{*}\right)\right]$ is the net fiscal revenue of the place-blind income tax, while $\mathbb{E}\left[\Delta \frac{S-j^{*}}{S(1-S)}\right]$ is the net fiscal revenue generated by the PBR scheme.

Letting $\phi$ denote the Lagrange multiplier on the government budget constraint, transferring a dollar to a household of type $\Theta$ leads to a welfare gain of $\omega(\Theta) \frac{\partial v^{*}(\Theta)}{\partial I}$ (where $I$ is unearned income) at a cost of $\phi$. We define

$$
\lambda^{*}(\Theta) \equiv \frac{\omega(\Theta) \frac{\partial v^{*}(\Theta)}{\partial I}}{\phi}
$$

as the social marginal welfare weight assigned to a household of type $\Theta$ by the planner at the initial equilibrium we are considering. This weight measures the dollar value (in terms of public funds) of increasing the consumption of a type $\Theta$ household by $\$ 1$. Note that the social marginal welfare weight $\lambda$ is, in general, a function of the whole vector of household characteristics $\Theta$, not just household skill $\theta$. Even when the Pareto weights $\omega$ only depend on $\theta$, locational preferences may shape marginal utility of income because location choice impacts earnings choice, cost of living, and amenities.

\subsection{Welfare consequences of place-based redistribution}

Consider an economy with a place-blind income tax $T(\cdot)$. Can adding a place-based redistribution scheme to this place-blind redistribution system improve welfare in this economy? To answer this question, we study the desirability of the simple PBR scheme defined in (3) and compute the welfare effect of an infinitesimal 
place-dependent tax reform of this nature. Despite its simplicity, this case is rich enough to highlight the key tradeoffs that characterize place-based redistribution. Of course, if redistribution that takes this simple form is desirable, then further efficiency gains can be achieved by fully indexing the income tax schedule to place. To simplify exposition, we make from now on the assumption that the optimal earnings function $z^{*}$ exhibits no income effects (i.e., that $\frac{d z^{*}}{d I}=0$ ), as this complication yields few insights in itself. The case of income effects on labor supply is fully covered in the Appendix.

We decompose the total welfare effect of the tax reform into two effects: a direct impact on welfare $\frac{d W}{d \Delta}$ and the corresponding fiscal cost of the reform attributable to behavioral household responses $\frac{d B}{d \Delta}$. Because the tax reform we consider is ex-ante budget neutral, we can write $\frac{d S W F}{d \Delta}=\frac{d W}{d \Delta}+\frac{d B}{d \Delta}$.

Welfare impact Implementing the PBR reform (3) generates a net transfer of utility from residents of Elsewhere to those of Distressed, measured by:

$$
\frac{d W}{d \Delta}=\mathbb{E}\left[\lambda^{*}\left(\frac{j^{*}}{S}-\frac{1-j^{*}}{1-S}\right)\right]=\bar{\lambda}_{1}-\bar{\lambda}_{0}
$$

where $\bar{\lambda}_{j}=\mathbb{E}\left[\lambda^{*} \mid j^{*}=j\right]$ is the average social marginal welfare weight of households located in community $j$. The expression in (5) is the equity gain from the transfer. PBR generates an equity gain so long as the average social marginal welfare weight of Distressed inhabitants is higher than that of residents of Elsewhere. When the weights depend only on pre-tax earnings, a sufficient condition for $\bar{\lambda}_{1}>\bar{\lambda}_{0}$ is that the earnings distribution in Elsewhere first-order stochastically dominates that of Distressed (Atkinson, 1970).

Two caveats are in order here. First, we have assumed so far that rents are not affected by the reform. Endogenizing rents would strengthen the case for PBR if housing supply in Elsewhere is less elastic than in Distressed. On the other hand, some of the equity gains associated with PBR could be capitalized into rents if Distressed has highly inelastic housing supply. These channels are explored more rigorously in the Appendix. Second, recall that we do not account in this model for any localized externalities that PBR may exacerbate or help internalize. Fajgelbaum and Gaubert (2020), who, in contrast, focus on these market failures as a rationale for place-based taxation, find that it is optimal to subsidize low wage areas and tax high wage areas that are too congested. In this case, the equity and efficiency motives for PBR arguably go in the same direction. 
Efficiency cost The equity gain of a PBR reform must be weighed against its corresponding efficiency loss, as this tax reform comes at a fiscal cost. Although the tax reform is ex ante budget neutral, there are two types of behavioral responses to the PBR reform that may generate fiscal externalities. First, some households change their location. These moves do not mechanically generate a first order fiscal externality when starting from a place-blind economy $(\Delta=0)$. However, workers who move may change their earnings, which does generate a first order fiscal effect. Second, households who do not move may adjust their labor earnings in response to the tax reform. Since PBR taxes are lump-sum from the perspective of households who do not move, this second effect is ruled out by our maintained assumption that labor supply fails to exhibit income effects.

To compute the impact of movers on social welfare, we define the share of households with skill-level $\theta$ who live in Distressed when the transfer is of size $\Delta$ as:

$$
S(\theta, \Delta)=\frac{\int_{\left(\varepsilon_{0}, \varepsilon_{1}\right) \in \mathbb{R}^{2}} j^{*}\left(\theta, \varepsilon_{0}, \varepsilon_{1}, \Delta\right) d F\left(\theta, \varepsilon_{0}, \varepsilon_{1}\right)}{\int_{\left(\varepsilon_{0}, \varepsilon_{1}\right) \in \mathbb{R}^{2}} d F\left(\theta, \varepsilon_{0}, \varepsilon_{1}\right)} .
$$

At each skill level $\theta$, the number of movers to Distressed, $\frac{d S(\theta, 0)}{d \Delta} \geq 0$, depends on the density of households initially indifferent between the two locations, and therefore on the distribution of their idiosyncratic shocks. However, since preference shocks are additively separable, movers to Distressed change earnings in a way that depends only on their skill $\theta$, not on locational preference heterogeneity - i.e., $z_{j}^{*}(\Theta)=z_{j}^{*}(\theta) .{ }^{4}$ Hence, the overall fiscal cost of movers is:

$$
\frac{d B}{d \Delta}=\mathbb{E}\left\{\frac{d S(\cdot, 0)}{d \Delta}\left[T\left(z_{1}^{*}\right)-T\left(z_{0}^{*}\right)\right]\right\}
$$

The fiscal cost of movers depends on the density of movers in response to the tax change $\left(\mathbb{E}\left[\frac{d S(\cdot, 0)}{d \Delta}\right] \geq 0\right)$, which may vary by skill level, and on the tax revenue losses of each mover $\left(T\left(z_{1}^{*}\right)-T\left(z_{0}^{*}\right)<0\right)$, which are driven by either the productivity gap or difference in labor supply behavior between the two locations.

Equity-Efficiency Tradeoff The following result summarizes the equity-efficiency tradeoff in place-based redistribution: ${ }^{5}$

\footnotetext{
${ }^{4}$ We consider in the Appendix the more general case where preference shocks are not additively separable. Results analogous to the ones we derive here are shown to hold at the expense of substantially more cumbersome notation.

${ }^{5}$ The $S W F$ is expressed here in dollar value.
} 
Lemma. The first order effect on welfare of a small PBR reform starting from a place-blind system is:

$$
\frac{d S W F}{d \Delta}=\bar{\lambda}_{1}-\bar{\lambda}_{0}+\mathbb{E}\left\{\frac{d S(\cdot, 0)}{d \Delta}\left[T\left(z_{1}^{*}\right)-T\left(z_{0}^{*}\right)\right]\right\}
$$

It is clear from this expression that PBR to a location where disadvantaged households sort is unambiguously welfare improving when the last term is zero rather than negative. This condition is verified in three specific cases: first, if there are no marginal households indifferent between locations, we have $\frac{d S(\theta, 0)}{d \Delta}=$ 0 ; second, if earnings do not differ across locations for households, then $T\left(z_{1}^{*}\right)-T\left(z_{0}^{*}\right)=0$; third, if movers are a selected sample of households for whom there is no earnings differences across locations then $\frac{d S(\theta, 0)}{d \Delta}\left[T\left(z_{1}^{*}\right)-T\left(z_{0}^{*}\right)\right]=0$. Hence, PBR is more likely to be beneficial when mobility responses are low, productivity differences between locations are limited, or mobility responses are dominated by households for which earnings differences across space are small. To illustrate these ideas, we briefly discuss three stylized examples encompassed by our modeling framework that capture situations in which PBR fails to generate any fiscal costs.

Example 1 (Neighborhood Zones). Many place-based policies subsidize particular neighborhoods. Consider a city in which workers live in one of two residential neighborhoods (Elsewhere or Distressed). All households work in the same business district, to which they may commute from either residential neighborhood at equal time $\operatorname{cost} \tau$. In this model, so long as amenities and housing prices have no independent effect on labor supply, location of residence does not impact job productivity or earnings. ${ }^{6}$ In this case, a within-city PBR scheme that subsidizes Distressed entails no fiscal cost: movers who change neighborhoods in response to the subsidy do not lose productivity or adjust their earnings.

Example 2 (Mobility costs). Mobility costs are an important determinant of household migration decisions (Sjaastad, 1962; Kennan and Walker, 2010, 2011; Bayer et al., 2016) that can lead to a dampening of the efficiency costs of PBR. To illustrate this point, suppose households inelastically demand a single unit of housing and have quasi-linear preferences taking the form $u_{j}(\Theta)=c+a_{j}-\frac{1}{\nu+1}\left(\frac{z}{w_{j}(\theta)}\right)^{\nu+1}+\varepsilon_{j}$, where $\varepsilon_{j} \leq 0$ now captures a pecuniary moving cost rather than an idiosyncratic taste. Each household must pay $\$ M$ to locate in a community other than the one in which it is "born," so that either $\left(\varepsilon_{1}=-M, \varepsilon_{0}=0\right)$ or $\left(\varepsilon_{1}=0, \varepsilon_{0}=-M\right)$. To fix ideas, assume that $a_{0}-r_{0}=a_{1}-r_{1}+1000$, so that each household is willing to pay

\footnotetext{
${ }^{6}$ This invariance of earnings choices to location arises for instance when $U=g\left(c-\frac{1}{\nu+1}\left(\frac{z}{(1-\tau) w(\theta)}\right)^{\nu+1}+\widetilde{u}(h, a)\right)$ for some $g$ weakly concave.
} 
$\$ 1,000$ to avoid living in Distressed. When $M>1,000$, every household born in Distressed will stay there, while every household born Elsewhere will strictly prefer to reside in Elsewhere. Hence, a small subsidy to Distressed will yield no migration response and therefore no fiscal cost.

Example 3 (Comparative advantage). The technically demanding jobs at which skilled workers excel are increasingly spatially concentrated (Moretti, 2012; Autor, 2019). Consider a model with two skill levels $\bar{\theta}>\underline{\theta}$ and bounded idiosyncratic taste shocks $\left(\varepsilon_{1}, \varepsilon_{0}\right)$. Suppose Elsewhere has only low skill jobs while Distressed has high and low skill jobs. We formalize this idea with the following assumption on community wages: $w_{0}(\bar{\theta})>w_{0}(\underline{\theta})=w_{1}(\underline{\theta})=w_{1}(\bar{\theta})$. For sufficiently large values of the ratio $w_{0}(\bar{\theta}) / w_{0}(\underline{\theta})$, no type $\bar{\theta}$ households will choose to locate in Distressed. If Distressed is subsidized, only type $\underline{\theta}$ households will migrate in response to the PBR scheme 3. When preferences are such that earnings depend only on wages (see Example 1), this type $\underline{\theta}$ migration entails no earnings losses.

\subsection{Optimal PBR}

Equation (8) gave conditions under which a place-blind tax system can be improved upon by introducing a small place-based transfer. We now derive some results characterizing the magnitude of an optimal PBR scheme. Starting from an optimal $\Delta^{*}$, a small place-based reform will have no first order effect on welfare. Relative to the expression in (7), an additional first order fiscal externality arises in this analysis due to starting at an optimal $\Delta^{*} \neq 0$. Movers from Elsewhere to Distressed generate a fiscal loss per capita of

$\frac{\Delta^{*}}{S(1-S)}$ as they go from being net contributors to becoming net beneficiaries of the PBR scheme. Equating $\frac{d S W F}{d \Delta}\left(\Delta^{*}\right)$ to zero leads to the following formula for the optimal place-based transfer $\Delta^{*}$.

Proposition 1. The optimal place-based transfer $\Delta^{*}$ obeys:

$$
\Delta^{*}=\frac{\bar{\lambda}_{1}\left(\Delta^{*}\right)-\bar{\lambda}_{0}\left(\Delta^{*}\right)+\mathbb{E}\left\{\frac{d S\left(\cdot, \Delta^{*}\right)}{d \Delta}\left[T\left(z_{1}^{*}\right)-T\left(z_{0}^{*}\right)\right]\right\}}{\mathbb{E}\left[\frac{d S\left(\cdot, \Delta^{*}\right)}{d \Delta}\right] /\left[S\left(\Delta^{*}\right)\left(1-S\left(\Delta^{*}\right)\right)\right]}
$$

The size of the optimal transfer is increasing in the degree of inequality between Elsewhere and Distressed, as measured by the difference $\bar{\lambda}_{1}\left(\Delta^{*}\right)-\bar{\lambda}_{0}\left(\Delta^{*}\right)$ in the average social marginal welfare weight of their inhabitants evaluated at the optimal value of the transfer. All else equal, the optimal transfer is larger if the two communities are of roughly similar size, if mobility is low, or if the earnings responses to migration are small. 
A limitation of the above formula is that all of the quantities are evaluated at the optimal transfer level $\Delta^{*}$. A non-recursive representation of the optimal transfer level can be had by linearizing $\frac{d S W F}{d \Delta}\left(\Delta^{*}\right)$ around the point $\Delta^{*}=0$. This approximation yields the following expression:

$$
\begin{aligned}
\frac{d S W F}{d \Delta}\left(\Delta^{*}\right) & \approx \bar{\lambda}_{1}(0)-\bar{\lambda}_{0}(0)+\mathbb{E}\left\{\frac{d S(\cdot, 0)}{d \Delta}\left[T\left(z_{1}^{*}\right)-T\left(z_{0}^{*}\right)\right]\right\} \\
& +\Delta^{*}\left\{\frac{d}{d \Delta}\left(\bar{\lambda}_{1}(0)-\bar{\lambda}_{0}(0)\right)+\mathbb{E}\left[\frac{d^{2} S(\cdot, 0)}{d \Delta^{2}}\left(T\left(z_{1}^{*}\right)-T\left(z_{0}^{*}\right)\right)\right]-\frac{1}{S(1-S)} \frac{d S}{d \Delta}\right\} .
\end{aligned}
$$

Relative to (8), starting at a point $\Delta^{*} \neq 0$ leads to additional distortions that are summarized in the second line of this expression. First, the more households move to Distressed, the lower the remaining equity motive, as captured by $\frac{d}{d \Delta}\left(\bar{\lambda}_{1}(0)-\bar{\lambda}_{0}(0)\right)$. Second, the fiscal externality of movers will be convex in the transfer size whenever $\frac{d^{2} S^{\theta}(., 0)}{d \Delta^{2}}>0$, i.e., when mobility accelerates with $\Delta$. Finally, the last term captures the direct fiscal externality of movers, who change from being contributors to being beneficiaries of PBR. Manipulating the above expression further leads to the following non-recursive expression for the optimal PBR scheme.

Corollary 1. Let $\Lambda(\Theta)=\frac{\partial \lambda(\Theta)}{\partial I}=\frac{1}{\phi} \omega(\Theta) \frac{\partial^{2} v^{*}(\Theta)}{\partial I^{2}}$ and $\bar{\Lambda}_{j}=\mathbb{E}\left[\Lambda(\cdot) \mid j^{*}=j\right]$, both evaluated at $\Delta=0$. Then the optimal place-based transfer $\Delta^{*}$ obeys:

$\Delta^{*} \approx \frac{\bar{\lambda}_{1}(0)-\bar{\lambda}_{0}(0)+\mathbb{E}\left\{\frac{d S(\cdot, 0)}{d \Delta}\left[T\left(z_{1}^{*}\right)-T\left(z_{0}^{*}\right)\right]\right\}}{\frac{1}{S(1-S)}\left\{\frac{d S}{d \Delta}-\mathbb{C}\left[\frac{d S(\cdot, 0)}{d \Delta},(1-S) \lambda_{1}(\cdot, 0)+S \lambda_{0}(\cdot, 0)\right]\right\}-\left(\bar{\Lambda}_{1}(0)+\bar{\Lambda}_{0}(0)\right)-\mathbb{E}\left\{\frac{d^{2} S(\cdot, 0)}{d \Delta^{2}}\left[T\left(z_{1}^{*}\right)-T\left(z_{0}^{*}\right)\right]\right\}}$,

where for two optimized variables $x^{*}$ and $y^{*}, \mathbb{C}\left(x^{*}, y^{*}\right) \equiv \mathbb{E}\left[x^{*}(\cdot) y^{*}(\cdot)\right]-\mathbb{E}\left[x^{*}(\cdot)\right] \mathbb{E}\left[y^{*}(\cdot)\right]$ denotes covariance.

The first term in the denominator captures the impact of the transfer on movers. Each additional dollar of the place-based transfer mechanically yields a windfall gain of $\frac{1}{S(1-S)}$ to movers. As discussed above, when $\frac{d S}{d \Delta}$ is large, there are many movers, which raises the fiscal cost of PBR. The covariance term $\mathbb{C}\left[\frac{d S(., 0)}{d \Delta},(1-S) \lambda_{1}(\cdot, 0)+S \lambda_{0}(\cdot, 0)\right]$ captures whether movers have above average marginal utilities of consumption, in which case transfers are more effective at raising the welfare of movers. The second term in the denominator, $-\left(\bar{\Lambda}_{1}(0)+\bar{\Lambda}_{0}(0)\right)$, measures the concavity of household utility and must be non-negative. When this term is large, the marginal utility of income is capable of being equalized across locations with small transfers. The final term captures the acceleration of efficiency costs due to migration, as discussed above, which limits the optimal size of the transfer. 


\section{When Can PBR Complement an Optimal Place-Blind Tax?}

We have established conditions under which using place as a "tag" for redistribution can lead to welfare gains. It remains to be shown that these conditions can be satisfied when place-blind taxes are chosen optimally. To shed light on this more stringent question, we now study whether expression in (8) can be positive when $T(\cdot)$ has been optimally chosen.

\subsection{Place-blind tax reform design}

Suppose the planner has implemented an optimal place-blind income tax $T(\cdot)$. We aim to compare the effect of a PBR reform to that of a small reform $\stackrel{\circ}{T}: \mathbb{R}_{\geq 0} \rightarrow \mathbb{R}$ of the income tax schedule, where the post-reform schedule is denoted:

$$
\tilde{T}(\cdot)=T(\cdot)+q \stackrel{\circ}{T}(\cdot)
$$

with $q \ll 1$. The place-blind tax reform is designed in such a way that the corresponding equity gains are easily compared to those of the PBR reform (3). Given that the PBR scheme imposes a net tax proportional to $\frac{S-j^{*}(\Theta)}{S(1-S)}$ on household $\Theta$, it is natural to define the place-blind tax reform at earnings level $z$ as:

$$
\stackrel{\circ}{T}(z)=\mathbb{E}\left[\frac{S-j^{*}}{S(1-S)} \mid z^{*}=z\right]
$$

That is, $T^{\circ}(z)$ is defined as the pointwise tax reform that, absent a behavioral response, has exactly the same average tax effect on individuals with earnings level $z$ as the PBR scheme (3). In particular, this tax perturbation is ex-ante budget neutral, as is the proposed PBR scheme. Letting $\rho(z) \equiv \mathbb{E}\left[j^{*} \mid z^{*}=z\right]$ denote the share of households with earnings level $z$ residing in Distressed, the tax perturbation is simply:

$$
\stackrel{\circ}{T}(z)=\frac{S-\rho(z)}{S(1-S)} .
$$

We note that in the empirically relevant case where $\rho(\cdot)$ is monotone decreasing with income, there exists an earnings threshold $\underline{z}$ such that the tax perturbation (9) is a subsidy for $z \leq \underline{z}$ and a tax for $z>\underline{z}$.

\subsection{Welfare impact}

For a small tax perturbation $\stackrel{\circ}{T}^{(\cdot)}$, the direct impact of the reform on household welfare is positive for those households that receive a subsidy, and negative for those households for whom $\stackrel{\circ}{T}(\cdot)$ is a tax. The

corresponding impact on the social welfare function is $\frac{d W}{d q}=-\mathbb{E}\left[\lambda^{*} \frac{S-\rho\left(z^{*}\right)}{S(1-S)}\right]$, which differs slightly from the 
equity impact of the PBR reform in (5). In terms of equity gains, the PBR scheme compares to the income tax perturbation as follows:

$$
\frac{d W}{d \Delta}-\frac{d W}{d q}=\frac{\mathbb{E}\left[\mathbb{C}\left(\lambda^{*}, j^{*} \mid z^{*}\right)\right]}{S(1-S)}
$$

where $\mathbb{C}\left(x^{*}, y^{*} \mid z^{*}=z\right)=\mathbb{E}\left[x^{*} y^{*} \mid z^{*}=z\right]-\mathbb{E}\left[x^{*} \mid z^{*}=z\right] \mathbb{E}\left[y^{*} \mid z^{*}=z\right]$ denotes the covariance between choices $x^{*}$ and $y^{*}$ among households with optimized earnings level $z$. That is, whether or not a PBR scheme yields additional equity gains relative to an income tax reform hinges on the conditional covariance in (11): PBR yields specific equity gains if households located in Distressed tend to have higher social marginal welfare weights than households with the same pre-tax earnings that reside in Elsewhere. The sign of this conditional covariance term depends on the planner's preferences and on how location impacts the marginal utility of income. Because within-income group equity considerations have received little formal attention in the literature on place-based policies, we defer the discussion of microfoundations for such spatial equity motives to the next section.

The PBR scheme and the income tax reform also differ in their efficiency cost, which we now compute. The income tax reform triggers two behavioral responses. First, the change in the tax schedule leads to a change in potential earnings in the two locations, and hence a change in their relative utilities. As a result, some households switch communities, leading to a change in earnings and a corresponding fiscal cost $T\left(z_{1}^{*}\right)-T\left(z_{0}^{*}\right)$ for households who move from Elsewhere to Distressed. Second, the change in marginal tax rates generates earnings responses for households who do not change location through a substitution effect. Taken together, we show in the Appendix that the fiscal cost of the income tax reform is:

$$
\frac{1}{S(1-S)} \underbrace{\mathbb{E}\left\{T^{\prime}\left(z^{*}\right) \rho^{\prime}\left(z^{*}\right) \frac{Z_{1-\tau}}{1+Z_{1-\tau} T^{\prime \prime}\left(z^{*}\right)}\right\}}_{\text {substitution effect }}+\underbrace{\mathbb{E}\left\{\frac{d S}{d q}\left[T\left(z_{1}^{*}\right)-T\left(z_{0}^{*}\right)\right]\right\}}_{\text {movers response }},
$$

where $Z_{1-\tau}(\Theta)=\frac{\partial z^{*}(\Theta)}{\partial(1-\tau)}>0$ denotes the compensated labor earnings response to a change in the marginal net of tax rate $1-T^{\prime}\left(z^{*}\right)$.

The net efficiency cost of the PBR scheme relative to the income tax perturbation is:

$$
\begin{aligned}
\frac{d B}{d \Delta}-\frac{d B}{d q} & =\mathbb{E}\left\{\left(\frac{d S(\cdot, 0)}{d \Delta}-\frac{d S(\cdot, 0)}{d q}\right)\left[T\left(z_{1}^{*}\right)-T\left(z_{0}^{*}\right)\right]\right\} \\
& -\mathbb{E}\left\{T^{\prime}\left(z^{*}\right) \frac{\rho^{\prime}\left(z^{*}\right)}{S(1-S)} \frac{Z_{1-\tau}}{1+Z_{1-\tau} T^{\prime \prime}\left(z^{*}\right)}\right\}
\end{aligned}
$$


To discuss the sign of (13), we focus on the plausible setting where $\rho^{\prime}(z)<0$ for all $z \in \mathbb{R}_{+}$, so that the probability of living in Distressed decreases with earnings. ${ }^{7}$ In this case, the last term is unambiguously positive because the income tax reform yields an increase in the marginal tax rate at all earnings levels, which distorts the labor supply of all infra-marginal households. In contrast, the place-based reform only affects the behavior of marginal households indifferent between the two communities. The first term in (13) captures the net cost of any PBR-induced moves relative to the corresponding moves induced by the tax reform. This term is weakly negative: PBR generates more moves from Elsewhere to Distressed than does a corresponding income tax, as PBR acts directly upon the relative attractiveness of the two locations. Because these two terms have opposite signs, the sign of (13) is theoretically ambiguous, implying that whether PBR generates efficiency costs larger or smaller than a corresponding income tax reform depends on the specific structure of household preferences and technology present in the economy. ${ }^{8}$

Overall, the welfare gain from PBR relative to a corresponding income tax reform hinges on the sign of the following expression:

$$
\frac{d S W F}{d \Delta}-\frac{d S W F}{d q}=\underbrace{\left(\frac{d W}{d \Delta}-\frac{d W}{d q}\right)}_{\text {equity }}+\underbrace{\left(\frac{d B}{d \Delta}-\frac{d B}{d q}\right)}_{\text {efficiency }}
$$

Place-blind income taxation will be dominated whenever the relative equity benefits of PBR outweigh the policy's relative efficiency costs.

To develop intuition for how PBR can improve upon an optimal income tax, consider a world where the equity term in (14) is zero, so that the planner only values redistribution between households with different pre-tax earning levels. Suppose further that PBR entails no efficiency costs, as in the examples of the previous section. Then, a sufficient condition for PBR to improve upon an optimal income tax is that there be spatial sorting, so that PBR deliver equity gains. What follows is a simple illustrative example of this argument.

Example 4 (Sorting based on skill-taste correlation). Suppose households have unit housing consumption (i.e., $\left.c=z-T(z)-r_{j}\right)$ and maximize utility $u(c, z, j ; \theta)=c-\left(\frac{z}{\theta}\right)^{\nu}+a_{j}(\theta)$, where $a_{1}(\theta)=0$ and $a_{0}(\theta)>0$.

\footnotetext{
${ }^{7}$ Note that this assumption implies that the distribution of pre-tax earnings in Elsewhere first order stochastically dominates the distribution in Distressed.

${ }^{8}$ If, in addition, there are income effects in labor supply, we show in the Appendix that under the assumptions invoked by Saez (2002) on the distribution of these income effects in labor supply conditional on pre-tax earnings, the PBR scheme and the income tax reforms would have the same impact on stayers. Consequently, adding income effects on labor supply to the analysis yields limited additional insight.
} 
The higher skilled value the amenities of Elsewhere more, yielding $a_{0}^{\prime}(\theta)>0$. Following Kleven et al. (2009), we introduce a preference for redistribution by having the planner maximize $S W F=\mathbb{E}\left[G\left(v^{*}\right)\right]$, where $G(\cdot)$ is a concave function. It is straightforward to verify that the optimal earnings choices of a type- $\theta$ household are identical in the two locations (i.e., $z_{1}^{*}(\theta)=z_{0}^{*}(\theta)$ ) and that there exists a skill threshold above which all workers sort to Elsewhere. PBR generates equity gains $\bar{\lambda}_{1}-\bar{\lambda}_{0}>0$ because residents of Elsewhere have both higher earnings and higher utility than those in Distressed. PBR yields no efficiency costs, however, as movers do not change their earnings. We now show that these features allow PBR to generate welfare gains even in the presence of optimal income taxes.

Proof. To compute the welfare effect of implementing a small reform to an initially optimal place-blind income tax that delivers the same equity gain as the PBR scheme above, consider the income tax perturbation $d \tilde{T}(z)=\left\{\begin{array}{ll}-\frac{d \Delta}{S} & \text { if } z \leq \underline{z} \\ \frac{d \Delta}{1-S} & \text { if } z>\underline{z}\end{array}\right.$, where $\underline{z}$ is the earnings threshold above which households choose to reside in Elsewhere. This reform targets exactly the same households as PBR, and, absent behavioral responses of households, imposes the same taxes and subsidies as the PBR scheme. In contrast to PBR, however, this reform generates a behavioral response. Specifically, households with initial income in the range $[\underline{z}, \underline{z}+d z]$ will bunch at earnings level $\underline{z}$ to avoid this tax. The earnings reductions associated with this bunching generate a fiscal loss for the government, which we denote $\frac{d B_{T}}{d \Delta}<0$. Given that we are considering a reform of an optimal tax system, this reform cannot yield a first order effect on welfare, as $\bar{\lambda}_{1}-\bar{\lambda}_{0}+\frac{d B_{T}}{d \Delta}=0$ by construction. Hence, PBR yields a positive first-order welfare gain $\bar{\lambda}_{1}-\bar{\lambda}_{0}$ even in the presence of optimal income taxes.

We conclude this section by moving away from the case above where PBR yields no efficiency cost and noting that, in general, the presence of spatial sorting is not in itself sufficient to justify PBR. For instance, in accord with the commodity taxation logic of Atkinson and Stiglitz (1976), PBR can be dominated by income taxation when spatial sorting is only driven by income effects, as the following example illustrates.

Example 5 (Income-based sorting). Suppose that households exhibit unit housing consumption and maximize preferences given by

$$
u_{j}(\Theta)=a_{j} \cdot(c)^{\gamma}-\frac{\eta}{1+\eta}\left(\frac{z}{\theta}\right)^{\frac{1+\eta}{\eta}}
$$

Because locational preferences are homogeneous (i.e., $\varepsilon_{j}=0$ for all households), spatial sorting is only driven by income effects. The high $\theta$ will sort into Elsewhere to benefit from higher amenities, while the low $\theta$, 
who are more sensitive to the cost of living, will sort into Distressed. If PBR generates equity gains, it also yields efficiency losses because movers change their earnings. We show formally in Appendix A.1.5 that these efficiency costs lead PBR to be dominated by the income tax. The proof applies standard arguments from Kaplow (2006) and Laroque (2005). The key features of this example that allow those results to be applied are that labor supply is weakly separable from consumption and the sub-utility of consumption $a_{j} \cdot(c)^{\gamma}$ is homogeneous across individuals.

\section{$5 \quad$ Spatial Equity Motives}

In this section we turn to exploring in more depth the factors generating possible net equity gains of PBR over and above those that can be achieved with income taxation. The income tax generates equity gains from redistributing across earnings levels. Depending on individual and social preferences, there can also be equity gains from redistributing within earnings levels from Elsewhere to Distressed that the income tax cannot achieve.

From (5), the equity gains of $\mathrm{PBR}$ are proportional to the covariance $\mathbb{C}\left(\lambda^{*}, j^{*}\right)$. We can decompose this covariance into between-earnings and within-earnings components as follows:

$$
\mathbb{C}\left(\lambda^{*}, j^{*}\right)=\underbrace{\mathbb{C}\left(\mathbb{E}\left[\lambda^{*} \mid z^{*}\right], \mathbb{E}\left[j^{*} \mid z^{*}\right]\right)}_{\text {between earnings }}+\underbrace{\mathbb{E}\left[\mathbb{C}\left(\lambda^{*}, j^{*} \mid z^{*}\right)\right]}_{\text {within earnings }}
$$

The between-earnings component is positive if Distressed has an over-representation of low-income households, as discussed above. However, this component can also be directly targeted by income-based redistribution. Therefore, in the presence of an optimally designed income tax, any unique equity gains of PBR must emanate from the within-earnings term. This within-earnings term makes PBR from Elsewhere to Distressed more desirable if and only if households residing in Distressed tend to have higher social marginal welfare weights than their peers in Elsewhere with the same pre-tax earnings $z^{*}$.

We now discuss microfounded rationales for such conditional differences in social welfare weights. The first rationale emphasizes the role played by cost of living differences in making PBR desirable, while the second highlights the role played by heterogeneous amenities in making PBR desirable. To isolate these motives, we focus on preferences that are separable in leisure and assume that preferences over amenities 
are weakly separable from housing and consumption as follows:

$$
U\left(c, h, a_{j}, \frac{z}{w(\theta)}\right)=\psi\left(g(c, h), a_{j}\right)-e\left(\frac{z}{w(\theta)}\right)
$$

where $g=g(c, h)$ is a homothetic consumption goods index, $\psi($.$) is a weakly concave aggregator, and e($. captures disutility of labor.

\subsection{A dollar goes further in Distressed}

To isolate the role of cost of living differences, we temporarily ignore amenity differences by assuming that $a_{0}=a_{1}$. Supposing that the planner values households with equal Pareto weights in (2), the corresponding social marginal welfare weight of a household with earnings level $z$ and location choice $j$ is

$$
\lambda_{z}^{j}=\frac{1}{\phi} \frac{1}{P_{j}} \psi^{\prime}\left(\frac{z}{P_{j}}\right)
$$

where $P_{j}$ is the cost-of-living index in location $j$ corresponding to $g(\cdot, \cdot)$. By assumption, this price index is higher in Elsewhere than in Distressed $\left(P_{0}>P_{1}\right)$.

We are interested in conditions under which, conditional on earnings $z$, the social marginal welfare weight $\lambda_{z}^{j}$ is higher in Distressed. Two opposite effects are at play. The quantity $\frac{1}{\phi P_{j}}$ is higher in Distressed, capturing the fact that a (nominal) dollar spent by the federal government always goes further in buying consumption in the low-price location. By contrast, among households with the same income, the term $\psi^{\prime}\left(\frac{z}{P_{j}}\right)$ tends to be higher in Elsewhere, as households are poorer in real terms in the high-price location. Which effect dominates depends on the concavity of $\psi(\cdot)$. Specifically, $\lambda_{z}^{1}>\lambda_{z}^{0}$ if and only if the mapping $x \mapsto x \psi^{\prime}(x)$ is increasing. ${ }^{9}$ Hence, if $\psi$ is not too concave, the "dollar goes further" argument motivates redistribution towards low cost-of-living places.

\subsection{Households in Distressed are worse off, conditional on income}

Heterogeneous amenities may also play a role in motivating redistribution between households with the same earnings. In general, this effect comes in addition to the cost-of-living effect above. To isolate the role of amenities, we assume that Distressed is a low amenity area $\left(a_{1}<a_{0}\right)$ but we ignore cost-of-living differences, i.e. we assume that $P_{0}=P_{1}$.

\footnotetext{
${ }^{9}$ For CRRA utility with coefficient of risk aversion $\gamma, \psi(x)=\frac{x^{1-\gamma}}{1-\gamma}$ and the condition is satisfied so long as $\gamma \leq 1$.
} 
Since social marginal welfare weights are given by:

$$
\lambda=\frac{1}{\phi} \frac{\partial \psi}{\partial g} \frac{\partial g}{\partial z}
$$

it follows that $\lambda_{z}^{1}>\lambda_{z}^{0}$ if and only if $\frac{\partial^{2} \psi}{\partial g \partial a}<0$, i.e. if consumption and amenities are q-substitutes. With q-substitutability, the low level of amenities in Distressed raises the marginal utility of consumption there, all else equal. The assumption of q-substitutability captures well the notion that consumption disamenities can raise the marginal utility of consumption. For example, pollution-induced asthma can raise the marginal utility of health care expenditures. Standard CES preferences of the form $U\left(g, a_{j}\right)=$ $\frac{1}{1-\gamma}\left(a_{j}^{\frac{\sigma-1}{\sigma}}+g^{\frac{\sigma-1}{\sigma}}\right)^{(1-\gamma) \frac{\sigma}{\sigma-1}}$, with $\gamma \in\left(\frac{1}{\sigma}, 1\right)$ capture such behavior. Interestingly, empirical models of spatial equilibrium (e.g., Moretti, 2011, 2013; Diamond, 2016; Suárez Serrato and Zidar, 2016) typically restrict preferences to obey a Cobb-Douglas functional form between amenities and consumption, which rules this channel out by imposing $\frac{\partial^{2} U}{\partial g \partial a}>0$.

\subsection{Equality and justice}

Thus far, our discussion of spatial equity motives has followed the logic of utilitarianism, whereby policies aim to equalize the marginal utility of consumption across households in order to maximize social welfare. However, place-based policies are sometimes motivated by additional considerations such as concerns over inequality in levels of well-being across space, even if levels do not correspond to marginal utilities. ${ }^{10} \mathrm{~A}$ conceptually distinct (but often empirically overlapping) concern has to do with the righting of perceived wrongs involving unequal treatment of places. For example, the 1992 Los Angeles riots are often cited as a motivation for the passage of the federal legislation authorizing the U.S. Empowerment Zones in 1993 (Liebschutz, 1995; Katz, 2015), perhaps because of a sense that living conditions in distressed urban areas were unacceptably poor or that the residents of these areas had been subjected to unfair treatment by police and other parties. Likewise, Gulf Opportunity Zones (GOZs) were instituted in 2005 for areas devastated by Hurricane Katrina. ${ }^{11}$ Finally, as mentioned in Section 2, many poor communities may continue to bear the burden of unfair historical practices.

Formally, the policy implications of a variety of redistributive motives can be explored rigorously in a

\footnotetext{
${ }^{10}$ Concern over inequality in well-being levels can be accommodated by making the planner value a concave function of indirect utilities as in Kleven et al. (2009) (see also Example 4).

${ }^{11}$ While the GOZs and other post-Katrina initiatives may be viewed as a means of addressing externalities involving rebuilding (Fu and Gregory, 2019), they can also plausibly be viewed as valuing redistribution to families with low levels of utility for reasons outside their control.
} 
utilitarian framework by choosing high Pareto weights $\omega(\Theta)$ and thus high social marginal social welfare weights $\lambda^{*}$ for households to which concerns pertain, as Saez and Stantcheva (2016) note. This approach has not traditionally been followed by the commodity taxation literature (e.g., Atkinson and Stiglitz, 1976; Saez, 2002), which typically assumes that social welfare weights $\lambda^{*}$ depend only on pre-tax earnings, thereby avoiding utilitarian dilemmas where the planner must redistribute to high income households with expensive tastes (Kaplow, 2008). While this stance may be reasonable for many, if not most, consumption goods, it is our impression that place-based policies are often motivated by spatial equality and justice motives. Unfortunately, little systematic evidence exists on such social preferences. Therefore, we now turn to exploring this question empirically.

\subsection{Social preferences}

To assess social preferences for distribution within earnings groups across space, we conducted a survey on Amazon's Mechanical Turk (MTurk) online labor market platform. MTurk has increasingly been used by social scientists to conduct surveys that have proven concordant with the General Social Survey and other representative national surveys (Paolacci et al., 2010; Horton et al., 2011; Weinzierl, 2014; Kuziemko et al., 2015; Fisman et al., 2020).

On July 9-10, 2020, we posted requests on MTurk for a cumulative total of 1,100 survey respondents with U.S. billing addresses and positive ratings from at least 90 percent of past requestors. ${ }^{12}$ Compensation for our ten-minute survey was $\$ 2$, which exceeds the typical MTurk wage. As in Fisman et al. (2020), we find that answers to a GSS question on redistributive preferences broadly conforms to representative survey data. Appendix B provides additional details on the survey.

In order to elicit relative social preferences for distribution within earnings levels across local areas, we asked respondents two main questions about government transfers, in random order and with randomly ordered answer choices. One question elicited within-earnings distributional preferences across neighborhoods with the following vignette:

\footnotetext{
${ }^{12}$ Thirty respondents had invalid MTurk IDs or failed an attentiveness question, yielding a final analysis sample of 1,070 respondents. We surveyed 1,100 in order to ensure at least 1,000 valid attentive responses.
} 
We have written a survey to try to understand how people think about the economy in relation to where people live. There are no right or wrong answers.

Background:

Think about America's cities and towns, which are divided into neighborhoods.

To keep things simple, let's think of there being only three kinds of neighborhoods.

A few neighborhoods are "distressed" and have low housing costs but also high poverty, high crime, high pollution, and struggling schools.

Many other neighborhoods are "thriving" and have high housing costs but also low poverty, low crime, low pollution, and great schools.

The remaining neighborhoods have typical housing costs, poverty, pollution, schools, and economies.

Also to keep things simple, let's think of there being only two income levels: rich and poor. Rich families earn $\$ 90,000$ per year. Poor families earn $\$ 30,000$ per year.

One percent of poor families live in the many thriving neighborhoods, mostly around rich families.

One percent of poor families live in the few distressed neighborhoods, in concentrated poverty.

The government uses a large tax credit to help poor families everywhere.

Question:

Let's pretend that the government has some extra money for new tax credits. It might target the tax credits based on where people live.

The government is deciding between three equally costly options. It wants you to choose the option that would do the most good. Which option would you choose?

(No one will work less or move as a result of your choice.)

- A $\$ 1$ tax credit for poor families everywhere

- A $\$ 100$ tax credit for poor families in the distressed neighborhoods

- A $\$ 100$ tax credit for poor families in the thriving neighborhoods

In telling the respondent that no one will work less or move as a result their choice, we aimed to remove efficiency considerations from their policy choice and therefore home in on social marginal welfare weight considerations.

A second question was identical to the above vignette, except that it elicited within-earnings distributional preferences across regions by replacing the first background sentence with "Think about American regions that are larger than cities but smaller than states." The distressed and thriving regions were described similarly to the distressed and thriving neighborhoods, except that a history of job losses/growth replaced high/low crime.

Figure 3a displays the frequency of each response option. Interestingly, we find that about half of respondents chose to target the benefit to poor families in distressed neighborhoods or regions (51\% in the neighborhood question and $48 \%$ in the region question). Roughly a quarter of respondents chose to distribute the benefit equally to all poor families, irrespective of where they live (25\% and $24 \%$ ), while the remaining quarter chose to distribute the benefit to poor families in the thriving neighborhoods or regions $(25 \%$ and $28 \%$ ). Hence, the survey evidence suggests social preferences that, on average, favor transfers to residents of 


\section{FIGURE 3: Survey Results on Distributive Preferences}

A. Where Should the Government Direct New Tax Credits for the Poor?

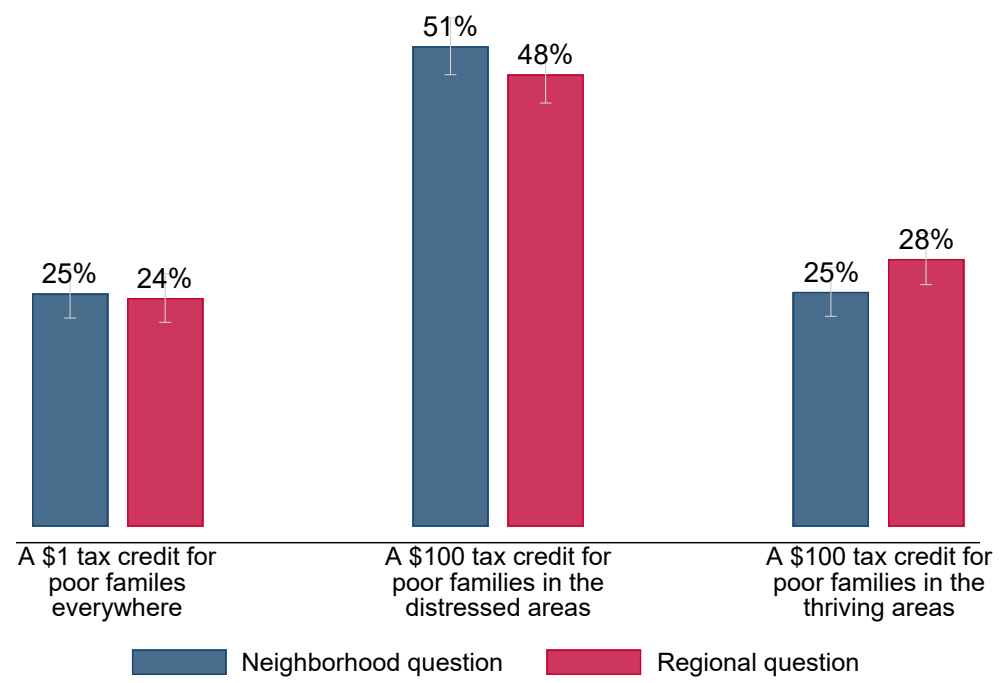

B. Why Should the Government Direct New Tax Credits to the Poor in Distressed Areas?

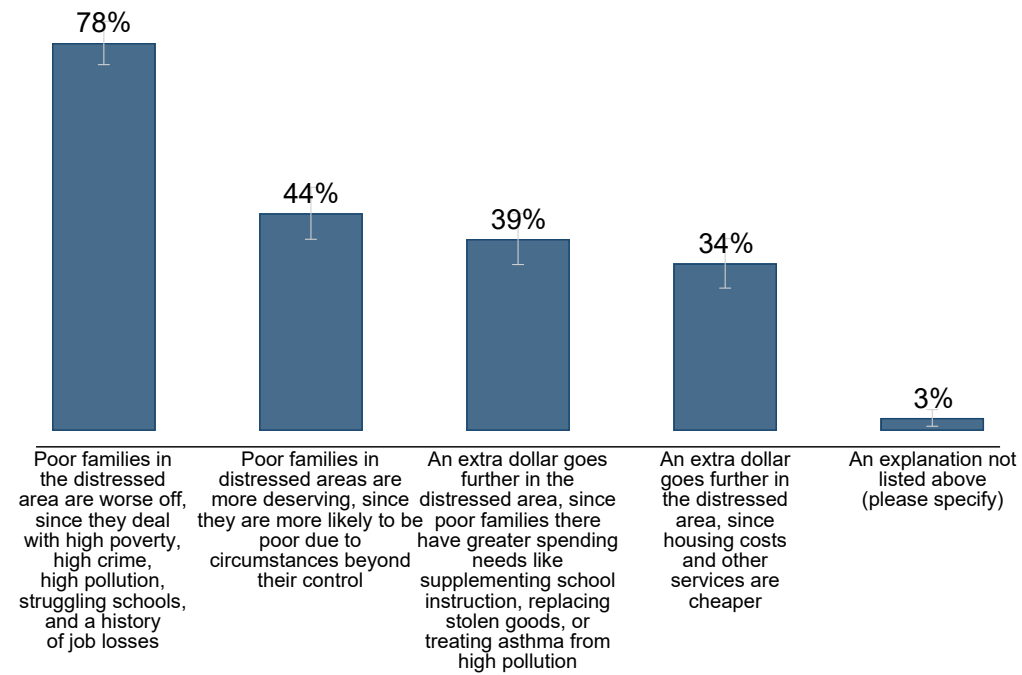

Notes: This figure presents results from our non-representative survey of 1,100 Americans (1,070 valid responses) on Amazon's Mechanical Turk (MTurk) online labor market platform. We told respondents to think of three types of neighborhoods (and separately regions) - "distressed", "thriving", and "typical" with two types of residents: rich families who earn $\$ 90,000$ and poor families who earn $\$ 30,000$. We then asked them to choose the option among three equally costly potential tax credits that would do the most good, under the assumption of no behavioral responses: $\$ 1$ to every poor family everywhere, $\$ 100$ to every poor family in the distressed areas, or $\$ 100$ to every poor family in thriving areas. Panel A plots the results along with $95 \%$ confidence intervals. Panel B presents results from a follow-up question to respondents who chose to give $\$ 100$ to poor families in distressed neighborhoods as well as in distressed regions, which asked them to select all options that explain their choice. See Online Appendix B and Online Appendix Tables 1-2 for more details and results. 
distressed areas conditional on earnings levels.

To understand the motives underlying these responses, we asked each respondent to explain their distributive choices. We focus here on the explanations provided by the respondents who chose to target the benefit to both distressed neighborhoods and distressed regions (Appendix B provides additional results). We prompted those respondents with the following question, the first four options of which were presented in random order:

In response to the previous questions, you chose a $\$ 100$ tax credit for poor families in distressed areas. Which of the following explains your choice? Select all that apply.

- An extra dollar goes further in distressed areas, since rent and other services are cheaper

- An extra dollar goes further in distressed areas, since poor families there have greater spending needs like supplementing school instruction, replacing stolen goods, or treating asthma from high pollution

- Poor families in distressed areas are worse off, since they deal with high poverty, high crime, high pollution, struggling schools, and a history of job losses

- Poor families in distressed areas are more deserving, since they are more likely to be poor due to circumstances beyond their control

- None of the above (please specify)

Figure $3 \mathrm{~b}$ displays the frequency with which each option was selected. A large majority (78\%) of respondents choosing within-earnings level transfers to distressed areas state that they do so because residents there lack basic amenities such as public safety, school quality, and environmental health. The view that poor households living in poor places are especially disadvantaged is notably consistent with a wide array of highly influential qualitative research on poor neighborhoods and regions (Wilson, 1987, 2011; Anderson, 2000; Vance, 2016). That this relative disadvantage is often cited as a justification for spatial targeting is suggestive of an aversion to extreme geographic inequality in certain local amenities. ${ }^{13}$ A near majority (44\%) of respondents cite the poverty of distressed area residents as being due to circumstances beyond their control, a form of the justice logic of Section 5.3. Slightly fewer (39\%) cite a higher marginal utility of consumption due to local disamenities as in the q-substitutes logic of Section 5.2, and $34 \%$ cite a higher marginal social value due to lower local prices, as in the dollar-goes-further logic of Section 5.1. Only $3 \%$ cite none of the above. In sum, these findings suggest that many Americans favor fostering spatial equity within earnings groups.

\footnotetext{
${ }^{13}$ Reconciling the normative view that Americans are entitled to certain basic amenities with the fact that many households willingly sort to distressed neighborhoods in order to economize on rent presents a challenge for quantitative spatial equilibrium models. One reason for favoring residents of distressed areas is that they may be "trapped" by a mix of pecuniary and nonpecuniary moving costs (Bergman et al., 2019). These mobility costs may be captured in our framework as described in Example 2 above. Likewise, information frictions (Bergman et al., 2020; Fujiwara et al., 2020) may lead households to make suboptimal location choices. Finally, children and some elderly and disabled individuals are dependent on the neighborhood choices of caregivers, who may not be fully altruistic.
} 


\section{How Large Might Optimal Place-Based Transfers Be?}

The theoretical analysis of Section 4 revealed that the ability of PBR to improve on income-based redistribution relied on a number of behavioral and normative factors. The desirability of PBR is therefore ultimately a quantitative question. In order to gauge what level of PBR might be optimal in the United States, we turn now to a quantitative calibration of a locational choice model and consider a lump-sum place-based transfer to the poorest $1 \%$ of local areas, which is roughly the population share of U.S. Empowerment Zones. ${ }^{14}$

\subsection{Model primitives}

In the quantification exercise, households choose one of 100 locations in which to live and work. To operationalize the model, we equate each community with an amalgamation of potentially non-contiguous Census tracts. Specifically, we rank tracts in the 2013-2017 American Community Survey (ACS) by their poverty rate and group them into communities $j \in\{1, \ldots, 100\}$ that each have one percent of the U.S. population.

Preferences Household preferences for living in community $j$ take the form:

$$
u_{j}(\Theta)=\ln \left(\left(\frac{c}{1-\alpha}\right)^{1-\alpha}\left(\frac{h-\underline{h}}{\alpha}\right)^{\alpha}-\frac{\eta}{1+\eta}\left(\frac{z}{w_{j}(\theta)}\right)^{\frac{1+\eta}{\eta}}\right)+a_{j}(\theta)+\frac{1}{\kappa} \varepsilon_{j} .
$$

The quantity $\underline{h} \geq 0$ gives a minimum subsistence level of housing services that agents require for survival. The parameter $\alpha \in(0,1)$ governs how many cents of each dollar of disposable income, above the minimum necessary to purchase $\underline{h}$, is spent on housing. The parameter $\eta>0$ gives the Frisch labor supply elasticity. The wage level in community $j$ for a worker of skill type $\theta$ is $w_{j}(\theta)$ and the mean valuation of community $j$ 's amenities by a household of skill type $\theta$ is governed by $a_{j}(\theta)$. The idiosyncratic locational preferences $\left\{\varepsilon_{j}\right\}_{j=1}^{100}$ are iid draws from a Type I Extreme Value (EV1) distribution and $\kappa>0$ is a scale parameter that governs the migration elasticity of households to local wage levels.

A few comments are in order here. First, we have followed the convention in urban economics of allowing high-skilled and low-skilled households to disagree on the valuation $a_{j}(\theta)$ of locational amenities (Moretti, 2013; Diamond, 2016). Second, in the special case where $\eta=0$ and $\underline{h}=0$, labor supply is completely inelastic and consumption is homothetic, yielding a formulation equivalent (via a log-transformation) to

\footnotetext{
${ }^{14} \mathrm{~A}$ list of the forty active U.S. Empowerment Zones (thirty urban and ten rural) is available at https://www.irs.gov/instructions/i8844.
} 
the preference specifications used in workhorse quantitative spatial economics models (Ahlfeldt et al., 2015; Redding and Rossi-Hansberg, 2017). Third, restricting amenities and locational preferences to be additively separable ensures that social marginal welfare weights do not depend directly on these factors, which are typically only identified up to a constant (see the discussion in Appendix A.2.4). When $\eta>0$, our preference formulation imposes that leisure and consumption are closer substitutes than amenities and consumption. We consider this restriction plausible given the substantial share of expenditures that are for services that could be produced at home (Becker, 1965; Hurst, 2008; Aguiar et al., 2012).

Household budget Households maximize utility subject to the budget constraint:

$$
c+r_{j} h=z-T(z)+1\{j=1\} \Delta,
$$

where $r_{j}$ denotes community $j$ 's rental cost of housing, $T(\cdot)$ is a place-blind tax schedule, and $\Delta$ is the subsidy to residents of the poorest community $j=1$ ("Distressed").

Wages and skills Skill types $\theta$ are drawn from a lognormal distribution with parameters $\left(\mu_{\theta}, \sigma_{\theta}\right)$ that we discretize into fifty equal-sized bins, each with two percent of the population. Borrowing the formulation of spatial comparative advantage adopted in Combes et al. (2012) and De La Roca and Puga (2017), we allow wages to depend on skill as follows

$$
\ln w_{j}(\theta)=\ln W_{j}+b_{j} \ln \theta
$$

where $W_{j}$ is a labor productivity shifter common to all skills in community $j$ and $b_{j}$ governs the degree to which skilled households possess a comparative advantage in community $j$. For calibration purposes, we model the community specific parameters as follows:

$$
W_{j} / W_{100}=\left(r_{j} / r_{100}\right)^{\beta_{1}}, \quad b_{j} / b_{100}=\left(W_{j} / W_{100}\right)^{\beta_{2}} .
$$

For convenience, we set rent in the lowest-poverty community $(j=100)$ to one, yielding the normalization $r_{100}=W_{100}=b_{100}=1$. In our baseline specification $\beta_{2}=0$, which eliminates comparative advantage but leaves absolute productivity differences across communities such that wages simply equal the product of community productivity and skill: $w_{j}(\theta)=W_{j} \theta=r_{j}^{\beta_{1}} \theta$. Hence, the parameter $\beta_{1}$ measures the productivity to rent elasticity. 
Social welfare function and government budget constraint Social preferences are utilitarian (i.e., $\left.S W F=\mathbb{E}\left[v^{*}\right]\right)$ and the planner faces an exogenous revenue requirement $R$ :

$$
\mathbb{E}\left[T\left(z^{*}\right)-1\left\{j^{*}=1\right\} \Delta\right]=R .
$$

For computational simplicity, we restrict the place-blind tax system $T(z)$ to be piecewise-linear with a lump-sum transfer and kinks at annual earning levels of $\$ 20,000$ and $\$ 80,000$.

\subsection{Implied sorting behavior}

Because place-based redistribution is motivated by the concentration of low-income households into particular geographic areas, it is instructive to characterize sources of skill sorting in our model. Absent taxes, the share of skill type- $\theta$ workers living in community $j$ can be written:

$$
s_{j}(\theta)=\frac{\left(w_{j}(\theta) r_{j}^{-\alpha}-(1+\eta) \underline{h} r_{j}^{1-\alpha}\right)^{\kappa(1+\eta)} \exp \left(\kappa a_{j}(\theta)\right)}{\sum_{i=1}^{100}\left(w_{i}(\theta) r_{i}^{-\alpha}-(1+\eta) \underline{h} r_{i}^{1-\alpha}\right)^{\kappa(1+\eta)} \exp \left(\kappa a_{i}(\theta)\right)} .
$$

Note that $\left.\frac{\partial \log s_{j}(\theta)}{\partial \log w_{j}}\right|_{\underline{h}=0}=\kappa(1+\eta)\left(1-s_{j}(\theta)\right)$. Consequently, under our homothetic baseline calibration $(\underline{h}=0)$, the migration-wage elasticity is approximately $\kappa(1+\eta)$ for a community with $1 \%$ of the population.

There are three key drivers of skill sorting captured in our preference formulation. The first is skilltaste correlation. In our baseline specification, which fixes $\underline{h}=0$ (no income effects in location choice) and $\beta_{2}=0$ (no comparative advantage), sorting of skill types across space arises solely due to skill variation in the community amenities $a_{j}(\theta) .{ }^{15}$ It is also important to note that this specification avoids spatial equity motives within earnings levels. Specifically, in the absence of income taxes, the planner's welfare weight can be written $\lambda^{*}(j, \theta) \propto(1+\eta) / z_{j}^{\theta}$. Hence, welfare weights vary across households with different earnings, but not across households with the same earnings. ${ }^{16}$ Recall that there are two broad classes of motives for PBR: (i) reducing the efficiency cost of redistributing between households with different pre-tax earnings levels; and (ii) redistributing between households with the same earnings who live in different locations. Although

\footnotetext{
${ }^{15}$ To see this, note that $s_{j}(\theta) \propto \exp \left(\kappa a_{j}(\theta)\right)\left(\frac{W_{j}}{r_{j}^{\alpha}}\right)^{\kappa(1+\eta)}$, which only depends on $\theta$ through the amenities term. In particular, the city-skill premium plays no role in incentivizing high-skill households to sort into high rent communities, as all skill types benefit proportionally from locating in high productivity (high- $W_{j}$ ) communities. We have abstracted, however, from non-linear income taxes, which can provide additional sorting incentives.

${ }^{16}$ Davis and Gregory (2020) consider a planner that values redistribution only between skill types $\theta$, but not across space within skill types. In our setup $\lambda^{*}(j, \theta) \propto \theta^{-(1+\eta)} r_{j}^{\alpha \eta-\beta_{1}(1+\eta)}$ where $\beta_{1}$ is the productivity-rent gradient. Therefore, when $\beta_{1}=\alpha \frac{\eta}{1+\eta}$, the planner values redistribution only between $\theta$ types. We explored a robustness check with this alternative calibration and find an optimal PBR that is slightly smaller but of the same order of magnitude as in our baseline.
} 
our survey results suggest that (ii) may indeed be aligned with social preferences in the U.S., such motives may remain controversial; we therefore opt in our baseline specification to evaluate the desirability of PBR based upon (i) alone, with spatially neutral social preferences. Incorporating (ii) as an additional motive would yield greater optimal PBR.

A second potential driver of sorting is income effects in community choice. This phenomenon arises when housing is modeled as a necessity $(\underline{h}>0)$, in which case the higher cost of housing in Elsewhere disproportionately hurts poorer households, leading the low skilled to sort into lower-rent locations. Formally,

since $\frac{\partial^{2} \log s_{j}(\theta)}{\partial \theta \partial r_{j}}>0$, skilled households sort differentially into higher-rent communities, which can help to rationalize the empirical fact that low income households are over represented in Distressed.

A last potential driver of locational sorting is comparative advantage, which emerges when $\beta_{2} \neq 0$. In the absence of income-based sorting $(\underline{h}=0)$ and skill-taste correlation $\left(a_{j}(\theta)=a_{j}\right)$, one can show that $s_{j}(\theta) \propto \exp \left(\kappa a_{j}\right)\left(\frac{W_{j} \theta_{j}}{r_{j}^{\alpha}}\right)^{\kappa(1+\eta)}$, which implies that $\frac{\partial^{2} \log s_{j}(\theta)}{\partial \theta \partial b_{j}}>0$. Hence, higher skilled households sort into higher $b_{j}$ locations where their wage premium is disproportionately large.

These three forces shape the heterogeneous location choices of households with different skill levels $\theta$, resulting in observed sorting by income. Note, however, that when communities differ in their productivity $W_{j}$, earnings will tend to be greater in high- $W_{j}$ communities even when all communities have the same distribution of skill types.

\subsection{Baseline calibration}

Our baseline calibration features a constant elasticity of labor supply, a constant wage-migration elasticity, and constant expenditure shares, in line with quantitative specifications typically adopted in the economic geography literature. Specifically, we set $\underline{h}=0$ and $\alpha=0.3$, which yields a $30 \%$ housing expenditure share (Davis and Ortalo-Magne, 2011). We choose $\eta=1 / 2$ to yield a labor supply elasticity of $1 / 2$ (Chetty et al., 2011). The scale parameter $\kappa$ is set to $1 / 2$ to match the long run wage-migration elasticities of roughly $3 / 4$ reported in Kennan and Walker (2011, Figure 1).

We set the rental rate $r_{j}$ of each community equal to the population-weighted average of its tractlevel median rents, as reported in the ACS. As noted earlier, we normalize the rent of the lowest-poverty community $(j=100)$ - which happens to have the highest rent - to one. The highest poverty community ("Distressed") has the lowest rent, which after normalization we write as $r_{1}=0.38$. To calibrate productivity 
differences between communities, we use the relationship between Metropolitan Statistical Area rent and productivity in Hornbeck and Moretti (2019), which yields a productivity-to-rent elasticity $\left(\beta_{1}\right)$ of 0.254 . Since $r_{j} \in[0.38,1]$, average labor productivity $\left(W_{j}\right)$ ranges from 0.78 in Distressed to one in the lowestpoverty community. Hence, each skill type's wage is $22 \%$ lower in Distressed than it is in the lowest-poverty community. We set $\beta_{2}=0$ and explore comparative advantage in alternative calibrations, as detailed below.

To choose the remaining parameters $\left\{\mu_{\theta}, \sigma_{\theta}, a_{j}(\theta)\right\}$, we minimize the distance between the model's predicted moments and an equivalent set of empirical moments. Specifically, these parameters are chosen to exactly match each community's share of each of nine nationwide household earnings bins based on the ACS tract-level aggregates. We furthermore minimize the sum of squared deviations between model predicted and actual values of the share of the nationwide population with earnings in the bottom two ACS-based bins (i.e., below $\$ 19,500$ ) and the share with earnings in the top three ACS-based bins (i.e., above $\$ 88,000$ ). The resulting communities each have approximately $1 \%$ of the nationwide population, by construction. ${ }^{17}$

\begin{tabular}{|c|c|c|c|c|c|c|}
\hline \multicolumn{7}{|c|}{$\begin{array}{c}\text { TABLE 1 } \\
\text { Parameters for the Baseline Calibration }\end{array}$} \\
\hline \multicolumn{7}{|l|}{ A. Community-Invariant Parameters } \\
\hline & \multicolumn{5}{|c|}{ Value } & Sources \\
\hline & \multicolumn{5}{|c|}{$(1)$} & $(2)$ \\
\hline Housing expenditure share $(\alpha)$ & \multicolumn{5}{|c|}{0.3} & Davis-Ortalo-Magne (2011) \\
\hline Labor supply elasticity $(\eta)$ & \multicolumn{5}{|c|}{0.5} & Chetty-Guren-Manoli-Weber (2011) \\
\hline Scale $(\kappa)$ governing migration elasticity & \multicolumn{5}{|c|}{0.5} & Kennan-Walker (2011) \\
\hline Current place-blind lump-sum transfer $(-T(0))$ & \multicolumn{5}{|c|}{11,300} & Piketty-Saez-Zucman (2018) \\
\hline Current marginal tax rate below $\$ 20 \mathrm{~K}$ & \multicolumn{5}{|c|}{$43.8 \%$} & Piketty-Saez-Zucman (2018) \\
\hline Current marginal tax rate $\$ 20 \mathrm{~K}-\$ 80 \mathrm{~K}$ & \multicolumn{5}{|c|}{$16.1 \%$} & Piketty-Saez-Zucman (2018) \\
\hline Current marginal tax rate above $\$ 80 \mathrm{~K}$ & \multicolumn{5}{|c|}{$27.1 \%$} & Piketty-Saez-Zucman (2018) \\
\hline Mean of the lognormal skill dist. $\left(\mu_{\theta}\right)$ & \multicolumn{5}{|c|}{2.73} & Calibrated to ACS earnings dist. \\
\hline Std. dev. of the lognormal skill dist. $\left(\sigma_{\theta}\right)$ & \multicolumn{5}{|c|}{0.67} & Calibrated to ACS earnings dist. \\
\hline \multicolumn{7}{|l|}{ B. Community-Varying Parameters } \\
\hline & $\begin{array}{l}\text { Poorest } \\
\text { community } \\
\text { (Distressed) }\end{array}$ & $\begin{array}{l}\text { 25th-poorest } \\
\text { community }\end{array}$ & $\begin{array}{c}\text { 50th-poorest } \\
\text { community }\end{array}$ & $\begin{array}{l}\text { 75th-poorest } \\
\text { community }\end{array}$ & $\begin{array}{l}\text { Least-poor } \\
\text { community }\end{array}$ & Sources \\
\hline & (3) & $(4)$ & (5) & (6) & (7) & $(8)$ \\
\hline $\operatorname{Rent}\left(r_{j}\right)$ & 0.38 & 0.50 & 0.59 & 0.72 & 1 & 2013-2017 American Community Survey \\
\hline Community productivity $\left(W_{j}\right)$ & 0.78 & 0.84 & 0.87 & 0.92 & 1 & Hornbeck-Moretti (2019) \\
\hline Community amenity level, least-skilled $\left(a_{i}(\underline{\theta})\right)$ & 2.48 & 0.78 & 0.00 & -0.81 & -3.06 & Calibrated to ACS tract pop. shares \\
\hline Community amenity level, most-skilled $\left(a_{i}(\bar{\theta})\right)$ & -3.77 & -1.21 & 0.00 & 0.78 & 2.81 & Calibrated to ACS tract pop. shares \\
\hline
\end{tabular}

When solving the model for the purpose of the calibration, we assume, based on Piketty et al. (2018), that the current income tax system is place-blind and involves a $\$ 11,300$ lump-sum transfer with effective marginal tax rate brackets of $43.8 \%$ up $\$ 20,000,16.1 \%$ up to $\$ 80,000$, and $27.1 \%$ above $\$ 80,000 .{ }^{18}$ We set

\footnotetext{
${ }^{17}$ Community populations deviate slightly from $1 \%$ because the nine-bin nationwide earnings distribution cannot be matched exactly with the two-parameter lognormal skill distribution.

${ }^{18}$ We estimate the tax system on the 2013-2017 sample of prime-age laborers in Piketty et al.'s distributional national accounts. Following Piketty et al.'s primary conventions, the tax system includes all taxes paid to and individualized transfers received
} 
$R$ in the constraint (19) equal to $10.1 \%$ of national income $\mathbb{E}\left[z^{*}\right]$ in order to hold fixed the net surplus that we find under this tax system in the calibration. ${ }^{19}$

Table 1 summarizes the calibrated parameters in our baseline specification, while Online Appendix Figure 1 illustrates calibrated parameters graphically. Poverty is highly skewed: the Distressed community has a poverty rate of $59 \%$, while the median community has a poverty rate of only $11 \%$ (Online Appendix Figure 1a). In order to generate strong sorting patterns across locations, the calibration requires strong differences in community-skill amenity levels and in particular requires strong skill-taste correlation: the high-skilled have a stronger taste $a_{j}(\theta)$ for affluent high-rent communities than for poorer lower-rent communities, while the low-skilled have a stronger taste for poor low-rent communities than for more-affluent higher-rent communities. See Appendix C for further calibration details.

\subsection{Optimal policy}

For every candidate level of $\Delta$ in $\$ 100$ increments between $-\$ 2,000$ and $\$ 8,000$, we search numerically using a Nelder-Mead algorithm for the optimal income tax and transfer system consistent with optimal household behavior. Table 2 summarizes the equilibrium attained at the level of PBR that maximizes social welfare. The first row corresponds to our baseline calibration. Social welfare is maximized when every resident of Distressed receives a transfer $\Delta^{*}$ of $\$ 5,500$. Hence, we find that substantial PBR is desirable even under the optimally chosen income tax. Our baseline calibration has no within-earnings redistributive motive; consequently, PBR improves social welfare by generating cross-earnings equity gains at lower efficiency cost than corresponding income-based transfers.

The optimal place-based transfer of $\$ 5,500$ is sizable relative to the place-blind lump-sum transfer of $\$ 22,357 .{ }^{20}$ It is also somewhat larger than the U.S. Empowerment Zone program, which provides a subsidy of about $\$ 3,000$ per eligible worker to zone firms. Absent PBR, the average social marginal welfare weight in Distressed would be $29 \%$ higher than the average social marginal welfare weight in Elsewhere. The optimal level of $\Delta$ sharply reduces this gap to $9 \%$ while modestly increasing the population of Distressed by $9 \%$ to approximately $1.1 \%$ of the U.S. population. The approximate efficiency cost of the transfer is summarized in

from all levels of government, except for contributory social insurance (e.g., Social Security) taxes which are excluded from pre-tax and post-tax income and their benefits which are included in pre-tax and post-tax income. The lump-sum transfer to zero-earners reflects transfers like food stamps and Medicaid.

${ }^{19}$ This net surplus can be thought of as representing government expenditures on public goods like national defense rather than individual benefits like food stamps. Setting $R=0$ would yield larger optimal levels of PBR.

${ }^{20}$ Mankiw and Weinzierl (2010) similarly find an optimal lump-sum transfer to all Americans of over $\$ 21,000$. 
column 3 of Table 2 by the marginal value of public funds (MVPF) (Mayshar, 1990; Hendren, 2016), which gives the willingness to pay for a small transfer (starting from $\Delta=0$ ) divided by the budgetary impact of the transfer when holding the tax system fixed. PBR's MVPF of .98 implies that 2 cents of every dollar of $\Delta$ are "lost" due to migration responses that yield reductions in earnings. For comparison we also report in column 4 the MVPF of an income tax reform that replicates the mechanical effects of PBR. This reform has a substantially lower MVPF than that of PBR, which corroborates the intuition that PBR lowers the efficiency costs of targeting poor households relative to an optimal income tax system.

TABLE 2 How Large Might Optimal Place-Based Transfers Be?

\begin{tabular}{|c|c|c|c|c|c|c|c|c|c|}
\hline & \multirow[b]{2}{*}{$\begin{array}{c}\text { Optimal level } \\
\text { of PBR }\end{array}$} & \multicolumn{3}{|c|}{ Under Optimal Income Tax and No PBR } & \multicolumn{5}{|c|}{ Under Optimal Income Tax and Optimal PBR } \\
\hline & & $\begin{array}{l}\text { Value of } \\
\text { redistributon } \\
\text { from } \\
\text { Elsewhere to } \\
\text { Distressed }\end{array}$ & $\begin{array}{c}\text { Marginal value } \\
\text { of public funds } \\
\text { (MVPF) of } \\
\text { PBR }\end{array}$ & $\begin{array}{c}\text { MVPF of } \\
\text { analogous } \\
\text { income tax } \\
\text { reform }\end{array}$ & $\begin{array}{l}\text { Value of } \\
\text { redistributon } \\
\text { from } \\
\text { Elsewhere to } \\
\text { Distressed }\end{array}$ & $\begin{array}{l}\text { Redistribution } \\
\text { value narrowed }\end{array}$ & $\begin{array}{l}\text { Increase in } \\
\text { population of } \\
\text { Distressed }\end{array}$ & $\begin{array}{c}\text { Place-blind } \\
\text { lump-sum } \\
\text { transfer }\end{array}$ & $\begin{array}{c}\text { Place-blind } \\
\text { marginal tax } \\
\text { rate above } \\
\$ 80 \mathrm{~K}\end{array}$ \\
\hline & $(1)$ & $(2)$ & (3) & (4) & (5) & (6) & (7) & $(8)$ & $(9)$ \\
\hline \multicolumn{10}{|l|}{ A. Lump-Sum PBR } \\
\hline Baseline & $\$ 5,500$ & 1.29 & 0.98 & 0.72 & 1.09 & $71 \%$ & $9 \%$ & $\$ 22,357$ & $46.5 \%$ \\
\hline $2 x$ productivity differences & $\$ 4,800$ & 1.29 & 0.94 & 0.65 & 1.11 & $63 \%$ & $8 \%$ & $\$ 22,309$ & $46.3 \%$ \\
\hline $2 x$ migration & $\$ 4,000$ & 1.29 & 0.97 & 0.72 & 1.14 & $53 \%$ & $13 \%$ & $\$ 22,378$ & $46.4 \%$ \\
\hline No prod. diffs. $+4 x$ migration & $\$ 3,200$ & 1.30 & 1.03 & 0.62 & 1.17 & $42 \%$ & $23 \%$ & $\$ 22,380$ & $46.4 \%$ \\
\hline Change top income tax bracket only & $\$ 3,600$ & 1.29 & 0.98 & 0.72 & 1.15 & $49 \%$ & $6 \%$ & $\$ 22,447$ & $47.0 \%$ \\
\hline Targeting the bottom $10 \%$ & $\$ 4,700$ & 1.24 & 0.98 & 0.78 & 1.07 & $69 \%$ & $6 \%$ & $\$ 21,716$ & $46.2 \%$ \\
\hline \multicolumn{10}{|l|}{ B. Capped Earnings Subsidy PBR } \\
\hline Baseline & $36 \%$ & 1.29 & 0.98 & 0.77 & 1.14 & $54 \%$ & $7 \%$ & $\$ 22,383$ & $46.5 \%$ \\
\hline $2 x$ productivity differences & $29 \%$ & 1.29 & 0.93 & 0.70 & 1.16 & $44 \%$ & $5 \%$ & $\$ 22,332$ & $46.3 \%$ \\
\hline $2 x$ migration & $25 \%$ & 1.29 & 0.96 & 0.77 & 1.18 & $39 \%$ & $10 \%$ & $\$ 22,399$ & $46.4 \%$ \\
\hline No prod. diffs. $+4 x$ migration & $24 \%$ & 1.30 & 1.03 & 0.67 & 1.19 & $37 \%$ & $19 \%$ & $\$ 22,363$ & $46.3 \%$ \\
\hline Change top income tax bracket only & $30 \%$ & 1.29 & 0.98 & 0.76 & 1.16 & $46 \%$ & $6 \%$ & $\$ 22,447$ & $47.0 \%$ \\
\hline Targeting the bottom $10 \%$ & $26 \%$ & 1.24 & 0.98 & 0.83 & 1.12 & $48 \%$ & $4 \%$ & $\$ 21,963$ & $46.4 \%$ \\
\hline
\end{tabular}

Notes - This table lists results of our numerical exercises of place-based redistribution (PBR) to the poorest simulated community ("Distressed"), which corresponds to the poorest $1 \%$ of U.S. Census tracts. Panel A lists results for lump-sum PBR: a flat dollar amount to every Distressed resident. Panel B lists results capped earnings subsidy PBR: a percentage subsidy to Distressed residents for their first $\$ 15,000$ of earnings. The Baseline rows denote the calibrated economy based on Table 1 's parameters. The other rows correspond to single variations to the baseline residents for their first $\$ 15,000$ of earnings. The Baseline rows denote the calibrated economy based on Table 1's parameters. The other rows correspond to single variations to the baseline
calibration. "Targeting the bottom $10 \%$ refers to offering PBR to residents of the ten communities (i.e. $10 \%$ of the population in the calibrated economy) with the highest poverty rate, rather than the one community with the highest poverty rate. Column 1 lists the PBR level that maximizes social welfare. Column 2 lists the relative value to the planner of distributing an extra dollar to the average resident of Distressed to the average resident elsewhere, when the planner maximizes social welfare using place-blind taxes but not PBR. Column 3 lists the marginal value of public funds (MVPF) of a non-budget-balanced $\$ 100$ lump-sum PBR reform (panel A) or $1 \%$ earnings subsidy PBR reform (panel B), while holding the income tax and transfer system fixed at its optimum under no PBR. MVPF equals the receipients' willingness to pay (i.e., the dollars distributed via the reform) divided by the net cost to the government (i.e., the dollars distributed via the reform plus lost tax revenue due to behavioral responses). Column 4 lists the MVPF of the income tax reform that transfers the same dollars on average to each earnings level as the non-budgetbalanced PBR reforms, while holding PBR fixed at zero. Column 5 repeats column 2, when the planner maximizes social welfare using both place-blind taxes and PBR. Column 6 lists the share of the no-PBR social value difference between distibuing a dollar to Distressed and distributing a dollar elsewhere that is narrowed by the use of PBR. Column 6 equals one minus [column 5 of the no-PBR social value difference between distibuing a dollar to Distressed and distributing a dollar elsewhere that is narrowed by the use of PBR. Column 6 equals one minus [column 5
minus one]/[column 2 minus one]. Column 7 lists the percentage increase in the population of Distressed under the optimal PBR. Columns 8 and 9 list the place-blind lump-sum transfer and the top-bracket income tax rate under the optimal PBR.

Robustness to parameterization We now consider some alternative parameterizations of our quantitative model, each of which deviates from the baseline in either one or two dimensions. Recall that our baseline parameterization of the productivity-rent gradient $\beta_{1}$ adopts the Hornbeck and Moretti (2019) gradient, which is estimated using differences across metropolitan areas over time. It is possible that the true productivity-rent gradient is steeper across regions or flatter across neighborhoods. We therefore consider 
two extreme differences in this productivity gradient: the second row of Table 2 assumes that all communities have the same productivity, while the third row allows productivity differences to be twice as high as those in the baseline. The optimal level of PBR rises to $\$ 5,800$ under no productivity differences and falls to $\$ 4,800$ when productivity differences are doubled, as productivity differences exacerbate the fiscal externalities associated with migration. In the absence of productivity differences, the MVPF of PBR actually rises slightly above 1, as moving to Distressed entails a slight increase in the real wage (relative to the cost of living), which yields a small increase in earnings.

Our baseline parameterization of the dispersion of idiosyncratic community tastes $\kappa$ is benchmarked to Kennan and Walker (2011)'s finding that the elasticity of a state's population with respect to the offered wage is roughly $3 / 4$. To gauge the sensitivity of optimal policy to $\kappa$, the fourth row of Table 2 reports the results of doubling the migration elasticity. As expected, increasing the migration elasticity raises the efficiency costs of PBR, which lowers the optimal level of $\Delta$ to $\$ 4,000$. In the fifth row of Table 2 , we aim to capture a within-city PBR scheme, where productivity differences between locations are muted, and migration is likely more responsive. To do so, we eliminate productivity differences and quadruple the migration elasticity. This change lowers the optimal level of $\Delta$ to $\$ 3,200$.

Our baseline parameterization allows the planner to fund PBR through any change in place-blind taxes. Political and other considerations may make it desirable to fund PBR only through raising taxes on high earners. The sixth row of Table 2 therefore constrains the planner to finance the lump-sum place-based subsidy to Distressed residents by adjusting only the top bracket of the place-blind tax system (which applies to earnings over $\$ 80,000)$. Doing so lowers the optimal level of $\Delta$ to $\$ 3,600$.

The final row of Table $2 \mathrm{a}$ redefines Distressed as the ten poorest communities, thereby expanding the share of the population mechanically targeted by the PBR scheme by an order of magnitude from approximately $1 \%$ to approximately $10 \%$. Because this policy is less targeted to the most disadvantaged, $\Delta^{*}$ falls to $\$ 4,700$. In sum, the finding of a large optimal transfer to Distressed is robust to deviations we consider from our baseline parameterization.

A place-based earnings subsidy Political considerations may make earnings subsidies more attractive than lump sum transfers. We therefore consider a capped earnings subsidy, rather than a lump-sum transfer, to every resident of Distressed. This formulation of the transfer is meant to mimic the current 
U.S. Empowerment Zone program, which provides a $20 \%$ firm-side earnings subsidy on the first $\$ 15,000$ in earnings of zone residents who work at zone firms.

Table $2 \mathrm{~b}$ reports the optimal subsidy rate on each Distressed household's first $\$ 15,000$ of earnings under various assumptions. The first row of the panel reveals that, under our baseline calibration, the optimal subsidy rate is $36 \%$. For households earning over $\$ 15,000$, the $36 \%$ subsidy rate happens to yield $\$ 5,400-$ nearly the same amount as the optimal lump-sum transfer amount reported in Table 2a. However, the capped earnings subsidy provides less aid to the poorest Distressed households and consequently eliminates less of the gap in social marginal welfare weights between Distressed and Elsewhere than the lump-sum transfer. The other rows of Table $2 \mathrm{~b}$ report a sensitivity analysis, which yields findings similar to the corresponding exercises reported in Table 2a. Notably, the "within-city" specification with no productivity differences and four times the baseline migration elasticity yields an optimal subsidy rate of $24 \%$, which is not too far from the $20 \%$ subsidy rate of actual Empowerment Zones.

TABLE 3

Exploration of Mechanisms for Large Optimal Place-Based Transfers

\begin{tabular}{lcc}
\hline \hline & $\begin{array}{c}\text { Optimal Level of PBR } \\
\text { Eliminate skill-taste correlation } \\
\text { after calibration }\end{array}$ \\
\hline Baseline & $(1)$ & $(2)$ \\
Income effects & $\$ 5,500$ & $\$ 400$ \\
Comparative advantage & $\$ 3,700$ & $-\$ 400$ \\
Income effects + Comparative advantage & $\$ 4,200$ & $\$ 1,600$ \\
& $\$ 3,100$ & $\$ 700$ \\
\hline $\begin{array}{l}\text { Notes - This table explores variations to the Baseline calibration. This table's upper-left cell refers to the calibration underlying the first } \\
\text { row of Table 2a. Column 2 repeats column 1, except that skill-taste correlation is eliminated by setting each type's valuation } a_{j}(\theta) \text { to }\end{array}$ \\
$\begin{array}{l}\text { zero. The remaining rows correspond to variations to the Baseline calibration. "Income effects" refers to income effects in location } \\
\text { choice to the calibration. "Comparative advantage" refers to the wage ratio between high and low skill types being larger in high-rent } \\
\text { communities than in low-rent communities. }\end{array}$
\end{tabular}

\subsection{Alternative sorting motives}

Our baseline calibration explains the sorting of high $\theta$ households to expensive communities in terms of taste differences across skill groups, as captured by our parameterization of $a_{j}(\theta)$. We now consider two alternative explanations for sorting: income effects in locational choice and spatial comparative advantage. Before doing so, we begin by examining the effects of removing skill-taste correlation by setting $a_{j}(\theta)=0$ for all skill 
groups. In our baseline calibration, this exercise nearly eliminates all skill differences in sorting behavior. ${ }^{21}$ The first row of Table 3 shows that zeroing out amenities lowers the optimal place-based transfer $\Delta^{*}$ from $\$ 5,500$ to $\$ 400$. Additional details on this counterfactual equilibrium are provided in Online Appendix Table 2. The transfer is not driven by the composition of locations: all communities have nearly the same skill composition in this counterfactual. Rather, the $\$ 400$ transfer serves to compensate residents of Distressed for the inferior living conditions they endure as a result of the low local productivity levels present in Distressed. Specifically, the lower wage in Distressed forces households to work more and reduce their level of leisure, which creates a motive for the planner to redistribute from Elsewhere to Distressed.

Income effects in location choice Income effects provide a potential explanation for the sorting of high skilled households to more expensive communities. Recall from Example 5 that income-based sorting need not provide a motive for indirect taxation, a point which has been studied extensively in the commodity taxation literature (Atkinson and Stiglitz, 1976; Saez, 2002). We therefore expect that income effects will tend to dampen the optimal place-based transfer size compared to the baseline calibration.

To capture income effects quantitatively we set $\underline{h}=6,000$ and $\alpha=0.15$, which yields a minimum possible housing expenditure share of $15 \%$ and a maximal empirical expenditure share of $52 \%$. Doing so generates non-homotheticity in consumption and a motive for higher-skilled households to sort into higher rent locations, while skill-taste correlation serves as the residual explanation for the skill sorting not captured by income effects.

This non-homotheticity mechanically yields social preferences that are no longer space-neutral. Specifically, the non-homotheticity generates a motive for the planner to redistribute within earnings levels away from Distressed residents and toward Elsewhere residents who pay higher rent and therefore have higher marginal utilities of consumption. Note that this within-earnings redistributive motive is in the opposite direction of the motive suggested by Section 5's online survey. Nevertheless, the second row of Table 3 shows that in this calibration, the optimal transfer to Distressed is still quite high, with $\Delta^{*}=\$ 3,700$. However, shutting down the remaining skill-taste correlation yields $\Delta^{*}$ of $-\$ 400$ because of the within-earnings redistributive motive.

\footnotetext{
${ }^{21}$ The only remaining force generating sorting is the fact that the income tax is non-linear.
} 
Comparative advantage Another reason why high-skilled households might sort to expensive communities is that they enjoy a comparative advantage in production there. Indeed, results in De La Roca and Puga (2017) suggest that the earnings of higher-skilled households are disproportionately elevated in large cities. To capture comparative advantage, we set $\beta_{2}=0.88$ to match the estimates in De La Roca and Puga. ${ }^{22}$ We recalibrate the model in order to match the same moments as in the baseline; in particular, skill-taste correlation is recalibrated to explain the residual sorting patterns not captured by comparative advantage. The third row of Table 3 reveals that, relative to the baseline, this modification lowers $\Delta^{*}$ to $\$ 4,200$, primarily because the distortionary earnings responses to migration are elevated.

As above, it is also interesting to study a counterfactual in which sorting attributable to comparative advantage is isolated by shutting down skill-taste correlation. Eliminating skill-taste correlation yields a fairly substantial optimal transfer of $\$ 1,600$, which suggests that comparative advantage, in itself, provides a motive for PBR. This finding extends the indirect taxation literature which, to the best of our knowledge, has not studied situations in which commodity choice impacts the marginal productivity of labor. ${ }^{23}$

Finally, the last row of Table 3 recalibrates the model allowing both income effects in location choice and comparative advantage. Under this calibration, residual skill differences in the valuation of amenities are dramatically smaller than in the baseline (illustrated in Online Appendix Figure 2): income effects and comparative advantage are now the main driving force behind locational sorting. We find that the resulting optimal place-based transfer to Distressed is still large, with $\Delta^{*}=\$ 3,100$. After shutting down the residual skill-taste correlation, we again find a positive optimal transfer of $\$ 700$. In sum, we conclude that while alternative motives for skill-sorting can dampen the optimal transfer size, plausible calibrations with substantially dampened skill-taste correlation still yield a role for sizable place-based transfers.

\section{Conclusion}

While the literature has focused on studying efficiency motives for place-based policies, we study the equity rationale for place-based policies. We ask whether it makes sense to index redistribution on place, beyond indexing it on income alone. If tagging on dimensions other than income has traditionally been viewed with

\footnotetext{
${ }^{22}$ We use De La Roca and Puga's estimate of the relative labor productivity in large vs small cities (relative $W_{j}$ in our notation), and of the difference in comparative advantage in the same cities (relative $b_{j}$ in our notation). This yields our estimate of $\beta_{2}=\frac{\ln b_{\text {large }}-\ln b_{\text {small }}}{\ln W_{\text {large }}-\ln W_{\text {small }}}$.

${ }^{23}$ Rothschild and Scheuer (2013) study optimal income taxation in the Roy model but do not allow for sector specific taxes, which would be the labor market analogue of PBR.
} 
skepticism in the public finance literature (Mankiw and Weinzierl, 2010), we note that tagging based on place is highly policy-relevant: unlike height and almost all other potential "tags" (Akerlof, 1978), governments around the world actually condition transfers on place.

We find that place-based redistribution is justified, first, if it lowers the efficiency costs of redistribution. In that sense, PBR will tend to be desirable when spatial transfers induce few moves, when productivity is uniform across space, when labor supply is especially elastic, and when incomes differ substantially across locations. Second, PBR can be also justified if it provides unique equity gains that income-based redistribution cannot achieve. A survey suggests that social preferences may align with this motive for place-based redistribution.

Ultimately, the desirability of place-based redistribution is a quantitative question that depends on the empirical context. We conduct a quantitative calibration and find that the optimal lump sum transfer for the poorest U.S. Census tracts may be sizable, over and above an optimally chosen income-based tax system. While the calibration results are necessarily specific to our modeling of household preferences, they accord closely with the broader theoretical message of our paper that the efficiency costs of place-based policies need to be weighed carefully against the corresponding equity gains of these programs. Household sorting generates tremendous geographic segregation of income groups, which makes location a natural tag. When living in poor areas signals disadvantage over and above one's own income, the case for place-based redistribution as a supplement to progressive income taxation is only strengthened. An important question for future research

is how implementation features such as statutory incidence, program salience, and compliance monitoring alter the equity-efficiency tradeoffs presented by actual place-based policies.

\section{References}

Aguiar, M., E. Hurst, and L. Karabarbounis (2012). Recent developments in the economics of time use. Annu. Rev. Econ. 4(1), 373-397.

Ahlfeldt, G. M., S. J. Redding, D. M. Sturm, and N. Wolf (2015). The economics of density: Evidence from the berlin wall. Econometrica 83(6), 2127-2189.

Akerlof, G. A. (1978). The economics of "tagging" as applied to the optimal income tax, welfare programs, and manpower planning. The American economic review 68(1), 8-19. 
Albouy, D. (2009). The unequal geographic burden of federal taxation. Journal of Political Economy 117(4), $635-667$.

Albouy, D. (2012). Evaluating the efficiency and equity of federal fiscal equalization. Journal of Public Economics 96(9-10), 824-839.

Anderson, E. (2000). Code of the street: Decency, violence, and the moral life of the inner city. WW Norton \& Company.

Atkinson, A. B. (1970). On the measurement of inequality. Journal of economic theory 2(3), 244-263.

Atkinson, A. B. and J. E. Stiglitz (1976). The design of tax structure: direct versus indirect taxation. Journal of public Economics 6(1-2), 55-75.

Austin, B., E. Glaeser, and L. Summers (2018). Jobs for the heartland: Place-based policies in 21st-century america. Brookings Papers on Economic Activity, 151-232.

Autor, D. (2019). Work of the past, work of the future, Volume 109.

Avenancio-León, C. and T. Howard (2019). The assessment gap: Racial inequalities in property taxation. Available at SSRN 3465010.

Bartik, T. J. (2020). Using place-based jobs policies to help distressed communities. olume 34, Number 3, 99.

Baum-Snow, N. and R. Pavan (2011). Understanding the city size wage gap. The Review of economic studies 79(1), 88-127.

Bayer, P., H. Fang, and R. McMillan (2014). Separate when equal? racial inequality and residential segregation. Journal of Urban Economics 82, 32-48.

Bayer, P., F. Ferreira, and R. McMillan (2007). A unified framework for measuring preferences for schools and neighborhoods. Journal of political economy 115(4), 588-638.

Bayer, P., R. McMillan, A. Murphy, and C. Timmins (2016). A dynamic model of demand for houses and neighborhoods. Econometrica 84(3), 893-942.

Becker, G. S. (1965). A theory of the allocation of time. The economic journal, 493-517. 
Bergman, P., E. W. Chan, and A. Kapor (2020). Housing search frictions: Evidence from detailed search data and a field experiment. Technical report, National Bureau of Economic Research.

Bergman, P., R. Chetty, S. DeLuca, N. Hendren, L. F. Katz, and C. Palmer (2019). Creating moves to opportunity: Experimental evidence on barriers to neighborhood choice. Technical report, National Bureau of Economic Research.

Berry, S., J. Levinsohn, and A. Pakes (1995). Automobile prices in market equilibrium. Econometrica: Journal of the Econometric Society, 841-890.

Busso, M., J. Gregory, and P. Kline (2013). Assessing the incidence and efficiency of a prominent place based policy. American Economic Review 103(2), 897-947.

Chetty, R. (2009). Sufficient statistics for welfare analysis: A bridge between structural and reduced-form methods. Annu. Rev. Econ. 1(1), 451-488.

Chetty, R., A. Guren, D. Manoli, and A. Weber (2011). Are micro and macro labor supply elasticities consistent? a review of evidence on the intensive and extensive margins. American Economic Review $101(3), 471-75$.

Colmer, J., I. Hardman, J. Shimshack, and J. Voorheis (2020). Disparities in pm2. 5 air pollution in the united states. Science $369(6503), 575-578$.

Combes, P.-P., G. Duranton, L. Gobillon, D. Puga, and S. Roux (2012). The productivity advantages of large cities: Distinguishing agglomeration from firm selection. Econometrica 80(6), 2543-2594.

Dahl, G. B. (2002). Mobility and the return to education: Testing a roy model with multiple markets. Econometrica $70(6), 2367-2420$.

Dauth, W., S. Findeisen, E. Moretti, and J. Suedekum (2018). Matching in cities. Technical report, National Bureau of Economic Research.

Davis, M. A. and J. Gregory (2020). Planning problems and redistribution of income in models of urban economics. Available at SSRN 3637555.

Davis, M. A. and F. Ortalo-Magne (2011, April). Household Expenditures, Wages, Rents. Review of Economic Dynamics 14(2), 248-261. 
De La Roca, J. and D. Puga (2017). Learning by working in big cities. The Review of Economic Studies 84(1), $106-142$.

Diamond, R. (2016). The determinants and welfare implications of us workers' diverging location choices by skill: 1980-2000. American Economic Review 106(3), 479-524.

Ehrlich, M. v. and H. G. Overman (2020). Place-based policies and spatial disparities across european cities. olume 34, Number 3, 128.

Epple, D., L. Quintero, and H. Sieg (2020). A new approach to estimating equilibrium models for metropolitan housing markets. Journal of Political Economy 128(3), 948-983.

Epple, D. and H. Sieg (1999). Estimating equilibrium models of local jurisdictions. Journal of political economy 107(4), 645-681.

Fajgelbaum, P. and C. Gaubert (2020). Optimal spatial policies, geography and sorting. The Quarterly Journal of Economics.

Fajgelbaum, P. D., E. Morales, J. C. Suárez Serrato, and O. Zidar (2018). State taxes and spatial misallocation. The Review of Economic Studies 86(1), 333-376.

Fisman, R., K. Gladstone, I. Kuziemko, and S. Naidu (2020). Do americans want to tax wealth? evidence from online surveys. Journal of Public Economics 188, 104207.

Flatters, F., V. Henderson, and P. Mieszkowski (1974). Public goods, efficiency, and regional fiscal equalization. Journal of Public Economics 3(2), 99-112.

Fowlie, M., E. Rubin, and R. Walker (2019). Bringing satellite-based air quality estimates down to earth. In AEA Papers and Proceedings, Volume 109, pp. 283-88.

Fu, C. and J. Gregory (2019). Estimation of an equilibrium model with externalities: Post-disaster neighborhood rebuilding. Econometrica 87(2), 387-421.

Fujiwara, T., E. Morales, and C. Porcher (2020). A revealed-preference approach to measuring information frictions in migration decisions. working paper.

Gaubert, C. (2018). Firm sorting and agglomeration. American Economic Review 108(11), 3117-53. 
Glaeser, E. and J. Gottlieb $(2008,11)$. The economics of place-making policies. Brookings Papers on Economic Activity 39.

Glaeser, E. L. (2008). Cities, agglomeration, and spatial equilibrium. Oxford University Press.

Glaeser, E. L. and D. C. Mare (2001). Cities and skills. Journal of labor economics 19(2), 316-342.

Hendren, N. (2016). The policy elasticity. Tax Policy and the Economy 30(1), 51-89.

Hornbeck, R. and E. Moretti (2019). Estimating who benefits from productivity growth: Direct and indirect effects of city manufacturing tfp growth on wages, rents. Technical report, and Inequality.

Horton, J. J., D. G. Rand, and R. J. Zeckhauser (2011). The online laboratory: Conducting experiments in a real labor market. Experimental economics 14(3), 399-425.

Hurst, E. (2008). The retirement of a consumption puzzle. Technical report, National Bureau of Economic Research.

Jackson, K. T. (1987). Crabgrass frontier: The suburbanization of the United States. Oxford University Press.

Jargowsky, P. A. (1997). Poverty and place: Ghettos, barrios, and the American city. Russell Sage Foundation.

Kaplow, L. (2006). On the undesirability of commodity taxation even when income taxation is not optimal. Journal of Public Economics 90(6-7), 1235-1250.

Kaplow, L. (2008). Optimal policy with heterogeneous preferences. The BE Journal of Economic Analysis \& Policy 8(1).

Katz, B. (2015). Los angeles 1992 to baltimore 2015: Washington's changed response to urban crisis.

Kennan, J. and J. R. Walker (2010). Wages, welfare benefits and migration. Journal of Econometrics 156(1), 229-238.

Kennan, J. and J. R. Walker (2011). The effect of expected income on individual migration decisions. Econometrica $79(1), 211-251$. 
Kessing, S. G., V. Lipatov, and J. M. Zoubek (2020). Optimal taxation under regional inequality. European Economic Review, 103439.

Kleven, H. (2020). Sufficient statistics revisited. Technical report, National Bureau of Economic Research.

Kleven, H. J., C. T. Kreiner, and E. Saez (2009). The optimal income taxation of couples. Econometrica $77(2), 537-560$.

Kline, P. (2010). Place based policies, heterogeneity, and agglomeration. American Economic Review 100(2), $383-87$.

Kline, P. and E. Moretti (2014a). Local economic development, agglomeration economies, and the big push: 100 years of evidence from the tennessee valley authority. Quarterly Journal of Economics 129(1), $275-331$.

Kline, P. and E. Moretti (2014b). People, places, and public policy: Some simple welfare economics of local economic development programs.

Kuziemko, I., M. I. Norton, E. Saez, and S. Stantcheva (2015). How elastic are preferences for redistribution? evidence from randomized survey experiments. American Economic Review 105(4), 1478-1508.

Laroque, G. R. (2005). Indirect taxation is superfluous under separability and taste homogeneity: a simple proof. Economics Letters 87(1), 141-144.

Liebschutz, S. F. (1995). Empowerment zones and enterprise communities: Reinventing federalism for distressed communities. Publius: The Journal of Federalism 25(3), 117-132.

Mankiw, N. G. and M. Weinzierl (2010). The optimal taxation of height: A case study of utilitarian income redistribution. American Economic Journal: Economic Policy 2(1), 155-76.

Mayshar, J. (1990). On measures of excess burden and their application. Journal of Public Economics 43(3), 263-289.

McFadden, D. (1978). Modeling the choice of residential location. Transportation Research Record (673).

Mirrlees, J. A. (1971). An exploration in the theory of optimum income taxation. The review of economic studies 38(2), 175-208. 
Moretti, E. (2011). Local labor markets. In Handbook of labor economics, Volume 4, pp. 1237-1313. Elsevier.

Moretti, E. (2012). The new geography of jobs. Houghton Mifflin Harcourt.

Moretti, E. (2013). Real wage inequality. American Economic Journal: Applied Economics 5(1), 65-103.

Moretti, E. and D. J. Wilson (2019). Taxing billionaires: Estate taxes and the geographical location of the ultra-wealthy. Technical report, National Bureau of Economic Research.

Nelson, R. K., L. Winling, R. Marciano, N. Connolly, et al. (2020). Mapping inequality.

Oates, W. E. (1999). An essay on fiscal federalism. Journal of economic literature 37(3), 1120-1149.

Paolacci, G., J. Chandler, and P. G. Ipeirotis (2010). Running experiments on amazon mechanical turk. Judgment and Decision making 5(5), 411-419.

Piketty, T., E. Saez, and G. Zucman (2018). Distributional national accounts: methods and estimates for the united states. The Quarterly Journal of Economics 133(2), 553-609.

Reardon, S. F. and K. Bischoff (2011). Income inequality and income segregation. American Journal of Sociology 116(4), 1092-1153.

Reardon, S. F., K. Bischoff, A. Owens, and J. B. Townsend (2018). Has income segregation really increased? bias and bias correction in sample-based segregation estimates. Demography 55(6), 2129-2160.

Redding, S. J. and E. Rossi-Hansberg (2017). Quantitative spatial economics. Annual Review of Economics 9, $21-58$.

Ross, S. L. and G. M. Tootell (2004). Redlining, the community reinvestment act, and private mortgage insurance. Journal of Urban Economics 55(2), 278-297.

Rossi-Hansberg, E., P.-D. Sarte, and F. Schwartzman (2019, September). Cognitive hubs and spatial redistribution. Working Paper 26267, National Bureau of Economic Research.

Rothschild, C. and F. Scheuer (2013). Redistributive taxation in the roy model. The Quarterly Journal of Economics 128(2), 623-668.

Saez, E. (2002). The desirability of commodity taxation under non-linear income taxation and heterogeneous tastes. Journal of Public Economics 83(2), 217-230. 
Saez, E. and S. Stantcheva (2016). Generalized social marginal welfare weights for optimal tax theory. American Economic Review 106(1), 24-45.

Sjaastad, L. A. (1962). The costs and returns of human migration. Journal of political Economy 70(5, Part 2), 80-93.

Slattery, C. R. and O. M. Zidar (2020). Evaluating state and local business tax incentives. Technical report, National Bureau of Economic Research.

Squires, G. (2011). From redlining to reinvestment: Community responses to urban disinvestment. Temple University Press.

Suárez Serrato, J. C. and O. Zidar (2016). Who benefits from state corporate tax cuts? a local labor markets approach with heterogeneous firms. American Economic Review 106(9), 2582-2624.

Vance, J. D. (2016). Hillbilly elegy: A memoir of a family and culture in crisis. New York, NY: Harper.

Weinzierl, M. (2014). The promise of positive optimal taxation: normative diversity and a role for equal sacrifice. Journal of Public Economics 118, 128-142.

Wilson, W. (1987). Truly disadvantaged: The inner city, the underclass, and public policy.

Wilson, W. J. (2011). When work disappears: The world of the new urban poor. Vintage. 


\section{ONLINE APPENDIX}

\section{A Theory Appendix}

\section{A.1 Proofs and derivation}

\section{A.1.1 Derivation of equations 8}

Taking into account the budget balance constraint, the Lagrangian for the social planner's problem is:

$$
\mathcal{L}=\int \omega(\Theta) v^{*}(\Theta) d F(\Theta)-\phi \int T\left(z^{*}(\Theta)\right) d F(\Theta)
$$

The total welfare effect of a PBR scheme expressed in terms of the value of public funds is:

$\mathcal{W}(\Delta)-W(0)=\frac{1}{\phi} \int_{\text {stayers }} \omega(\Theta)\left[v^{*}(\Theta, \Delta)-v^{*}(\Theta, 0)\right] d F(\Theta)+\frac{1}{\phi} \int_{\text {movers }} \omega(\Theta)\left[v_{1}(\Theta, \Delta)-v_{0}(\Theta, 0)\right] d F(\Theta)$

where $v(\Theta, \Delta)$ is the indirect utility of household $\Theta$ under PBR scheme $\Delta$. As $\Delta \rightarrow 0$, the first order effect of the reform on the utility of movers is 0 , as movers in response to an infinitesimal PBR are initially indifferent between the two communities. Second, the number of movers is infinitesimal. Denote with $F_{\xi \mid \theta}($.$) the cdf$ of $\xi=\varepsilon_{1}-\varepsilon_{0}$ for households with skill $\theta, f_{\xi \mid \theta}($.$) the corresponding pdf, and F_{\theta}(\theta)$ the marginal distribution of $\theta$, and write $U_{j}(\theta, \Delta)=U\left(c_{j}(\theta), h_{j}(\theta), a_{j}, \frac{z_{j}(\theta)}{w_{j}(\theta)}\right)$. We have:

$$
\begin{aligned}
\int_{v_{1}(\Theta, 0)<v_{0}(\Theta, 0), v_{1}(\Theta, \Delta)>v_{0}(\Theta, \Delta)} d F(\Theta) & =\int\left[F_{\xi \mid \theta}\left(U_{1}(\theta, \Delta)-U_{0}(\theta, \Delta)\right)-F_{\xi \mid \theta}\left(U_{1}(\theta, 0)-U_{0}(\theta, 0)\right)\right] d F_{\theta}(\theta) \\
& \approx \Delta \int f_{\xi \mid \theta}\left(U_{1}(\theta, 0)-U_{0}(\theta, 0)\right)\left(\frac{d U_{1}(\theta, 0)}{d \Delta}-\frac{d U_{0}(\theta, 0)}{d \Delta}\right) d F_{\theta}(\theta) \\
& =O(\Delta)
\end{aligned}
$$

Therefore, the integration of the stayers term can be done on all households, irrespective of whether they move or not. Taking the appropriate limits, and using the envelope theorem (income is chosen optimally by households) the first order effect of a PBR simplifies to:

$$
\begin{aligned}
\frac{d W}{d \Delta} & =\frac{1}{\phi} \int \omega(\Theta) \frac{\partial U}{\partial c} \frac{j(\Theta)-S}{S(1-S)} d F(\Theta) \\
& =\int \lambda(\Theta) \frac{j(\Theta)-S}{S(1-S)} d F(\Theta) \\
& =\bar{\lambda}_{1}-\bar{\lambda}_{0}
\end{aligned}
$$

We now compute the effect of the PBR on the fiscal revenues, as households move hence change their 
income as a response to the PBR. Each mover moves necessarily to community 1, which is made relatively more attractive by the PBR scheme. This entails a revenue change per mover $T\left(z_{1}(\Theta)\right)-T\left(z_{0}(\Theta)\right)=$ $T\left(z_{1}(\theta)\right)-T\left(z_{0}(\theta)\right)$ so that the change in fiscal revenues due to movers, starting at no PBR, is:

$B_{T, \text { movers }}(\Delta)-B_{T, \text { movers }}(0)=\iint_{v_{1}(\Theta, 0)<v_{0}(\Theta, 0), v_{1}(\Theta, \Delta)>v_{0}(\Theta, \Delta)}\left(T\left(z_{1}(\Theta)\right)-T\left(z_{0}(\Theta)\right)\right) d F(\Theta) d F_{\xi \mid \theta}(\xi) d F_{\theta}(\theta)$

which leads to:

$$
\begin{aligned}
\frac{d B_{T, \text { mover }}(\Delta)}{d \Delta} & =\mathbb{E}\left\{f_{\xi \mid \theta}\left(V_{1}(\cdot, 0)-V_{0}(\cdot, 0)\right)\left(\frac{1}{S} \frac{\partial U_{1}}{\partial c}+\frac{1}{1-S} \frac{\partial U_{0}}{\partial c}\right)\left[T\left(z_{1}\right)-T\left(z_{0}\right)\right]\right\} \\
& =\mathbb{E}\left\{\frac{d S(\cdot, 0)}{d \Delta}\left[T\left(z_{1}\right)-T\left(z_{0}\right)\right]\right\}
\end{aligned}
$$

where $\frac{d S(\theta, 0)}{d \Delta}$ is the density of movers at skill $\theta$, starting from 0 PBR.

\section{A.1.2 Derivation of Proposition 1}

We compute the first order welfare effect of a PBR reform starting from $\Delta_{0}$. Derivations are as above, noting that social welfare weights are now evaluated at PBR level $\Delta_{0}$, that is:

$$
\frac{d W}{d \Delta}=\bar{\lambda}_{1}\left(\Delta_{0}\right)-\bar{\lambda}_{0}\left(\Delta_{0}\right)
$$

The behavioral response has an additional term. We start at a budget neutral PBR scheme of $\frac{S\left(\Delta_{0}\right)-j^{*}}{S\left(\Delta_{0}\right)\left(1-S\left(\Delta_{0}\right)\right)} \Delta_{0}$.

Fiscal revenues from PBR are 0 , but the fiscal effect of movers on the PBR budget is $-\frac{\Delta_{0}}{S\left(\Delta_{0}\right)\left(1-S\left(\Delta_{0}\right)\right)} \frac{d S}{d \Delta}\left(\Delta_{0}\right)$ so that overall the welfare effect of the PBR reform is:

$$
\frac{d S W F}{d \Delta}\left(\Delta_{0}\right)=\bar{\lambda}_{1}\left(\Delta_{0}\right)-\bar{\lambda}_{0}\left(\Delta_{0}\right)+\mathbb{E}\left\{\frac{d S\left(\cdot, \Delta_{0}\right)}{d \Delta}\left[T\left(z_{1}^{*}\right)-T\left(z_{0}^{*}\right)\right]\right\}-\Delta_{0} \mathbb{E}\left\{\frac{1}{S\left(\Delta_{0}\right)\left(1-S\left(\Delta_{0}\right)\right)} \frac{d S}{d \Delta}\left(\cdot, \Delta_{0}\right)\right\}
$$

At the optimal PBR scheme $\Delta^{*}, \frac{d S W F}{d \Delta}\left(\Delta^{*}\right)=0$. Rearranging terms leads to the formula in Proposition 1 .

\section{A.1.3 Derivation of Corollary 1}

We now derive a first order approximation of this expression around $\Delta_{0}=0$ :

$$
\begin{aligned}
\frac{d S W F}{d \Delta}(\Delta) & =\bar{\lambda}_{1}(0)-\bar{\lambda}_{0}(0)+\mathbb{E}\left\{\frac{d S(\cdot, 0)}{d \Delta}\left[T\left(z_{1}^{*}\right)-T\left(z_{0}^{*}\right)\right]\right\} \\
& +\Delta\left\{\frac{d}{d \Delta} \bar{\lambda}_{1}(0)-\frac{d}{d \Delta} \bar{\lambda}_{0}(0)+\mathbb{E}\left\{\frac{d^{2} S(\cdot, 0)}{d \Delta^{2}}\left[T\left(z_{1}^{*}\right)-T\left(z_{0}^{*}\right)\right]\right\}-\frac{1}{S(1-S)} \mathbb{E}_{\theta}\left\{\frac{d S(\cdot, 0)}{d \Delta}\right\}\right\}
\end{aligned}
$$


Let $\Lambda(\Theta)=\frac{\partial \lambda(\Theta)}{\partial I}=\frac{1}{\phi} \omega(\Theta) \frac{\partial^{2} v^{*}(\Theta)}{\partial I^{2}}$ and $\bar{\Lambda}_{j}=\mathbb{E}\left[\Lambda(\cdot) \mid j^{*}=j\right]$, evaluated at $\Delta=0$. We have:

$$
\frac{d \bar{\lambda}_{1}(\Delta)}{d \Delta}-\frac{d \bar{\lambda}_{0}(\Delta)}{d \Delta}=\bar{\Lambda}_{1}(0)+\bar{\Lambda}_{0}(0)+\mathbb{E}\left[\frac{d S(., 0)}{d \Delta}\left(\frac{\lambda_{1}(\theta, 0)-\bar{\lambda}_{1}(0)}{S}+\frac{\lambda_{0}(\theta, 0)-\bar{\lambda}_{0}(0)}{1-S}\right)\right]
$$

Overall, at the optimal PBR, so long as it small, we have:

$$
\Delta^{*}=\frac{\bar{\lambda}_{1}(0)-\bar{\lambda}_{0}(0)+\mathbb{E}\left\{\frac{d S(\cdot, 0)}{d \Delta}\left[T\left(z_{1}^{*}\right)-T\left(z_{0}^{*}\right)\right]\right\}}{\mathbb{E}\left[\frac{d S(\cdot, 0)}{d \Delta}\left(\frac{\bar{\lambda}_{1}(0)-\lambda_{1}(\theta, 0)}{S}+\frac{\bar{\lambda}_{0}(0)-\lambda_{0}(\theta, 0)}{1-S}\right)\right]+\mathbb{E}\left\{\frac{d^{2} S(\cdot, 0)}{d \Delta^{2}}\left[T\left(z_{1}^{*}\right)-T\left(z_{0}^{*}\right)\right]\right\}+\frac{1}{S(1-S)} \mathbb{E}\left\{\frac{d S(\cdot, 0)}{d \Delta}\right\}-\left(\bar{\Lambda}_{0}(0)+\bar{\Lambda}_{1}(0)\right)},
$$

\section{A.1.4 Derivation of equations (11), (12) and (13)}

We compute the first order effect of the income tax perturbation on the SWF. In this derivation, we assume that preferences can give rise to income effects of labor supply. We make the following technical assumption:

Assumption. The income tax schedule $T($.$) is smooth and T^{\prime}(z)>0$.

The first-order effect of the income tax perturbation on utility, expressed in terms of the value of public funds, is:

$$
\begin{aligned}
\frac{d W}{d q} & =-\frac{1}{\phi} \int \omega(\Theta) \frac{\partial U}{\partial c} \stackrel{\circ}{T}(z(\Theta)) d F(\Theta) \\
& =-\int \lambda(\Theta) \stackrel{\circ}{T}(z(\Theta)) d F(\Theta) \\
& =-\int \lambda(\Theta)\left(\frac{S-\rho(z(\Theta))}{S(1-S)}\right) d F(\Theta)
\end{aligned}
$$

The behavioral responses to the tax reform are twofold. First, households who do not move get a hit by a simple income tax reform change and adjust their earnings. The corresponding first order loss in tax revenue is:

$$
\frac{d B}{d q}=\mathbb{E}\left\{T^{\prime}\left(z^{*}\right) \frac{d z^{*}}{d T^{\prime}\left(z^{*}\right)} \frac{d T^{\prime}\left(z^{*}\right)}{d q}\right\}
$$

A change in the tax schedule affects earnings $z$ through income and substitution effects. For a given household with skill $\theta$ located in city $j$, we denote by $z_{j}^{\theta}(1-\tau, I)$ the earnings they would supply with a linear budget constraint with tax rate $\tau$ and virtual income $I$. An arbitrary small income tax change $\stackrel{T}{T}(z) d q$ produces a change in earnings:

$$
d z^{*}=-\frac{\partial z^{*}}{\partial(1-\tau)} d \tau+\frac{\partial z^{*}}{\partial I} d I
$$


The change in marginal tax rate $d \tau$ is equal to:

$$
d \tau=\stackrel{\circ}{T}^{\prime}\left(z^{*}\right) d q+T^{\prime \prime}\left(z^{*}\right) d z^{*}
$$

where the first term comes from the direct change in the tax rate and the second one comes from the fact that $z$ adjusts and that the initial tax schedule has some curvature, leading to a change in marginal rate when $z$ change. The virtual income shock is :

$$
d I-z^{*} d \tau=-\stackrel{\circ}{T}\left(z^{*}\right) d q
$$

Hence:

$$
d z_{j}=\frac{-\left(\frac{\partial z^{*}}{\partial(1-\tau)}-\frac{\partial z^{*}}{\partial I} z^{*}\right) \stackrel{\circ}{T}^{\prime}\left(z^{*}\right) d q-\frac{\partial z^{*}}{\partial I} \stackrel{\circ}{T}\left(z_{j}^{\theta}\right) d q}{1+\left(\frac{\partial z^{*}}{\partial(1-\tau)}-\frac{\partial z^{*}}{\partial I} z^{*}\right) T^{\prime \prime}\left(z^{*}\right)},
$$

where the first term in parenthesis is the substitution effect. We now apply this computation to the tax perturbation that mimics a PBR scheme. To do so, we make the following assumption:

Assumption 1. The function $\rho(z)$ is differentiable in $z$.

Under this assumption, we get:

$$
\frac{d z^{*}}{d q}=\frac{1}{S(1-S)} \frac{\left(\frac{\partial z^{*}}{\partial(1-\tau)}-\frac{\partial z^{*}}{\partial I} z^{*}\right) \rho^{\prime}\left(z^{*}\right)-\frac{\partial z^{*}}{\partial I}\left(S-\rho\left(z^{*}\right)\right)}{1+\left(\frac{\partial z^{*}}{\partial(1-\tau)}-\frac{\partial z^{*}}{\partial I} z^{*}\right) T^{\prime \prime}\left(z^{*}\right)}
$$

Denote the substitution effect and income effect as follows:

$$
\begin{aligned}
& Z_{c}(\Theta)=\frac{\partial z^{*}}{\partial(1-\tau)}-\frac{\partial z^{*}}{\partial I} z^{*} \\
& Z_{I}(\Theta)=\frac{\partial z^{*}}{\partial I}
\end{aligned}
$$

Then

$$
\frac{d z^{*}}{d q}=\frac{1}{S(1-S)} \frac{Z_{c}(\Theta) \rho^{\prime}\left(z^{*}\right)-Z_{I}(\Theta)\left(S-\rho\left(z^{*}\right)\right)}{1+Z_{c}(\Theta) T^{\prime \prime}\left(z^{*}\right)}
$$

The loss in tax revenue from the income tax reform is therefore equal to:

$$
\frac{1}{S(1-S)} \mathbb{E}\left\{T^{\prime}\left(z^{*}\right) \frac{Z_{c} \rho^{\prime}\left(z^{*}\right)-Z_{I}\left(S-\rho\left(z^{*}\right)\right)}{1+Z_{c} T^{\prime \prime}\left(z^{*}\right)}\right\}
$$

Second, households who do move also adjust their labor supply. The change in fiscal revenues due to movers in response to the income tax perturbation is: 


$$
\begin{aligned}
& \mathbb{E}\left\{f_{\xi \mid \theta}\left(V_{1}^{*}(0)-V_{0}^{*}(0)\right)\left\{\frac{\partial U_{o}^{*}(\Theta)}{\partial c}\left(S-\rho\left(z_{0}^{*}\right)\right)-\frac{\partial U_{1}^{*}(\Theta)}{\partial c}\left(S-\rho\left(z_{1}^{*}\right)\right)\right\}\left[T\left(z_{1}^{*}\right)-T\left(z_{1}^{*}\right)\right]\right\} \\
& =\mathbb{E}\left\{\frac{d S}{d q}\left[T\left(z_{1}^{*}\right)-T\left(z_{1}^{*}\right)\right]\right\} .
\end{aligned}
$$

in which for some skills the term inside \{\} can be negative: if the behavioral response induces a move from 1 to 0 , it leads to increased tax revenues for the government. We compare the movers term of PBR to the one of the Income Tax reform that mimics it. We compare the movers term of PBR to the one of the Income Tax reform that mimics it, for households with skill $\theta$ :

$$
\frac{d B_{\text {movers }}}{d \Delta}-\frac{d B_{\text {movers }}}{d q}=f_{\xi \mid \theta}\left(V_{1}^{*}(0)-V_{0}^{*}(0)\right)\left(\rho\left(z_{0}^{*}\right) \frac{\partial U_{0}^{*}(\Theta)}{\partial c}+\left(1-\rho\left(z_{1}^{*}\right)\right) \frac{\partial U_{1}^{*}(\Theta)}{\partial c}\right)\left[T\left(z_{1}^{*}\right)-T\left(z_{1}^{*}\right)\right]
$$

Which is clearly $<0$ since the first two terms are positive and $T\left(z_{1}^{*}\right)-T\left(z_{1}^{*}\right)<0$. We conclude that $\frac{d B_{\text {movers }}}{d \Delta}-\frac{d B_{\text {movers }}}{d q}<0$

Overall,

$$
\frac{d S W F}{d q}=\mathbb{E}\left[\lambda\left(\frac{\rho\left(z^{*}\right)-S}{S(1-S)}\right)\right]+\frac{1}{S(1-S)} \mathbb{E}\left\{T^{\prime}\left(z^{*}\right) \frac{Z_{c}(\Theta) \rho^{\prime}\left(z^{*}\right)-Z_{I}(\Theta)\left(S-\rho\left(z^{*}\right)\right)}{1+Z_{c}(\Theta) T^{\prime \prime}\left(z^{*}\right)}\right\}+\mathbb{E}\left\{\frac{d S}{d q}\left[T\left(z_{1}^{*}\right)-T\left(z_{1}^{*}\right)\right]\right\}
$$

and without income effects on labor supply:

$$
\frac{d S W F}{d q}=\mathbb{E}\left[\lambda\left(\frac{\rho(z)-S}{S(1-S)}\right)\right]+\frac{1}{S(1-S)} \mathbb{E}\left\{T^{\prime}\left(z^{*}\right) \rho^{\prime}\left(z^{*}\right) \frac{Z_{1-\tau}}{1+Z_{1-\tau} T^{\prime \prime}\left(z^{*}\right)}\right\}+\mathbb{E}\left\{\frac{d S}{d q}\left[T\left(z_{1}^{*}\right)-T\left(z_{1}^{*}\right)\right]\right\}
$$

where $Z_{1-\tau}(\Theta)=\frac{\partial z^{*}(\Theta)}{\partial(1-\tau)}>0$ denotes the compensated labor earnings response to a change in the marginal net of tax rate $1-T^{\prime}\left(z^{*}\right)$.

\section{A.1.5 Proof of Example 5}

Consider an equilibrium with place-blind tax system $T(\cdot)$ and place based transfers, where $\Delta_{j}$ is the lumpsum tax on $j$. We aim to show that there is perfect sorting of $\theta$ into $j$ and $z$ (that is, $\left(z^{*}, j^{*}\right)$ and $\theta$ are one-to-one). We first show that each observed pre-tax earnings level $z$ corresponds to only 1 location. The proof is by contradiction. Assume there exists $\theta \neq \theta^{\prime}$ such that $j^{*}(\theta)=0, j^{*}\left(\theta^{\prime}\right)=1$ but $z^{*}(\theta)=z^{*}\left(\theta^{\prime}\right)=$ $\tilde{z}$ for some pre-tax earnings $\tilde{z}$. Consider the subutility of consumption function conditional on income, $v\left(z, j^{*}\right)=\max _{j} a_{j} \cdot\left(z-\Delta_{j}-r_{j}\right)^{\gamma}$. In the interesting non-degenerate case where $a_{j}$ and $r_{j}+\Delta_{j}$ are both higher in community 1 than in 0 , the corresponding optimal choice of location $j^{*}(z)$ is a step function. 
WLOG, assume that $j^{*}(\tilde{z})=1$, so that $v(\tilde{z}, 1)>v(\tilde{z}, 0)$. In turn, $U(v(\tilde{z}, 1), \tilde{z})>U(v(\tilde{z}, 0)$, $\tilde{z})$, so that both $\theta$ and $\theta^{\prime}$ are better off in 1, a contradiction. This implies, in turn, that $z$ and $\theta$ are one-to-one. Indeed, if $\theta$ and $\theta^{\prime}$ are in the same location, it is clear that $\theta \neq \theta^{\prime} \Rightarrow z \neq z^{\prime}$. Furthermore, if $\theta \neq \theta^{\prime}$ are in different locations, they must have different incomes by the point above. Therefore, there is perfect sorting of $\theta$ into $z$ and into $j$.

Next, we show that in this context, PBR is dominated by using the income tax alone. The proof closely follows Kaplow (2006) and Laroque (2005). Starting at an equilibrium with taxes and PBR $(T(\cdot), \Delta)$, remove $\operatorname{PBR} \Delta$. For each individual with income $z$, compute a new tax system $(\bar{T}(z), 0)$ such that each household at each level of income $z$ attains the subutility of consumption $v\left(z, j^{*}\right)$ they had under the previous tax scheme $(T(\cdot), \Delta)$. Note that the exercise is well defined given that income is one for one with $\theta$ and $j^{*}$ : an observed $z$ corresponds to a unique $\theta$, hence a unique change in utility between the two schemes (with and without PBR), so that the compensating change in income tax $\bar{T}(z)$ is well defined. Because the level of subutility of consumption at every $z$ is unchanged with the scheme $(\bar{T}(z), 0)$ compared to before, all households will make the same choice of labor supply as under $(T(\cdot), \Delta)$.

Finally, we show that in the new scheme $(\bar{T}(z), 0)$, government revenues are higher: attaining the new consumption bundle costs at least $z-\bar{T}(z)$. The same utility would be reached when consuming the initial choice $\left(c^{*}, j^{*}\right)$, which now costs $c^{*}+r_{j^{*}}$. Therefore $c^{*}+r_{j^{*}} \geq z-\bar{T}(z)$. But, given the budget constraint of the initial equilibrium, we have that $c^{*}+r_{j^{*}}+\Delta_{j^{*}}=z-T(z)$. This leads to $z-T(z)-\Delta_{j^{*}} \geq z-\bar{T}(z)$ and therefore $T(z)+\Delta_{j^{*}} \leq \bar{T}(z)$. The government collects more taxes with the income tax alone than with an income tax and PBR, for the same level of utility of households. QED.

\section{A.2 Extensions}

\section{A.2.1 Preferences with income effects on labor supply}

We assume here that the utility function displays income effects on labor supply, i.e., $\frac{\partial z_{j}^{\theta}}{\partial I}<0$. An additional behavioral response to both tax reforms (PBR and income tax) emerges, which we discuss here. The other terms computed in the main text remain unaffected. With income effects on labor supply, the effect of an infinitesimal lump-sum transfer $\Delta$ on tax revenues is:

$$
\frac{d B_{T, \text { stayers }}}{d \Delta}=\mathbb{E}\left\{T^{\prime}\left(z^{*}\right) \frac{d z^{*}}{d \Delta} \mid \text { stayers }\right\}=\mathbb{E}\left\{T^{\prime}\left(z^{*}\right) \frac{d z^{*}}{d \Delta}\right\}
$$


since the number of movers is infinitesimal.

Households who do not move in response to the PBR now adjust their earnings in response to the lump-sum PBR. Applying (20) to the PBR reform, we get:

$$
d z^{*}=\frac{d z^{*}}{\partial I} \frac{S-j}{S(1-S)} d \Delta
$$

The additional change in tax revenue from the PBR reform through behavioral effect on $z$ for stayers is therefore:

$$
\frac{d B_{T}}{d \Delta}=-\mathbb{E}\left\{T^{\prime}(z) \mathbb{E}\left[\frac{1}{S(1-S)} \frac{Z_{I}(\Theta)(S-j)}{1+Z_{c}(\Theta) T^{\prime \prime}(z)} \mid z^{*}=z\right]\right\}
$$

Regarding the income tax reform, the computation were made above. The additional term only present with income effects on labor supply is:

$$
\frac{d B_{T}}{d q}=-\mathbb{E}\left\{T^{\prime}(z) \frac{S-\rho(z)}{S(1-S)} \mathbb{E}\left[\frac{Z_{I}(\Theta)}{1+Z_{c}(\Theta) T^{\prime \prime}(z)} \mid z^{*}=z\right]\right\}
$$

Comparing the two income effects The difference between these two terms is:

$$
\frac{d B_{T}}{d \Delta}-\frac{d B_{T}}{d q}=\mathbb{E}\left\{T^{\prime}(z) \mathbb{E}\left[\frac{Z_{I}(\Theta)}{1+Z_{c}(\Theta) T^{\prime \prime}(z)}\left(\frac{j-\mathbb{E}\left[j \mid z^{*}=z\right]}{S(1-S)}\right) \mid z^{*}=z\right]\right\}
$$

Consider the following assumption (Saez (2002)):

Assumption 2. Conditional on each income level, behavioral response $\frac{Z_{I}(\theta, j)}{1+Z_{c}(\theta, j) T^{\prime \prime}(z)}$ is independent of where the household lives.

Under Assumption 2, location choice $j$ can be pulled out of the conditional expectation and averaged out conditional on $z$, leading to $\frac{d B_{T}}{d \Delta}-\frac{d B_{T}}{d q}=0$. The behavioral responses to PBR and the equivalent income tax reform coming through the income effect are exactly equal.

\section{A.2.2 Endogenous rents}

We release the assumption made throughout the main text that house prices are fixed and exogenous. Assume that housing in community $j$ is provided by landowners according to a housing supply function:

$$
H_{j}=H_{0 j} r^{\gamma_{j}}
$$


There is no a priori ordering of $\gamma_{1}$ vs $\gamma_{0}$. On the one hand, one could think that housing tends to be supplied less elastically in high wage/high skilled city, so that: $\gamma_{0}<\gamma_{1}$. On the other hand, one could think that distressed areas are on the vertical part of their housing supply function, since they are under populated compared to their historical stock of housing (Glaeser and Gyourko 2005). In this case, one could think that $\gamma_{0}>\gamma_{1}$. This is ultimately an empirical question. The price of housing can be written as a function of city population $L_{j}=j S(\Delta)+(1-j)(1-S(\Delta))$ :

$$
r_{j}\left(L_{j}\right)=\left(\frac{L_{j}}{H_{0 j}}\right)^{\frac{1}{\gamma_{j}}}
$$

For a PBR scheme $\Delta$, population is $L_{j}=j S(\Delta)+(1-j)(1-S(\Delta))$. We assume that landlords are valued in the social welfare function at some weight $\omega^{\text {land: }}$

$$
S W F \equiv \mathbb{E}\left[\omega^{h} G\left(v^{h}\right)\right]+\mathbb{E}\left[\omega^{\text {land }} r\right]
$$

where possibly $\omega^{\text {land }}=0$ (absentee landlords assumption). Let $L_{j}^{l}$ denote the number of landowners in $j$, $\bar{\lambda}_{j}^{l}$ their average welfare weight. We define $\bar{\Gamma}_{j}=\frac{L_{j}^{l}}{L_{j}} \bar{\lambda}_{j}^{l}$.

A PBR reform generates a net transfer of utility from inhabitants of community 0 to those of community 1, measured by:

$$
\left.\frac{d W}{d \Delta}\right|_{\Delta=0}=\bar{\lambda}_{1}-\bar{\lambda}_{0}+\frac{d S}{d \Delta}\left(\frac{r_{0}}{\gamma_{0}}\left(\bar{\lambda}_{0}-\bar{\Gamma}_{0}\right)-\frac{r_{1}}{\gamma_{1}}\left(\bar{\lambda}_{1}-\bar{\Gamma}_{1}\right)\right)
$$

where $\bar{\lambda}_{j}-\bar{\Gamma}_{j}$ measures the social value of transferring a dollar from landlords to households in community $j$. Under the assumption of absentee landlords, the formula becomes:

$$
\left.\frac{d W}{d \Delta}\right|_{\Delta=0}=\bar{\lambda}_{1}-\bar{\lambda}_{0}+\frac{d S}{d \Delta}\left(\frac{r_{0}}{\gamma_{0}} \bar{\lambda}_{0}-\frac{r_{1}}{\gamma_{1}} \bar{\lambda}_{1}\right)
$$

We see that taking into account endogenous rents leads to an additional effect of the PBR, as movers change the price of housing for all infra-marginal households. The sign of this additional term is a priori ambiguous, as $r_{1}<r_{0}$ but $\lambda_{1}>\lambda_{0}$. It is interesting to note the role played by the difference in housing supply elasticity $\gamma_{j}$ between locations on the welfare effect of PBR. To highlight it, we assume for simplicity that $r_{j} \lambda_{j} \sim$ constant, so that the sign of the extra term is the sign of $\frac{1}{\gamma_{0}}-\frac{1}{\gamma_{1}}$. If high-income areas also happen to be housing-supply inelastic, while low income area have more elastic housing supply $\left(\gamma_{0}<\gamma_{1}\right)$, then 
the rent effect is favorable to PBR. Movers relocate out of congested places, prices react downwards strongly to these moves, while they react mildly upwards in the destination area. Taxing highly inelastic areas like Manhattan, and redistributing to more elastic areas like its suburbs leads to this additional positive effect of PBR. On the other hand, it can be that distressed areas are on the vertical part of their housing supply curve $\left(\gamma_{1}\right.$ low $)$, when they are areas like Detroit or the Appalachian with a large stock of unused housing (Glaeser and Gyourko (2005)). In this case, the rent effect can turn to negative - increase in housing costs in the Distressed area, because of movers, outweighs the decrease in housing cost in Elsewhere, acting as an additional efficiency cost to account for when evaluating the effect of a PBR scheme. Beyond this additional welfare term, there is no other efficiency cost to account for when recognizing that prices are endogenous (we do not take into account property taxes in this derivation). We can then derive the overall effect of a PBR scheme when rents are endogenous:

Lemma. The first order effect on welfare of a small PBR reform starting from a place-blind system is:

$$
\frac{d S W F}{d \Delta}(0)=\bar{\lambda}_{1}-\bar{\lambda}_{0}+\frac{\partial S}{\partial \Delta}\left(\frac{r_{0}}{\gamma_{0}}\left(\bar{\lambda}_{0}-\bar{\Gamma}_{0}\right)-\frac{r 1}{\gamma_{1}}\left(\bar{\lambda}_{1}-\bar{\Gamma}_{1}\right)\right)+\mathbb{E}_{\theta}\left\{\frac{d S^{\theta}(0)}{d \Delta}\left[T\left(z_{1}^{\theta}\right)-T\left(z_{0}^{\theta}\right)\right]\right\}
$$

where $\bar{\Gamma}_{j}=0$ with absentee landlords.

\section{A.2.3 Alternative specification of locational preferences}

In this section, rather than assuming that idiosyncratic choices of locations are driven by additive preference shocks as in the main text, we consider a more general formulation where households have idiosyncratic productivity in both locations, as well as idiosyncratic preferences for location. They are therefore characterized by a quadruple $\Theta=\left\{w_{0}, w_{1}, \varepsilon_{1}, \varepsilon_{2}\right\}$ distributed according to the CDF $F($.$) . Furthermore, we do not restrict$ the preference shocks to enter additively in the utility function. That is, we assume that:

$$
u_{j}(\Theta)=U\left(c, h, a_{j}, \frac{z}{w_{j}}, \varepsilon_{j}\right)
$$

We first discuss how our main results carry through to these more general cases. We then discuss the pitfalls of non-additive idiosyncratic preferences in the context of normative questions. 
Main results The logic of the derivations in the main text is unchanged, but notations need to be adjusted. In particular, we define the share of households who live in Distressed when the transfer is of size $\Delta$ as:

$$
S(\Delta)=\int_{\Theta \in \mathbb{R}^{4}} j^{*}(\Theta, \Delta) d F(\Theta)
$$

We have

$$
\frac{d S}{d \Delta}=\lim _{\Delta \rightarrow 0} \int_{\Theta \in \mathbb{R}^{4}}\left[\frac{j^{*}(\Theta, \Delta)-j^{*}(\Theta, 0)}{\Delta}\right] d F(\Theta)
$$

The fiscal cost of movers still corresponds to the earnings losses of movers, which now writes more generally:

$$
\begin{aligned}
\frac{d B}{d \Delta} & =\lim _{\Delta \rightarrow 0} \int_{\Theta \in \mathbb{R}^{4}}\left[\frac{\left[j^{*}(\Theta, \Delta)-j^{*}(\Theta, 0)\right]\left[T\left(z_{1}^{*}(\Theta, \Delta)\right)-T\left(z_{0}^{*}(\Theta, 0)\right)\right]}{\Delta}\right] d F(\Theta) \\
& =\lim _{\Delta \rightarrow 0} \int_{\Theta \in \mathbb{R}^{4}}\left[\frac{j^{*}(\Theta, \Delta)-j^{*}(\Theta, 0)}{\Delta}\left[T\left(z_{1}^{*}(\Theta, 0)\right)-T\left(z_{0}^{*}(\Theta, 0)\right)\right]\right] d F(\Theta)
\end{aligned}
$$

where the last line follows because $T\left(z_{1}^{*}(\Theta, \Delta)\right)=T\left(z_{1}^{*}(\Theta, 0)\right)$ : absent an income effect on labor supply, stayers do not adjust their earnings following a lump-sum tax/subsidy. We write this expression with a more convenient notational shortcut:

$$
\begin{aligned}
\frac{d B}{d \Delta} & =\mathbb{E}\left[T\left(z_{1}^{*}(\Theta, 0)\right)-T\left(z_{0}^{*}(\Theta, 0)\right) \mid \text { move }\right] P(\text { move })+\mathbb{E}\left[T\left(z_{1}^{*}(\Theta, 0)\right)-T\left(z_{0}^{*}(\Theta, 0)\right) \mid \text { stay }\right] P(\text { stay }) \\
& =\mathbb{E}\left[T\left(z_{1}^{*}(\Theta, 0)\right)-T\left(z_{0}^{*}(\Theta, 0)\right) \mid \text { move }\right] \frac{d S}{d \Delta}
\end{aligned}
$$

The main results of the paper are amended as follows (nothing is changed in the equity computations, only in the efficiency cost computations):

- The first order effect on welfare of a small PBR reform starting from a place-blind system is:

$$
\frac{d S W F}{d \Delta}=\bar{\lambda}_{1}-\bar{\lambda}_{0}+\frac{d S}{d \Delta} \mathbb{E}\left\{\left[T\left(z_{1}^{*}(., 0)\right)-T\left(z_{0}^{*}(., 0)\right)\right] \mid \text { move }\right\}
$$

- The difference between the efficiency cost of a PBR and the one of a corresponding income tax reform is: 


$$
\begin{aligned}
\frac{d B}{d \Delta}-\frac{d B}{d q} & =\lim _{\Delta \rightarrow 0} \int_{\Theta \in \mathbb{R}^{4}}\left[\frac{j^{*}(\Theta, \Delta)-j^{*}(\Theta, 0)}{\Delta}\left(\left[T\left(z_{1}^{*}(\Theta, 0)\right)-T\left(z_{0}^{*}(\Theta, 0)\right)\right]\right)\right] d F(\Theta) \\
& -\lim _{q \rightarrow 0} \int_{\Theta \in \mathbb{R}^{4}}\left[\frac{j^{*}(\Theta, q)-j^{*}(\Theta, 0)}{q}\left(\left[T\left(z_{1}^{*}(\Theta, 0)\right)-T\left(z_{0}^{*}(\Theta, 0)\right)\right]\right)\right] d F(\Theta) \\
& -\mathbb{E}\left\{T^{\prime}\left(z^{*}\right) \frac{\rho^{\prime}\left(z^{*}\right)}{S(1-S)} \frac{Z_{1-\tau}}{1+Z_{1-\tau} T^{\prime \prime}\left(z^{*}\right)}\right\}
\end{aligned}
$$

Technical results are therefore similar to what is in the main text with an additive formulation of idiosyncratic preferences, except that they call for a more cumbersome notation. We now discuss the advantage of choosing additively separable idiosyncratic preferences for location when it comes to normative questions.

\section{A.2.4 Pitfalls of non-additive idiosyncratic shocks}

With additively separable idiosyncratic preferences for location, the social welfare weights $\lambda_{z}^{j}$ are not direct functions of $\varepsilon_{j}$ - they are only indirectly impacted by idiosyncratic preferences through their effect on choice of city $j$. So welfare weights are functions of $j$ (as well as $z, w_{j}(\theta)$ ), but not of $\varepsilon_{j}$. The reason why this is an advantage is that welfare weights - hence welfare implications of policies - do not depend on the specification and values of the unobserved shocks $\varepsilon_{j}$, they only depend on their indirect impact on the observed location choice $j$. In contrast, when the $\lambda$ 's directly depend on the value of $\varepsilon_{j}$, the definition of $\varepsilon_{j}$ obviously matters for welfare. Unfortunately, as we show in the example below, one can easily build examples where two alternative models of $\varepsilon_{j}$ lead to observationally equivalent equilibria, hence they cannot be disentangled using data, but have opposite welfare implications. It makes it undesirable to rest a normative argument on such a model. ${ }^{24}$ Finally, it is easy to see that a similar argument applies to the case where idiosyncratic preferences for location are additively separable but the planner has concave preferences over levels of indirect utility, i.e. $S W F=\int G\left(U^{h}\right) d h$, as examined for instance in Kessing et al. (2020).

Example Consider a simple utility function:

$$
U\left(c^{\alpha} h^{1-\alpha}+\varepsilon_{j}\right)
$$

\footnotetext{
${ }^{24}$ Davis and Gregory (2020) discuss a related point: multiplicative preference shocks commonly used in Economic Geography model are typically not identified but influence marginal utility of consumption, hence social preferences. They propose to adjust the planner's problem to neutralize the influence of these shocks on marginal utility of consumption. Our setup with additive shocks avoids this pitfall.
} 
with $U($.$) concave. Households supply labor inelastically. Type \theta$ gets income $z_{j}(\theta)$ in city $j$. Households choose city $j=1$ iff

$$
U\left(\frac{z_{1}(\theta)}{P_{1}}+\varepsilon_{1}\right)>U\left(\frac{z_{0}(\theta)}{P_{0}}+\varepsilon_{0}\right)
$$

i.e., iff

$$
\varepsilon_{1}-\varepsilon_{0}>\frac{z_{0}(\theta)}{P_{0}}-\frac{z_{1}(\theta)}{P_{1}}
$$

Note that the values of $\varepsilon_{1}$ and $\varepsilon_{0}$ separately play no role in any of the observable choices of households, so that $\varepsilon_{1}$ and $\varepsilon_{0}$ are not separately identified. We then consider two alternative models: in model (a), $\varepsilon_{0}=0$ while $\varepsilon_{1}$ is an iid shock with some positive variance. In model (b), $\varepsilon_{1}=0$ while $\varepsilon_{0}$ is an iid shock with some positive variance. Both models can rationalize the exact same same sorting equilibrium, as they can rationalize the same distribution of $\varepsilon_{1}-\varepsilon_{0}$, which drives sorting. The two models are therefore observationally equivalent. Interestingly though, they have opposite welfare (PBR-related) implications. To make the point very stark, we assume that $P_{1}=P_{0}$ and normalize it to 1 , and we also assume that $z_{0}(\theta)=z_{1}(\theta)(\equiv z(\theta))$ in what follows. We compute $\lambda_{j}^{\theta}$ the social welfare weight of type $\theta$ in city $j$ :

$$
\lambda_{j}^{\theta}=U^{\prime}\left(z(\theta)+\varepsilon_{j}\right) \frac{1}{\phi}
$$

We now compare $\lambda_{0}^{z}$ to $\lambda_{1}^{z}$ to determine the direction of desirability of redistribution within earnings ${ }^{25}$ implied by the two models. In model (a), households are in 1 iff

$$
\varepsilon_{1}-\varepsilon_{0}>\frac{z_{0}(\theta)}{P_{0}}-\frac{z_{1}(\theta)}{P_{1}}
$$

i.e., given our simplifying assumptions, iff $\varepsilon_{1}>0$. Therefore, given that $U$ is concave

$$
\lambda_{1}^{z}=U^{\prime}\left(z+\varepsilon_{1}\right) \frac{1}{\phi}<U^{\prime}(z) \frac{1}{\phi}=\lambda_{0}^{z}
$$

and redistribution within-earnings from 1 to 0 is desirable.

In model (b), households are in 1 iff

$$
\varepsilon_{1}-\varepsilon_{0}>\frac{z_{0}(\theta)}{P_{0}}-\frac{z_{1}(\theta)}{P_{1}},
$$

\footnotetext{
${ }^{25}$ If we had productivity differences, we would be comparing here within-skill redistribution, but the point would still hold.
} 
i.e., given our simplifying assumptions, iff $\varepsilon_{0}<0$. Therefore households who live in 0 are such that $\varepsilon_{0}>0$,

$$
\lambda_{1}^{z}=U^{\prime}(z) \frac{1}{\phi}>U^{\prime}\left(z+\varepsilon_{0}\right) \frac{1}{\phi}=\lambda_{0}^{z}
$$

and redistribution within-earnings from 0 to 1 is desirable.

This example illustrate the pitfalls of allowing welfare weights to directly depend on $\varepsilon_{j}$, rather than indirectly based on city choice only.

\section{B Survey Appendix}

Section 5.4 presented results from our online survey of Amazon Mechanical Turk (MTurk) U.S. online laborers. We now present further details on the survey and its results.

We conducted the survey in two batches. We launched one request for 550 responses at 10am Pacific Time on Thursday July 9, 2020, and a second request for 550 responses at 10am Pacific Time on Friday, July 10, 2020. We surveyed 1,100 users in order to ensure at least 1,000 valid responses. We chose 10am Pacific Time so that the survey would be launched during business hours throughout the continental United States. We used unique MTurk identification numbers to prevent MTurk users who took the survey on July 9 from taking it again on July 10, or from retaking either day's survey again on the same day. Thirty respondents had invalid MTurk IDs or failed an attentiveness question (identifying a hand-drawn picture of a flower as a flower), leaving us with 1,070 valid responses.

The survey asked questions in the following order: the neighborhood and regional questions displayed in Figure 3a (in random order), a single follow-up question eliciting explanations from the respondent for their neighborhood and regional answers, a General Social Survey question on redistribution attitudes, demographic questions, and the attentiveness question.

MTurk survey respondents need not conform to nationally representative respondents. Indeed, MTurk respondents tend to be younger and more highly educated than the average American, despite the low wages offered on MTurk. In order to gauge how representative MTurk attitudes for redistribution may be, we followed Fisman et al. (2020) in asking respondents a standard question from the General Social Survey (GSS) on redistributive attitudes: 
Some people think that the government in Washington ought to reduce the income differences between the rich and the poor, perhaps by raising the taxes of wealthy families or by giving income assistance to the poor. Others think that the government should not concern itself with reducing this income difference between the rich and the poor. Here is a card with a scale from 1 to 7 . Think of a score of 1 as meaning that the government ought to reduce the income differences between rich and poor, and a score of 7 meaning that the government should not concern itself with reducing income differences. What score between 1 and 7 comes closest to the way you feel?

In the 2018 GSS, 50\% of respondents reported that the government ought to reduce income differences between rich and poor (i.e., gave a score between 1 and 3), 33\% reported that the government should not concern itself with reducing income differences (i.e., gave a score between 5 and 7 ), and $17 \%$ reported the middle score of $4 .^{26}$ As in Fisman et al., we find a similar distribution of scores in our MTurk survey: $44 \%$ reported that the government ought to reduce income differences between rich and poor, $32 \%$ reported that the government should not concern itself with reducing income differences, and $24 \%$ reported the middle score.

Figure 3a presented our main survey results with $95 \%$ confidence intervals: the share of respondents selecting each option for distributing tax credits to poor families across space. Online Appendix Table 1a lists the precise numbers in table form, with standard errors in parentheses. Online Appendix Table $1 \mathrm{~b}$ lists the full joint distribution of answers to the urban and regional questions. Approximately half of respondents ( $51 \%$ in the urban question and $48 \%$ in the regional question) chose to target the hypothetical tax credit to poor families in the distressed areas. One-third (32\%) chose to target the tax credit to both distressed urban areas and distressed rural areas while two-thirds $(66 \%)$ chose to target the tax credit to either distressed urban areas or distressed rural areas or both. ${ }^{27}$

Figure $3 \mathrm{~b}$ presented survey responses to the follow-up question asked of the subset of respondents who chose to distribute the tax credit to poor families in distressed areas. Online Appendix Table $2 \mathrm{~b}$ lists the precise numbers in table form, with standard errors in parentheses. The remaining panels of the table list the analogous responses to the follow-up question asked of the other four subsets of respondents, as listed in the panel headings. Each panel lists responses in descending order of response frequency; respondents were asked to select all that apply.

As noted in the main text and shown in Online Appendix Table 2ba, a large majority - 78\% - of those

\footnotetext{
${ }^{26}$ These answers can be accessed in NORC's GSS Data Explorer: https://gssdataexplorer.norc.org/variables/243/vshow.

${ }^{27} \mathrm{We}$ do not find that question order significantly predicts answers. If one restricts attention to respondents who provided the same answer to the urban question as they did to the regional question - i.e., when restricting to the 583 respondents lying along the diagonal of Online Appendix Table $2 \mathrm{~b}$ who are especially unlikely to have provided random answers - one finds that $60 \%$ prefer distribution to poor families in distressed areas.
} 
choosing to target the tax credit to poor residents of distressed areas explain their choice with the reasoning: "Poor families in distressed areas are worse off, since they deal with high poverty, high crime, high pollution, struggling schools, and a history of job losses." That response suggests an emphasis on utility levels rather than marginal utility. Interestingly, Online Appendix Table 2a shows that a substantial majority - $67 \%$ - of those choosing to spread the tax credit evenly to poor residents everywhere explain their choice with marginal utility reasoning: "Extra money given to poor families is equally valuable to poor families no matter where they live." Hence, standard notions of earnings being a sufficient statistic for marginal social welfare weights due to diminishing marginal utility of income do find support in the data, albeit among only a subset of respondents.

\section{Calibration Appendix}

Section 6.3 described the calibration of our quantification exercise. We provide further details here.

\section{C.1 Community Productivity}

As described in Section 6.2, we use the Hornbeck and Moretti (2019) Metropolitan Statistical Area productivityrent gradient in order to assign a productivity level to each community based on its adjusted median rent. Specifically, in the year-2000 Hornbeck-Moretti data (the most recent year available), we regress HornbeckMoretti's estimated log MSA total factor productivity on log MSA mean rent (see their Table 2). We find a coefficient of 0.254 (robust standard error 0.052). Hence, we set community productivity equal to community rent raised to 0.254 . Because the community with the minimum normalized rent (which happens to be the Distressed community) equals 0.38 , the minimum community productivity equals 0.78 . Because the community with the maximum normalized rent (which happens to be the lowest-poverty community) mechanically equals 1 , the maximum community productivity equals 1.

\section{C.2 Community Earnings Distribution}

As described in Section 6.3, we use community earnings distributions from the 2013-2017 ACS in order to calibrate the skill distribution parameters $\left\{\mu_{\theta}, \sigma_{\theta}\right\}$ and the amenity valuation parameters $\left\{a_{j}(\theta)\right\}$. Specifically, the tract-level ACS aggregates contain each tract's annual household income distribution along ten income bins defined by nine annual household income thresholds: $\$ 10,000, \$ 15,000, \$ 25,000, \$ 35,000, \$ 50,000$, 
$\$ 75,000, \$ 100,000, \$ 150,000$, and $\$ 200,000$. We aggregate these household income distributions across tracts within our hundred communities in order to obtain a household income distribution for each community.

The ACS household income measure includes labor earnings, capital income, and some government transfers. In contrast, our quantitative model does not include capital income and does not distinguish among different types of government transfers. We therefore calibrate the model to match each community's labor earnings distribution, after translating each household income threshold into an analogous household earnings threshold. Specifically, in the 2013-2017 individual-level ACS, we compute mean household labor earnings (wages, salary, commissions, bonuses, and tips from all jobs) within symmetric two-thousanddollar ranges around each of the nine household income thresholds in the 2013-2017 tract-level ACS. For example, we find that mean household labor earnings among households with household income in the range $[\$ 9,000, \$ 11,000]$ is $\$ 4,300$.

In this way, we arrive at nine annual household labor earnings thresholds, each rounded to the nearest one hundred dollars: $\$ 4,300, \$ 9,600, \$ 19,500, \$ 28,500, \$ 42,000, \$ 64,700, \$ 88,000, \$ 132,400$, and $\$ 180,200$. For each community, we assign each the mass in each household income bin to the analogous household earnings bin. Finally, we combine the bottom two bins into one, which we found aided simulation fit in certain permutations. Hence, our final nine earnings bins are defined by the eight thresholds: $\$ 9,600, \$ 19,500$, $\$ 28,500, \$ 42,000, \$ 64,700, \$ 88,000, \$ 132,400$, and $\$ 180,200$.

\section{C.3 Current Tax-and-Transfer System}

Our calibration requires an approximation of the current all-in tax-and-transfer system that applies to the average U.S. household, including redistribution at all levels of government. Specifically, we require an approximation of taxes-paid-minus-transfers received ("net taxes") as a function of pre-tax-and-transferincome ("pre-tax income"). We obtain that approximation using the distributional national accounts (DINA) of Piketty, Saez, and Zucman (2018), which distributes across U.S. individuals all U.S. national income and all taxes paid to all levels of U.S. governments.

We adopt the following sample restrictions in the public-use DINA files. We compile all individuals in the 2013-2017 DINA files, analogous to our use of the 2013-2017 ACS. We aggregate DINA's annual records of individuals to the annual tax unit level, in order to reflect the tax code. Because our quantification exercise includes labor income but not capital income, we restrict attention to annual household records in which 
the wages, salaries, and tips reported on tax returns comprise between $99 \%$ and $100 \%$ of their total income reported on tax returns. ${ }^{28}$ Because our model abstracts from savings and because the elderly consume out of savings and pay concomitant consumption taxes, we restrict attention to annual household records in which the taxpaying adults (either the lone taxpayer or both taxpayers of a married couple) are aged 30-55. We restrict to households with pre-tax income (defined below) under $\$ 500,000$, which exceeds the maximum pre-tax income we find in our baseline quantitative exercises.

We define pre-tax income and net taxes as follows. Because our quantification exercise includes labor income but not capital income, we define pre-tax income as pre-tax-and-transfer labor income. Hence, our income concept does not include actual or imputed capital income, such as imputed rental income from owner occupied housing. Similarly, we define net taxes as taxes paid on labor income and consumption minus government transfers. Hence, our net taxes concept does not include taxes directly attributable to wealth or capital income, such as property taxes or corporate income taxes (whose incidence DINA assumes falls entirely on capital). We handle contributory social insurance taxes - i.e., taxes like Social Security taxes, unemployment insurance taxes, and workers compensation taxes that fund future transfers to contributing individuals - in the same way that Piketty, Saez, and Zucman do in their main pre-tax income concept: we exclude those taxes and the accompanying transfers from our net taxes concept. That is: contributory social insurance taxes are excluded from both pre-tax income and post-tax income, while contributory social insurance payments are included in both pre-tax income and post-tax income. ${ }^{29}$

We implement our pre-tax income and net taxes definitions in the DINA files as follows. We set pretax income equal to DINA personal factor labor income. Personal factor labor income equals employee compensation (equal to employee wages and benefits) plus the labor component of mixed income (i.e., selfemployment income assumed attributable to labor rather than capital) plus assumed sales and excise taxes falling on labor. ${ }^{30}$ We set net taxes equal to the sum of DINA federal and state personal income taxes, sales

\footnotetext{
${ }^{28}$ For households that do not file taxes, the DINA files include synthetic records with values imputed based on the Current Population Survey and other data sources.

${ }^{29}$ See PSZ's discussion between pre-tax factor income and pre-tax national income. Alternative approaches from the one we adopt are difficult to implement in annual cross-sectional data. For example, counting Social Security taxes as a pure tax on working-age households ignores the large transfers that those benefits will trigger later in life. Panel data would permit a researcher to compute lifetime Social Security taxes paid minus lifetime Social Security benefits received, but the DINA files are annual cross sections.

${ }^{30}$ In terms of DINA variables, pre-tax-and-transfer income equals flinc ("personal factor labor income", equal to employee wages and benefits plus the labor component of mixed income plus the labor component of sales and excise taxes). Employee wages and benefits includes employer payroll taxes and unemployment insurance contributions. Sales and excise taxes are part of national income and are part of the taxes that households pay when consuming after-tax-and-transfer income, so those taxes must be counted as pre-tax-and-transfer income as well. DINA allocates those taxes to individuals according to their labor and capital income; personal factor labor income includes only the portion of sales and excise taxes attributable to their labor income.
} 
and excise taxes, and non-contributory social insurance taxes (essentially Medicare taxes), minus the sum of DINA cash and cash-like transfers (e.g., refundable tax credits, food stamps, and Supplemental Security Income) and in-kind transfers (e.g., Medicaid, Medicare, and Pell grants). ${ }^{31}$ Taxes paid tend to be negative for low-pre-tax-income households, which indicates that they receive net transfers from the tax-and-transfer system, while taxes paid tend to be positive for high-pre-tax-income households. ${ }^{32}$

Our quantitative exercise uses a three-bracket income tax-and-transfer system, with bracket kink points at $\$ 20,000$ and $\$ 80,000$ and with a universal lump-sum transfer. We therefore estimate the best-fit three-bracket income tax-and-transfer system on the DINA data, using OLS regression of net taxes on a three-segment linear spline in pre-tax income. The resulting coefficients equal our approximation of net taxes $T(z)$ as a function of pre-tax income $z$ :

$$
\begin{aligned}
T(z) & =-11300 \\
& +\quad .438 \times \min \{z, 20000\} \\
& +1\{z>20000\} \times .161 \times \min \{z-20000,80000-20000\} \\
& +1\{z>80000\} \times .271 \times(z-80000)
\end{aligned}
$$

where $1\{z>20000\}$ and $1\{z>80000\}$ are indicators for pre-tax income lying above $\$ 20,000$ and $\$ 80,000$, respectively. In the DINA data, the lump-sum transfer of $\$ 11,300$ reflects a combination of cash and cashlike transfers like Supplemental Security Income and food stamps and in-kind transfers like Medicaid. The high effective marginal tax rate of $43.8 \%$ in the $\$ 0-\$ 20,000$ income tax bracket largely reflects the phase-out ranges of transfers to low earners. The low effective marginal tax rate of $16.1 \%$ in the $\$ 20,000-\$ 80,000$ income tax bracket reflects relatively low statutory income tax rates after deductions and exemptions. The higher effective marginal tax rate of $27.1 \%$ in the $\$ 80,000+$ income tax bracket reflects higher statutory income tax rates at higher earnings. ${ }^{33}$ Notably, standard optimal income tax systems similarly exhibit a U-shaped

\footnotetext{
${ }^{31}$ Medicare taxes are non-contributory taxes: Medicare is an "entitlement" that is not limited to those who have paid in to the system. Medicare is available to working-age households with specific conditions, such as end stage renal disease or a disability that qualifies them for Social Security Disability Insurance. In terms of DINA variables, taxes paid the sum of ditaf ("Federal personal income tax gross of refundable tax credits"), ditas ("State personal income tax"), salestax ("Sales and excise taxes"), and othercontrib ("Contributions for government social insurance other than pension, UI, DI"), minus the sum of dicab ("Social assistance benefits in cash") and inkindinc ("Social transfers in kind").

${ }^{32}$ The average value of taxes paid is positive, primarily because we exclude public goods consumption - including defense procurement, most government salaries, and other government expenditures that are not individualized transfers - from net taxes.

${ }^{33}$ The 2015 federal marginal tax rate for a married couple earning $\$ 80,000$ was $15 \%$ and for a single filer was $25 \%$. Our best-fit approximation somewhat overestimates actual taxes paid among middle earners and underestimates actual taxes paid among the highest earners in the DINA data.
} 
pattern of marginal tax rates with a five-digit lump-sum transfer (e.g., Saez 2001). ${ }^{34}$

\section{C.4 Calibration Procedure}

We jointly choose the discretized lognormal skill distribution parameters $\left\{\mu_{\theta}, \sigma_{\theta}\right\}$ and the amenity parameters $\left\{a_{j}(\theta)\right\}_{j=1, \theta=1}^{100,50}$ via a minimum distance algorithm that seeks to equate certain model-predicted moments to the equivalent moments in the ACS data. The amenity parameters are chosen to exactly match each community's share of each of nine nationwide household earnings bins based on the ACS tract-level aggregates described in Appendix C.2. The nine household earnings bins are the same as those computed from the ACS in Appendix C.2 and are defined by the following eight earnings thresholds: $\$ 9,600, \$ 19,500, \$ 28,500, \$ 42,000$, $\$ 64,700, \$ 88,000, \$ 132,400$, and $\$ 180,200$. The skill-distribution parameters are chosen to minimize the sum of square deviations from the share of the nationwide population with earnings in the bottom two ACS-based bins (i.e., below $\$ 19,500$ ) and the share with earnings in the top three ACS-based bins (i.e., above $\$ 88,000$ ).

The calibration algorithm consists of two optimization steps: an outer loop and an inner loop. Let $d(z)$ denote the ACS earnings bin into which earnings level $z$ falls. We allow each of the one hundred communities to have nine amenity levels, one for each earnings bin $d \in\{1, \ldots, 9\}$, so that $a_{j}(\theta)=a_{j d\left(z_{j}^{*}(\theta)\right)}$. In the outer loop, we take these earnings-indexed amenity levels $\left\{a_{j d}\right\}_{j=1, d=1}^{100,9}$ as given and find the skill distribution parameters $\left\{\mu_{\theta}, \sigma_{\theta}\right\}$ that minimize the sum of squared residuals between the model-predicted and actual shares of households with earnings less than $\$ 19,500$ and greater than $\$ 88,000$.

In the inner loop, we find amenity levels needed to exactly match each community $j$ 's share of each of the nine nationwide household earnings bins $d$ using a fixed point algorithm analogous to that of Berry et al. (1995). Specifically, we update the amenity parameters as follows until convergence:

$$
a_{j d}^{(t+1)}=a_{j d}^{(t)}+\ln \pi_{j d}^{\mathrm{truth}}-\ln \pi_{j d}^{(t)} \quad \text { for } j=1, . ., 100, d=1, \ldots, 9
$$

where $t$ is the iteration step, $\pi_{j d}^{(t)}$ is the model-predicted share of households with pre-tax earnings in bin $d$ that locate in community $j$ given the current guess $\left\{a_{j d}^{(t)}\right\}_{j=1, d=1}^{100,9}$ of amenities, and $\pi_{j d}^{\text {truth }}$ is the empirical share of households with earning in bin $d$ that locate in community $j$ according to the ACS data.

After the inner loop has converged, for each skill type $\theta \in\{1, \ldots, 50\}$, we recenter the amenity parameters $a_{j}(\theta)$ to equal zero in the community with the median poverty rate (i.e., the 50th poorest community).

\footnotetext{
${ }^{34}$ Note that Piketty, Saez, and Zucman (2018) and Saez and Zucman (2019) report relatively flat average tax rates across the income distribution using the DINA data. Their calculations include contributory social insurance taxes and do not include transfers.
} 
Specifically, for final iteration $T$, we set

$$
a_{j}^{(T)}(\theta)=a_{j d\left(z_{j}^{*}(\theta)\right)}^{(T)}-a_{50 d\left(z_{50}^{*}(\theta)\right)}^{(T)}, \quad \text { for } j=1, \ldots, 100, \theta=1, \ldots, 50
$$

which yields 5,000 amenity levels, one for each community and skill type combination. Because skill type location decisions only depend on differences in amenity levels across communities, this final recentering step has no effect on behavior.

While the inner loop adjusts the nine hundred amenity parameters to exactly match the share of each earnings bin that resides in each community in the ACS, the outer loop's two lognormal parameters do not yield an exact match to the nationwide earnings distribution in the ACS. As a result, each community's population deviates from $1 \%$. However, the deviations are relatively small in practice: community populations range from $0.94 \%$ to $1.07 \%$, with the highest-poverty and lowest-poverty communities having lower population than middle-poverty communities, because the lowest earners and highest earners are slightly underrepresented nationally. 
ONLINE APPENDIX TABLE 1

Survey Results on Distributional Preferences

\begin{tabular}{|c|c|c|c|c|}
\hline \multicolumn{5}{|l|}{ A. Marginal Distributions } \\
\hline & $\begin{array}{l}\text { A } \$ 100 \text { tax credit for } \\
\text { poor families in the } \\
\text { distressed area }\end{array}$ & $\begin{array}{l}\text { A } \$ 1 \text { tax credit for poor } \\
\text { familes everywhere }\end{array}$ & $\begin{array}{l}\text { A } \$ 100 \text { tax credit for } \\
\text { poor families in the } \\
\text { thriving area }\end{array}$ & \\
\hline & (1) & (2) & (3) & \\
\hline Regional question & $\begin{array}{c}48 \% \\
(1.53 p p)\end{array}$ & $\begin{array}{c}24 \% \\
(1.31 \mathrm{pp})\end{array}$ & $\begin{array}{c}28 \% \\
(1.38 p p)\end{array}$ & \\
\hline City/Town question & $\begin{array}{c}51 \% \\
(1.53 p p)\end{array}$ & $\begin{array}{c}25 \% \\
(1.32 p p)\end{array}$ & $\begin{array}{c}25 \% \\
(1.32 \mathrm{pp})\end{array}$ & \\
\hline \multicolumn{5}{|l|}{ B. Joint Distribution } \\
\hline & \multicolumn{4}{|c|}{ Answer to City/Town question } \\
\hline & $\begin{array}{l}\text { A } \$ 100 \text { tax credit for } \\
\text { poor families in the } \\
\text { distressed area }\end{array}$ & $\begin{array}{l}\text { A } \$ 1 \text { tax credit for poor } \\
\text { familes everywhere }\end{array}$ & $\begin{array}{l}\text { A } \$ 100 \text { tax credit for } \\
\text { poor families in the } \\
\text { thriving area }\end{array}$ & All responses \\
\hline & (4) & (5) & (6) & (7) \\
\hline \multicolumn{5}{|l|}{ Answer to Regional question } \\
\hline $\begin{array}{l}\text { A } \$ 100 \text { tax credit for poor families in } \\
\text { the distressed area }\end{array}$ & $\begin{array}{c}32 \% \\
(1.43 p p)\end{array}$ & $\begin{array}{c}7 \% \\
(0.78 p p)\end{array}$ & $\begin{array}{c}8 \% \\
(0.84 p p)\end{array}$ & $\begin{array}{c}48 \% \\
(1.53 p p)\end{array}$ \\
\hline $\begin{array}{l}\text { A } \$ 1 \text { tax credit for poor familes } \\
\text { everywhere }\end{array}$ & $\begin{array}{c}7 \% \\
(0.78 p p)\end{array}$ & $\begin{array}{c}11 \% \\
(0.97 p p)\end{array}$ & $\begin{array}{c}6 \% \\
(0.71 \mathrm{pp})\end{array}$ & $\begin{array}{c}24 \% \\
(1.31 p p)\end{array}$ \\
\hline $\begin{array}{l}\text { A } \$ 100 \text { tax credit for poor families in } \\
\text { the thriving area }\end{array}$ & $\begin{array}{c}11 \% \\
(0.97 p p)\end{array}$ & $\begin{array}{c}6 \% \\
(0.74 p p)\end{array}$ & $\begin{array}{c}11 \% \\
(0.95 p p)\end{array}$ & $\begin{array}{c}28 \% \\
(1.38 p p)\end{array}$ \\
\hline All responses & $\begin{array}{c}51 \% \\
(1.53 p p)\end{array}$ & $\begin{array}{c}25 \% \\
(1.32 \mathrm{pp})\end{array}$ & $\begin{array}{c}25 \% \\
(1.32 \mathrm{pp})\end{array}$ & $100 \%$ \\
\hline
\end{tabular}

Notes - Panel A repeats in the table format the survey results plotted in Figure 3a. See the notes to that table for details. Panel B lists the full cross-tabulation of responses that underlie Panel A. Standard errors are listed in parentheses. 
ONLINE APPENDIX TABLE 2

Survey Results on Rationales for Distributional Preferences

A. Subset of respondents who answered to both questions: $A \$ 1$ tax credit for poor familes everywhere.

Extra money given to poor families is equally valuable no matter where they live.

$(4.29 \mathrm{pp})$

Poor families are no worse off in one place or another.

$(4.39 \mathrm{pp})$

I might want to help poor families in one place over another place, but it is wrong for the government to treat people with the same earnings differently.

$5.55 \mathrm{pp}$

An explanation not listed above (please specify).

$(0.83 \mathrm{pp})$

B. Subset of respondents who answered to both questions: $A \$ 100$ tax credit for poor families in the distressed area.

An extra dollar goes further in distressed areas, since housing costs and other services are cheaper.

An extra dollar goes further in distressed areas, since poor families there have greater spending needs like supplementing school instruction, replacing stolen goods, or treating asthma from high pollution.

(2.62pp)

Poor families in distressed areas are worse off, since they deal with high poverty, high crime, high pollution, struggling schools, and a history of job losses.
(2.22pp)

Poor families in distressed areas are more deserving, since they are more likely to be poor due to circumstances beyond their control.

$44 \%$

$(2.67 \mathrm{pp})$

An explanation not listed above (please specify).

$3 \%$

$(0.85 \mathrm{pp})$

C. Subset of respondents who answered to both questions: $A \$ 100$ tax credit for poor families in the thriving area.

An extra dollar goes further in thriving areas, since poor families there have less money left over after paying high housing costs.

Poor families in thriving areas are worse off, since housing costs more there.

$(4.68 \mathrm{pp})$

Poor families in thriving areas feel poorer because they interact with more rich neighbors.

$49 \%$

$(4.68 \mathrm{pp})$

Poor families in thriving areas are more deserving, since they are more likely to be poor due to circumstances beyond their control.

$46 \%$

(4.67pp)

An explanation not listed above (please specify).

D. Subset of respondents who gave more monev to poor families in distressed urban areas than to poor families in distressed regions.

The poor in distressed urban areas are worse off than the poor in distressed rural areas.

A dollar goes further in distressed urban areas than in distressed rural areas.

Distressed urban areas have suffered greater racial injustices than distressed rural areas.

$40 \%$

$(3.03 \mathrm{pp})$

$51 \%$

(3.09pp)

$2 \%$

An explanation not listed above (please specify).

(0.93pp)

E. Subset of respondents who gave more money to poor families in distressed regions than to poor families in distressed urban areas.

The poor in distressed rural areas are worse off than the poor in distressed urban areas.

A dollar goes further in distressed rural areas than in distressed urban areas.

$43 \%$

$(3.31 \mathrm{pp})$

$41 \%$

(3.28pp)

Distressed rural areas have suffered greater racial injustices than distressed urban areas.

$57 \%$

(3.30pp)

Poor families in distressed rural areas are more deserving, since they are more likely to be poor due to circumstances beyond their control. distressed areas were given five potential explanations and asked to select all that apply. All potential explanations other than "An explanation not listed above (please specify)." were presented in random order. Panels A, C, D, and E present analogous results to the follow-up question asked of the other four subset of respondents, as specified in the panel heading. As an example of interpretation, Panel B shows that -- among those who chose to distribute the tax credit only to poor families in distressed areas -- 78\% selected as at least of one explanation for their choices: "Poor families in distressed areas are worse off, since they deal with high poverty, high crime, high pollution, struggling schools, and a history of job losses." 
ONLINE APPENDIX TABLE 3

Exploration of Mechanisms for Large Optimal Place-Based Transfers - Additional Results

\begin{tabular}{|c|c|c|c|c|c|c|c|c|c|}
\hline & \multirow[b]{2}{*}{$\begin{array}{c}\text { Optimal level } \\
\text { of PBR }\end{array}$} & \multicolumn{3}{|c|}{ Under Optimal Income Tax and No PBR } & \multicolumn{5}{|c|}{ Under Optimal Income Tax and Optimal PBR } \\
\hline & & $\begin{array}{l}\text { Value of } \\
\text { redistributon } \\
\text { from } \\
\text { Elsewhere to } \\
\text { Distressed }\end{array}$ & $\begin{array}{c}\text { Marginal value } \\
\text { of public funds } \\
\text { (MVPF) of } \\
\text { PBR }\end{array}$ & $\begin{array}{l}\text { MVPF of } \\
\text { analogous } \\
\text { income tax } \\
\text { reform }\end{array}$ & $\begin{array}{l}\text { Value of } \\
\text { redistributon } \\
\text { from } \\
\text { Elsewhere to } \\
\text { Distressed }\end{array}$ & $\begin{array}{l}\text { Redistribution } \\
\text { value narrowed }\end{array}$ & $\begin{array}{l}\text { Increase in } \\
\text { population of } \\
\text { Distressed }\end{array}$ & $\begin{array}{l}\text { Place-blind } \\
\text { lump-sum } \\
\text { transfer }\end{array}$ & $\begin{array}{c}\text { Place-blind } \\
\text { marginal tax } \\
\text { rate above } \\
\$ 80 \mathrm{~K}\end{array}$ \\
\hline & (1) & (2) & (3) & (4) & (5) & (6) & (7) & (8) & (9) \\
\hline \multicolumn{10}{|l|}{ A. Calibration } \\
\hline Baseline & $\$ 5,500$ & 1.29 & 0.98 & 0.72 & 1.09 & $71 \%$ & $9 \%$ & $\$ 22,357$ & $46.5 \%$ \\
\hline Income effects & $\$ 3,700$ & 1.26 & 0.98 & 0.60 & 1.11 & $59 \%$ & $7 \%$ & $\$ 22,721$ & $46.9 \%$ \\
\hline Comparative advantage & $\$ 4,200$ & 1.29 & 0.91 & 0.61 & 1.12 & $57 \%$ & $7 \%$ & $\$ 21,983$ & $45.7 \%$ \\
\hline Income effects + Comp. adv. & $\$ 3,100$ & 1.26 & 0.89 & 0.61 & 1.13 & $50 \%$ & $6 \%$ & $\$ 22,497$ & $46.3 \%$ \\
\hline \multicolumn{10}{|c|}{ B. Eliminate skill-taste correlation after calibration } \\
\hline Baseline & $\$ 400$ & 1.04 & 0.97 & 0.82 & 1.02 & $34 \%$ & $1 \%$ & $\$ 21,902$ & $46.0 \%$ \\
\hline Income effects & $-\$ 400$ & 1.01 & 0.96 & 0.78 & 1.02 & $-116 \%$ & $-1 \%$ & $\$ 22,254$ & $46.4 \%$ \\
\hline Comparative advantage & $\$ 1,600$ & 1.18 & 0.87 & 0.70 & 1.12 & $32 \%$ & $2 \%$ & $\$ 21,759$ & $45.8 \%$ \\
\hline Income effects + Comp. adv. & $\$ 700$ & 1.16 & 0.85 & 0.67 & 1.13 & $17 \%$ & $1 \%$ & $\$ 22,688$ & $46.6 \%$ \\
\hline
\end{tabular}

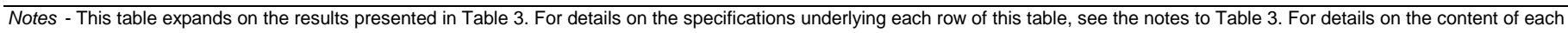
column, see the notes to Table 2. As explained in Section 6.5, the optimal level of PBR in the second row of Panel B is negative because the planner favors redistribution towards Elsewhere conditional on earnings. The column 2 value exceeds one in that specification because low earners sort to Distressed in order to enjoy low rent. 


\section{ONLINE APPENDIX FIGURE 1}

\section{Community Poverty Rates and Calibration Parameters}
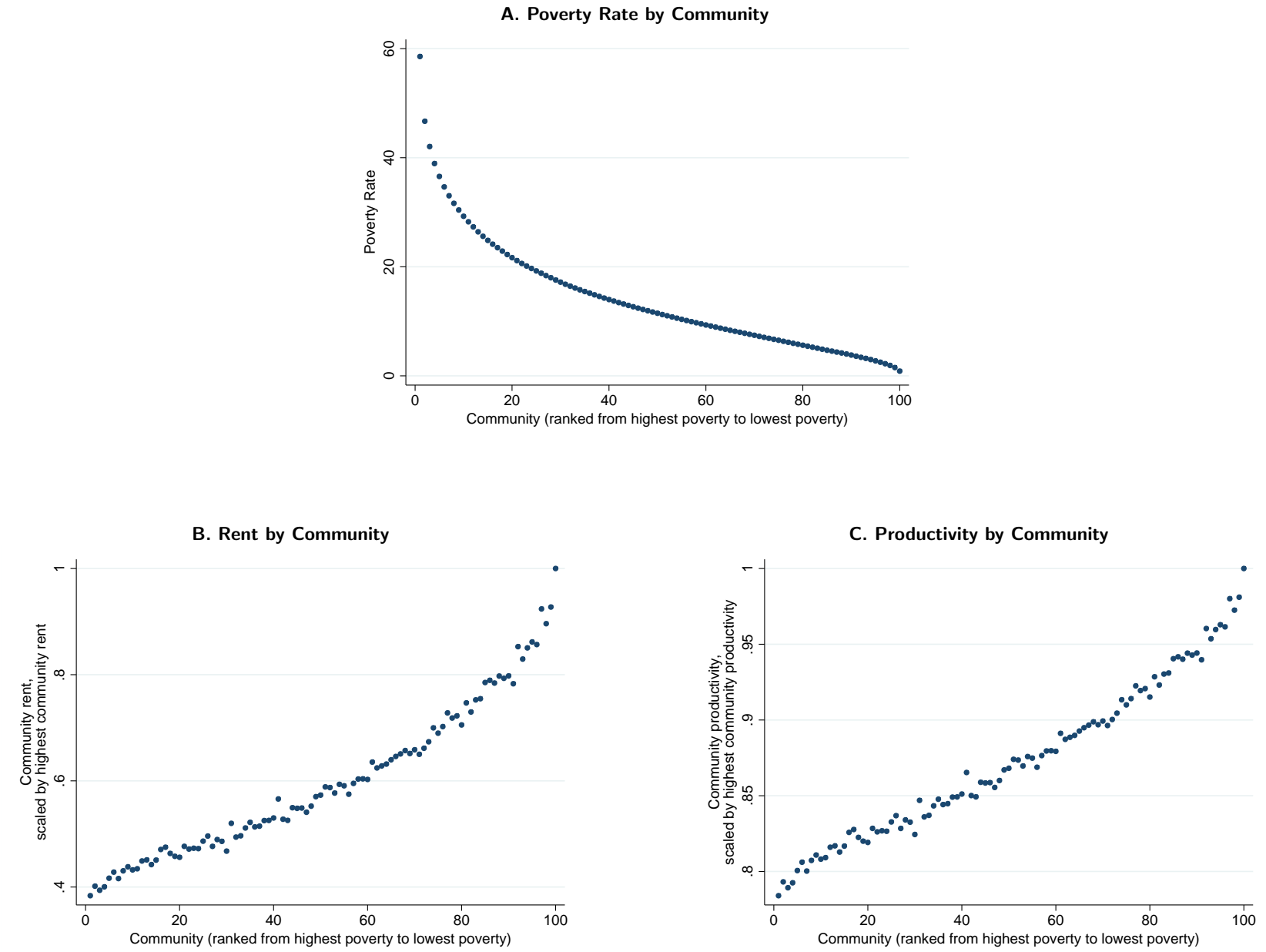

Notes: Our quantitative exercise is based on an amalgamation of U.S. Census tracts into one hundred equalsized communities based on tract poverty rate in the 2013-2017 ACS. Panel A plots community poverty rates, which is not a direct input to the quantitative exercise. Panels B-C plot direct inputs to the quantitative exercise under baseline preferences. Community rent equals the population-weighted mean of median tract rent, normalized to one in the highest rent tract. Community productivity equals community rent raised to 0.254, based on Hornbeck-Moretti's productivity-rent elasticity. 


\section{ONLINE APPENDIX FIGURE 2}

Skill-Taste Correlation across Preference Specifications

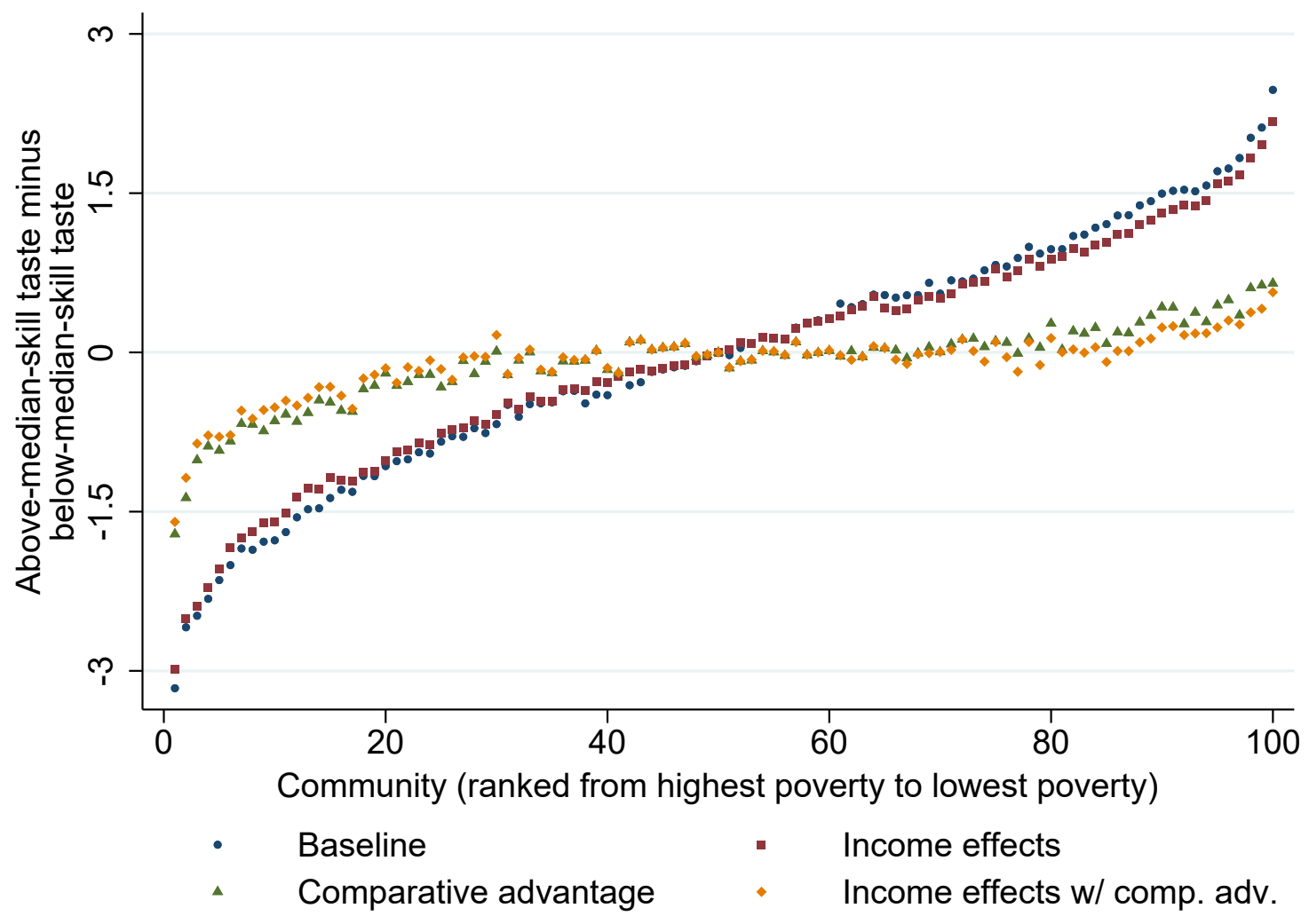

Notes: This figure plots calibrated skill-taste correlation - i.e., the degree to which the high skilled and low skilled disagree on community valuations - across four preference specifications. For each specification and each community $j$, the figure plots the unweighted mean valuation $a_{j}(\theta)$ of those with above-median skill (i.e., the twenty-five highest skill types $\theta$ ) minus the unweighted mean valuation of those with below-median skill (i.e., the twenty-five lowest skill types $\theta$ ). Each of the fifty skill types constitutes two percent of the simulated economy's population. The four preference specifications are the same as those underlying Table 3 , as described in Section 6.5. 